\title{
ACTUALIZING HUMAN RIGHTS
} GLOBAL INEQUALITY, FUTURE PEOPLE, AND MOTIVATION

Jos Philips

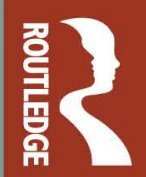




\section{Actualizing Human Rights}

This book argues that ultimately human rights can be actualized, in two senses. By answering important challenges to them, the real-world relevance of human rights can be brought out; and people worldwide can be motivated as needed for realizing human rights.

Taking a perspective from moral and political philosophy, the book focuses on two challenges to human rights that have until now received little attention, but that need to be addressed if human rights are to remain plausible as a global ideal. First, the challenge of global inequality: how, if at all, can one be sincerely committed to human rights in a structurally greatly unequal world that produces widespread inequalities of human rights protection? Second, the challenge of future people: how to adequately include future people in human rights and how to set adequate priorities between the present and the future, especially in times of climate change? The book also asks whether people worldwide can be motivated to do what it takes to realize human rights. Furthermore, it considers the common and prominent challenges of relativism and of the political abuse of human rights.

This book will be of key interest to scholars and students of human rights, political philosophy and, more broadly, political theory, philosophy and the wider social sciences.

Jos Philips is Assistant Professor of Philosophy, Utrecht University, the Netherlands. 


\title{
Routledge Studies in Human Rights
}

Series Editors:

Mark Gibney

UNC Asheville, USA

Thomas Gammeltoft-Hansen

University of Copenhagen, Denmark

and

Bonny Ibhawoh

McMaster University, Canada

The Routledge Studies in Human Rights series publishes high quality and crossdisciplinary scholarship on topics of key importance in human rights today. In a world where human rights are both celebrated and contested, this series is committed to creating stronger links between disciplines and exploring new methodological and theoretical approaches in human rights research. Aimed towards both scholars and human rights professionals, the series strives to provide both critical analysis and policy-oriented research in an accessible form. The series welcomes work on specific human rights issues as well as on cross-cutting themes and institutional perspectives.

\section{Human Rights and US Foreign Policy}

Prevarications and Evasions

Clair Apodaca

Politics of International Human Rights Law Promotion in Western Europe

Order versus Justice

Koldo Casla

\section{Extending International Human Rights Protections to Vulnerable Populations}

Raymond A. Smith

\author{
Fundamental Rights Challenges in Border Controls and \\ Expulsion of Irregular Immigrants in the European Union \\ Complaint Mechanisms and Access to Justice \\ Edited by Sergio Carrera and Marco Stefan
}

Why Human Rights Still Matter in Contemporary World Affairs

Edited by Mahmood Monshipouri

\section{Actualizing Human Rights}

Global Inequality, Future People, and Motivation

Jos Philips 


\title{
Actualizing Human Rights Global Inequality, Future People, and Motivation
}

\author{
Jos Philips
}


First published 2020

by Routledge

2 Park Square, Milton Park, Abingdon, Oxon OX14 4RN

and by Routledge

52 Vanderbilt Avenue, New York, NY 10017

Routledge is an imprint of the Taylor \& Francis Group, an informa business

(C) 2020 Jos Philips

The right of Jos Philips to be identified as author of this work has been asserted by him in accordance with sections 77 and 78 of the Copyright, Designs and Patents Act 1988.

The Open Access version of this book, available at www.taylorfrancis.com, has been made available under a Creative Commons Attribution-Non Commercial-No Derivatives 4.0 license.

Trademark notice: Product or corporate names may be trademarks or registered trademarks, and are used only for identification and explanation without intent to infringe.

British Library Cataloguing in Publication Data

A catalogue record for this book is available from the British Library

Library of Congress Cataloging in Publication Data

A catalog record has been requested for this book

ISBN: 978-0-367-82038-1 (hbk)

ISBN: 978-1-003-01156-9 (ebk)

Typeset in Times New Roman

by Wearset Ltd, Boldon, Tyne and Wear 
To the musicians 


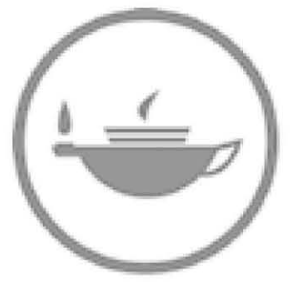

Taylor \& Francis Taylor \& Francis Group

http://taylorandfrancis.com 


\section{Contents}

Acknowledgements

1 Introduction: two new challenges to human rights and the question of motivation

\section{PART I}

Preparing the ground

2 Human rights: a conception

2.1 The book's conception of human rights: human rights and global justice 11

2.2 What are the minimum requirements of global justice? 13

3 Common challenges to human rights: the relativist and the political pawns challenge

3.1 The relativist challenge 24

3.2 The political pawns challenge 30

3.3 To conclude 34

\section{PART II}

Novel challenges to human rights

4 The challenge of global inequality

4.1 A largely state-based world order and equal human rights protection: a tension? 45

4.2 A largely state-based world order and human rights: reconsidering our commitments 47 
viii Contents

4.3 Some objections 53

4.4 To conclude 56

5 The challenge of future people

5.1 Which claims can qualify as human rights claims? 65

5.2 How to prioritize among human rights claims including between the present and the future 67

5.3 Priority-setting among human rights: uncertainties, and assumptions, concerning future people 76

5.4 To conclude 85

\section{PART III}

Getting to realization

6 The question of motivation: can people be motivated as needed for realizing human rights?

6.1 How best to approach the motivational question 99

6.2 What motivates individuals to act in accordance with human rights? 101

6.3 Some objections 105

6.4 To conclude 112

7 Conclusion

Bibliography

Index 


\section{Acknowledgements}

This book has been a long time in the making. It is impossible to thank everyone who helped me over the years and stimulated my thoughts, but some people I want expressly to mention: Mary Biezeman-Roest, Marcus Düwell, Joel Anderson, Koen Bavelaar, Monika Bobbert, Frans Brom, Rutger Claassen, Marie Göbel, Carla Kessler, Peter Lawrence, Titia Loenen, Sem de Maagt, Henry Shue, Dick Timmer and, at Routledge, Sophie Iddamalgoda, Andrew Taylor and the series editors and anonymous reviewers, as well as Ashleigh Phillips, Amit Prasad and Paul Martin. Thank you! (Of course, the shortcomings of the present book remain entirely my own.) I am also grateful to audiences at various places in the Netherlands and at Heidelberg and Graz, and I want to thank all my colleagues at Utrecht University, who make the Ethics Institute such a friendly environment and fertile place to work. Last but not least, I thank my students. Working with you is always very enriching and enjoyable!

Hopefully, this book can to some extent offer, in the words of Seamus Heaney, a 'glimpsed alternative' - one that, thankfully, at times already has a foothold in reality. 


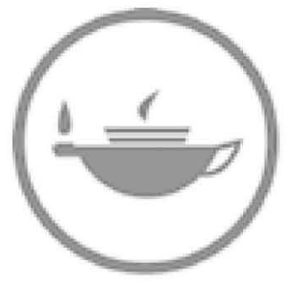

Taylor \& Francis Taylor \& Francis Group

http://taylorandfrancis.com 


\title{
1 Introduction
}

\author{
Two new challenges to human \\ rights and the question of motivation
}

Many people regard human rights as the minimum requirements of global justice. Human rights are meant, for now, in the colloquial sense that everyone should be guaranteed freedom from torture, freedom to express themselves, as well as being guaranteed enough food and a decent minimum standard of living, etc. In such an everyday understanding, human rights will frequently first of all be a moral notion rather than a juridical one. They would, more precisely, be a minimum ideal (if I may use this somewhat strange expression, which combines the elementary and the elevated) for the world. Moreover, this ideal would at least implicitly include future people, inasmuch as it would usually sketch a vision for both the present and the future.

Of course human rights, so understood, ${ }^{1}$ have faced outspoken criticisms. The criticisms may, for example, be of a relativist nature and deny that human rights are universally valid. Or they may be criticisms - which could be called 'realist' ${ }^{2}-$ saying that human rights are only pawns in games of political power. Such fundamental criticisms are both important and prominent, and I will return to them soon.

Many people, however, are in principle quite willing to embrace human rights as an ideal for the world. This is true for many policymakers, lawyers, academics, activists, and citizens in general. At the same time, many of them are, although relatively favourably disposed towards human rights, by no means uncritical about them. These people are the intended audience of this book. The core of this book discusses two 21st-century challenges to human rights - as they might be called - as well as, third, the arguably more practical question of how to motivate people and institutions actually to realize human rights. None of these three issues have received much discussion, while they are bound particularly to trouble the readers of this book. I will refer to the first challenge as the challenge of global inequality: How, if at all, can there be a sincere commitment to human rights, with their outspoken idea of the equality of all human beings, in a world of great inequalities that are not coincidental, but structural? The second challenge, which I will call the challenge of future people, is especially urgent in the current times of climate change: How adequately to include future people in human rights, and how to set adequate priorities between the present and the future? And how, in relation to these questions, to deal with key 


\section{Introduction}

uncertainties concerning the future - such as how many people will live in the future, what their interests will be, and what exactly may threaten those interests? And third, there is the question of motivation: How actually to motivate people and institutions to do what it takes to realize human rights in societies worldwide?

The two challenges and the motivational question will be the subject of the central chapters of the book (Chapters 4-6) and will be discussed in greater detail in a moment. But let me first say something about two more all-out challenges to human rights that are very prominent in the current debates about human rights and which will be the subject of Chapter 3 - a chapter that (along with Chapter 2, which details the book's conception of human rights) prepares the ground for the central chapters.

These more all-out challenges are the relativist challenge and (what I will call) the political pawns challenge. The former states that human rights lack universal validity, while the latter says that they are merely pawns in political power games. These common and influential challenges need to be discussed, among other things because they are linked to currently prominent debates about the end/future of human rights. ${ }^{3}$ My argument will be that the relativist and political pawns challenges, in the versions of them that matter most, can be answered: ${ }^{4}$ relativism about human rights is implausible at a general level; and where the political pawns challenge asserts, as it usually does, that more than 'local' repairs (my term) to human rights are needed, it is unconvincing. Thus, as far as these challenges are concerned, there will in the end turn out to be no reason to fear for the future of human rights. The next chapters will then ask whether there is bad news for human rights (1) based on large global inequalities or (2) based on difficulties arising from the justified claims of future people, especially in the light of climate change; or, more practically, whether human rights run into problems (3) because of what it takes actually to motivate people and institutions to act in accordance with them. I will now elaborate on these three issues.

First, the challenge of global inequality. Can one, in a world of vast inequalities such as ours, be sincerely committed to human rights and to the ideal of equality that they embody? More particularly, many of the inequalities in our world are not accidental, but arise on account of key structural features of that world. I am thinking above all of the important role that largely sovereign states play in realizing human rights. Among other things, some states are much richer than others and function much more smoothly and, as a result, large inequalities are bound to arise between states in the realization of human rights. ${ }^{5}$ Can one, then, accept and perhaps also (as is often the case) in certain ways promote and help to maintain a world order where largely sovereign states are very prominent and at the same time be seriously committed to human rights, that is, to the idea that all human beings equally should have certain freedoms and rights? (For the moment, the notion of human rights employed is still the rather colloquial notion presented above.) Or is this hypocritical? I will call the commitment to human rights hypocritical if it turns out to be mere talk, while one's actual actions - which 
help, perhaps, to maintain certain core structural features of the world - serve to undermine the realization of human rights.

There is, on the face of it, no easy way out of this challenge. It is not as if one can easily embrace alternatives for a largely state-centred world order, or even clearly conceive what such alternatives might be. Nor can we easily give up the idea that a sincere commitment to human rights entails a sincere commitment to some robust form of equality and of equal treatment of all human beings - to more equality, it may seem, than can be delivered by a largely state-centred world order, with its inevitable differences in wealth and in quality of institutional functioning. Thus, it is a real and large question whether a sincere commitment to human rights can go together with being committed to and supporting a largely state-centred world order.

The second challenge on which I want to elaborate, and which is particularly urgent in an age of climate change, is the challenge of future people. If one understands human rights in a colloquial sense, future people will, I have said, be included (as subjects of concern, rights bearers, etc.), although perhaps in an implicit way. But when one develops a more elaborate conception of human rights as an ideal for the world, many questions remain with regard to the inclusion of future people ${ }^{6}$ - while including them is clearly vital for a global ideal in an age of climate change. I mainly want to focus on the urgent question of when to give priority to the future over the present, and when the other way around. ${ }^{7}$ This is not to suggest that future and present are always in conflict; thankfully that is not so. But sometimes there will be conflicts and, in such cases, determining which of the two should get priority is often both fraught and difficult. Fraught, because if the future gets precedence, those presently alive frequently stand to lose something real - not only superfluous luxuries, but also important freedoms and real opportunities for an improved life. And this unlikely to be only a theoretical concern: considering how much the interests of future people are in jeopardy because of climate change, and considering how many people may potentially live in the future, it seems that the future should sometimes win out.

Furthermore, the matter is not only fraught but also difficult. This is partly because it seems to require clarity about a number of more general issues, which are relatively unexplored, concerning how to set priorities among human rights (how to take the numbers into account, how to treat particularly vulnerable people, etc.). And it is also difficult because the future, often even more than the present, is full of uncertainties. These are of various kinds - different sorts of unknowns - and some of them seem rather intractable. The uncertainties pertain, among other things, to what the numbers of future people will be and what their interests will be, and also to what could threaten their interests and provide protection against these threats. All this contributes greatly to making the inclusion of future people in human rights a hard problem. For, the urgency of climate change does not mean that the future is necessarily always to get precedence. There are also, for example, the needs etc. of people in the present and various uncertainties concerning the future. Hence the challenge of future people. 


\section{Introduction}

I will argue that we can, in the end, often deal satisfactorily with both the challenge of global inequality and with that of future people. Frequently, a nonhypocritical commitment to human rights is ultimately possible, even in a world of great inequalities - although this cannot come easily. And human rights can take future people into account in a justifiable way, even if, in times of climate change, hard choices can by no means always be avoided.

Human rights will of course have to deal with other challenges as well. Regarding these, this book will particularly focus on one more question, which is arguably more practical and which I will call the question of motivation (or the motivational question). ${ }^{8}$ Motivation is understood here in the sense of individual people and institutions actually being brought to act and function in accordance with human rights. More specifically, the point is that, for human rights to be plausible as a global ideal, it must be possible for societies actually to function in accordance with human rights. Moreover, they should be capable of so functioning from generation to generation, ${ }^{9}$ and achieve this by acceptable means, for example without using manipulation or certain kinds of coercion. At the minimum, all this should be the case for societies that are as good as human societies can be: if even such societies cannot function in accordance with human rights, human rights certainly forfeit their plausibility as a global ideal. ${ }^{10}$

Whether societies worldwide can function in accordance with human rights is a large question, and I will argue that historical evidence does in any case not suffice to answer it affirmatively. I will start my own exploration with Richard Rorty's remark that, to establish and maintain a human rights culture, it is enough to have generations of 'nice ... well-off, secure ... students'. ${ }^{11}$ This suggestion is promising but it also has, I will argue, a number of problems. Improvements and alternatives will be considered. The chapter devoted to the motivational question will be the most explorative one of the book. This question has not, for all I can see, been much discussed. I will try to get a first sense of the robust empirical evidence while also taking the relevant non-empirical aspects (such as considerations of acceptability) into account.

The chapter will, in order to keep things manageable, be confined to motivation of individuals. But indirectly, institutions will be addressed in some ways as well. For of course, a society's functioning in accordance with human rights is not least an institutional matter. Institutions such as the government, and various organizations in civil society, should be moved actually to respect and realize human rights. Yet individual support for human rights is, I will argue, both a necessary condition and ultimately also a sufficient one for maintaining institutional motivations.

What binds together the challenge of global inequality, the challenge of future people and the (arguably more practical) question of motivation is that, for all three, meeting them is very urgent if human rights are to be actualized. I mean this in a double sense of 'actualized' (the two senses are, to be sure, related): in the sense of not losing their relevance (and thus becoming somehow 'un-real') and also in the sense of actually getting individuals - and institutions into movement ('action'). To elaborate, meeting these challenges is vital in 
order to make sure, first, that human rights do not lose their plausibility as a global ideal and, thus, in a way become irrelevant and closer to mere talk. Human rights will lose their plausibility if certain pressing issues are not addressed, among others those which are at the centre of this book: how (if at all) can a genuine commitment to human rights be upheld in a world of vast and structural inequalities? How (if at all) can future people and their claims find an adequate place in human rights? And how (if at all) can societies actually function in accordance with human rights?

Second, as for actualization in the other sense, of actually getting individuals and institutions to act and function in accordance with human rights, this is what the motivational challenge is expressly concerned with. And, in a somewhat more complex way, the challenges of inequality and of future people are concerned with it, too. For these two challenges must be met in order for it to be reasonably expectable from people worldwide and from future people that they will be motivated to act in accordance with human rights. After all, how can one expect them to be motivated to act in accordance with human rights unless there is at least a plausible account of how people from all places and times can defensibly be included in human rights? It must be clear, then, how future people could be included in human rights in a plausible way, and it must likewise be clear what a commitment to human rights entails in the face of vast global inequalities.

The very broad thrust of this book will be as follows. Concerning the challenge of global inequality, I will argue that it is often incompatible with human rights to endorse inequalities between persons in the protection of important interests. But this is not always so and even structurally engendered inequalities (engendered, for example, by a largely state-centred world order) are sometimes, but only sometimes, compatible with human rights. Or so I will argue. One should work towards better institutional arrangements whenever possible; and only where this is not possible, a less demanding interpretation (to the extent necessary) of the equality of all humans may be embraced.

Concerning the challenge of future people, a first outline will be defended of a model for how to set priorities among human rights - a model that (among other things) offers a tool to start thinking about priority-setting between the present and the future. Many factors have a place in this model - not only the importance of people's interests, the number of people concerned as well as various constraints to do with equal treatment, but also various uncertainties and (in the background) certain assumptions about future people.

With regard to the motivational question, a hypothesis about the motivation of individuals will be defended (starting from Rorty's suggestion, mentioned above). This hypothesis concentrates on people being safe in the fulfilment of their important interests and being able to develop and exercise their key capacities. This hypothesis also makes clear when a society can be effectively ordered in accordance with human rights - while keeping in mind that this societal ordering should take place in acceptable ways, and that the claims of future people need to be taken into account as well. The chapter will, in addition, 


\section{Introduction}

briefly discuss some important and prominent suggestions about individual motivation (such as ideas to do with nudging and self-interest-based motivation) and their (in)compatibility with the chapter's main hypothesis. The chapter's conclusion will be (although cautiously) that it is possible for individuals and societies actually to realize human rights.

In the end, then, I will argue that human rights can meet various challenges, most importantly those central to the book, the challenges of global inequality and of future people, addressed in Chapters 4 and 5; and that important questions about human rights' motivational capacity, to which Chapter 6 is devoted, can be answered. Human rights can, in short, be actualized. Chapter 7, the book's conclusion, points the way to some things that remain to be further investigated in future research.

Chapters 2 and 3 are preparatory chapters. As I have already mentioned, Chapter 3 tries to answer two common (indeed, arguably the most common) and quite radical challenges to human rights, the relativist challenge and the political pawns challenge. Chapter 2, for its part, will propose the conception of human rights that I will use. To elaborate: this conception will in some ways develop the colloquial understanding of human rights that has been proposed above that everyone should be able to count on having enough to eat, be guaranteed freedom from torture and to express themselves, etc. In some ways, however, the conception developed in Chapter 2 will take distance from this colloquial understanding.

This book's envisaged audience is, as remarked, broad: all those, be they policymakers, lawyers, academics, activists or citizens in general, who are interested in and broadly sympathetic towards human rights, but certainly also critical towards them. ${ }^{12}$ At the same time, the book speaks more particularly to the philosophical human rights literature. This is in line with regarding human rights first of all as a moral category, specifically as an ideal for the world. Such an understanding is, as indicated, often a central feature of a colloquial notion of human rights. But the more complex and detailed conception of human rights developed in the next chapter will also hold on to this understanding.

In addition to the philosophical human rights literature, I will also speak, more broadly, to the philosophical literature in global and intergenerational justice. For each of the three issues central to the book there is, I believe, a gap in this literature. I will come back to this in the chapters concerned, and will only give a brief indication now. As for the challenge of global inequality, it is fairly common ground in the literature that human rights protection should be equal everywhere on earth. The literature frequently regards human rights as global minimum standards of justice; and only when equal human rights protections have been secured does the literature tend to regard differences between individuals in the protection of their interests as potentially compatible with justice. That the requirement of globally equal human rights protection has to reckon with certain structural features of the world that may be in tension with it is not much discussed. ${ }^{13}$ Nor, consequently, is the question addressed of how - if at all - this tension could or should be resolved. 
The challenge of future people is confronted, first, with the fact that the philosophical literature has not been much concerned with questions of priority-setting among human rights. To be sure, all questions of justice are, one may say, about priority-setting, but priority-setting and human rights have not often been brought together. Moreover, if certain problems with regard to future people have, for instance in the context of climate change, received discussion - such as various uncertainties and assumptions about future people's needs and numbers - the discussion has not usually been in the context of human rights. ${ }^{14}$

The motivational challenge, finally, is vast and in very important respects interdisciplinary. It has received some attention in the philosophical literature, but hardly, as far as I can see, specifically with regard to human rights (apart from passing remarks such as Rorty's, mentioned above); and there is even less discussion striving to consider both robust empirical evidence and requirements of acceptability. ${ }^{15}$

Thus, the book strives to open new ground both with regard to the challenges of global inequality and future people and with regard to the motivational question. ${ }^{16}$ Before turning to the challenges, I will now, in Chapter 2, develop the book's conception of human rights. This is necessary preparatory work. But it is relatively technical, and some readers may prefer to skip this chapter and turn to Chapter 3 directly.

\section{Notes}

1 In Ch. 2 below this colloquial notion of human rights will be developed and revised, and its relationship to the post-WWII practice of human rights will be discussed.

2 See e.g. Caney (2005), pp. $7 \mathrm{ff}$.

3 Cf. authors such as Bob (2019); Douzinas (2007); Hopgood (2013); Kennedy (2004).

4 While my discussion of these challenges aims, of course, to be adequate in the light of the literature, it is above all in Chs. 4, 5 and 6 that the discussion strives to be novel.

5 These remarks may seem to commit me to a particular view on the causes of poverty, etc. But I do not think that they do; see Ch. 4.

6 It may be noted that the inclusion of future people is often doubtful in the post-WWII practice of human rights. For the relation of this book's conception of human rights to that practice, see Ch. 2.

7 Philosophers, and also lawyers, have often concentrated on other questions about future people, such as the question of whether they can have entitlements if they do not yet exist and if it is not yet clear concretely what person could be harmed, benefited or (dis)respected. Cf. Ch. 5.

8 To be sure, the motivational 'question' is a challenge for human rights. I call it a 'question' to indicate that it may be of a different kind - more practical, less fundamental - than the other two challenges. But that itself is a moot point and not much may in the end depend on whether it is so.

9 'Generation' is meant colloquially here, not in any technical sense.

10 It may be thought it should also be possible for (at least certain) less ideal societies. Cf. Section 6.4.

11 Rorty (1994), p. 127.

12 I take it that most readers of this book will not to such an extent be critical towards human rights as to be drawn to the relativist and political pawns challenges. But these challenges are still so prominent and important that they warrant discussion. 


\section{Introduction}

13 It should be noted that the challenge of global inequality, as I articulate it here, is different from the question of whether human rights are 'enough' (cf. Moyn 2018). Concerning the question whether they are 'enough', Chapter 2 will make it clear that I regard human rights as articulating only the minimum requirements of global justice.

14 Henry Shue, one of the pioneers of philosophical debates about human/basic rights, also has one of the best discussions of what may be called precaution in the context of climate change (Shue 2010). But even he does not specifically discuss this in the context of (human) rights. Many other discussions, such as Caney (2009), are very brief, some exceptions being Bos and Düwell (2016) and Düwell, Bos and Van Steenbergen (2018).

15 One example of an outstanding contribution is Judith Lichtenberg's (2014) book on poverty (Ch. 10). Some other examples can be found in Birnbacher and Thorseth (2015).

16 By contrast, Ch. 3 (on the relativist and political pawns challenges) does not aim to break new ground, but only strives to argue in a way that is adequate in light of the existing philosophical literature.

This book will typically engage in ideal theory, which thinks about possibilities and ideals taking as a given how human beings are (with the best possible upbringing and education, etc., and more generally living under the best possible institutions), but not taking changeable features of humans and of the world as given (cf. Sections 4.2 and 6.1 below). As will become clear below, human rights will often have particularly severe problems if certain issues cannot even be solved in ideal theory. I will concentrate on ideal theory when thinking about the (in)compatibility of human rights and a largely state-based world order; about how to set priorities among human rights, including human rights of future people; and about the question of whether societies worldwide can function in accordance with human rights. Yet these problems evidently, and very importantly, also have relevance for the world in the 21 st century, with its vast inequalities, rapid climate change and widespread nonobservance of human rights. 


\section{Part I}

\section{Preparing the ground}




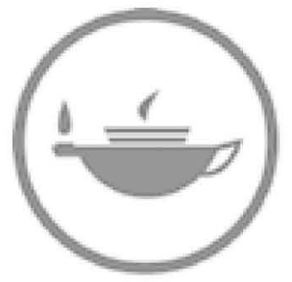

Taylor \& Francis Taylor \& Francis Group

http://taylorandfrancis.com 


\section{Human rights A conception}

So far, a rather colloquial conception of human rights has been used. According to this conception, human rights are about ensuring that everyone is free from torture, can freely express their views, has enough to eat, etc. ${ }^{1}$ This is too thin, however, to serve as a basis for the rest of the book. Therefore, the present chapter will develop in detail what this book's conception of human rights will look like, and also justify the conceptual choices made. I will proceed in two steps. First, the book's general conception of human rights will be proposed, that is, its broad answer to the question of what human rights are. In one sentence: human rights will be regarded as the minimum requirements of global justice, and the content of these requirements as having to do with (reliably) protecting the very important interests of all human beings (Section 2.1). I will explain why human rights are understood in this way and also how, in this understanding, they relate to the post-World War II practice of human rights. Second, I will go into the contents of human rights, further than that they have to do, as said, with protecting the very important interests of all human beings (Section 2.2): What, more precisely, is a human right and what, approximately, could a plausible list of human rights look like? Who bears duties with regard to human rights? And how weighty are human rights? The discussion will be confined to those elements of the book's human rights conception that urgently need clarification as a basis for the discussions in Chapters 3,4 and $5 .^{2}$

\subsection{The book's conception of human rights: human rights and global justice}

This section presents the main thrust of this book's conception of human rights. ${ }^{3}$ Human rights will be understood as the minimum requirements of global justice, and the content of these requirements concerns the protection of very important interests of all human beings. ${ }^{4}$

I start off with a more methodological point. There are two requirements that any plausible conception of human rights will, I believe, have to meet. I will first briefly state them and then explain and discuss them further. First, a conception of human rights will in some way have to be continuous with everyday usage (even though it may at the same time be considerably revisionist towards it, as 


\section{Preparing the ground}

will become clear). Second, there has to be clarity about the role(s) that a conception of human rights is supposed to fulfil, as different roles will ask for different contents of a conception.

To further clarify these requirements and why they are sensible, it may be helpful to take a look at another complex concept, autonomy. ${ }^{5}$ (I might also have taken, say, democracy. ${ }^{6}$ ) I start with the first requirement, that of a conception being to some extent continuous with daily usage; in discussing it, my stance on the second requirement will become clear as well.

'Autonomy' as a term in daily life - I mean in policy making, education, medical practice, etc. - is used to refer to very many different ideas (which are often, to be sure, not very clearly articulated). Yet if someone were to say: I am now going to call by the name of autonomy what everyone else calls, say, privacy, then this would completely 'change the subject'7 and only cause confusion. Worse even than the confusion, the subject would also be changed away from what got people interested in a discussion allegedly about autonomy in the first place - they were presumably interested in some of the ideas that are often referred to by that term. ${ }^{8}$ Similarly, most activists, policymakers, lawyers, etc. are interested in human rights because of the ideas, etc. connected to the term in daily usage or, more specifically, in the post-World War II practice of human rights. ${ }^{9}$ A conception of human rights had better not change the subject entirely away from that. ${ }^{10}$

Yet what exactly that means - not entirely to change the subject - is by no means crystal-clear. Taking the example of autonomy again, I think that one could sensibly say: I am going to discuss autonomy in one of the roles with which the term is often connected, for example in the role where a lack of autonomy is a necessary condition for forced admission to a psychiatric clinic - and autonomy then refers to something like the ability to make one's own choices. Here, a host of possible meanings of autonomy are left aside and, furthermore, the analysis might (by drawing, for example, on philosophical debates about autonomy) go on in a way that is considerably revisionist vis-à-vis certain practical usages. For example, the analysis might go on to say that, in the role of its lack being necessary for forced admission to a mental health institution, autonomy should be understood very differently than it usually is when people consider this role; or one might even doubt that a lack of autonomy could, in any understanding of autonomy (which preserved some kind of connection with 'the ability to make choices of one's own'), be a suitable necessary condition for forced admission to a psychiatric clinic.

I propose something quite similar for human rights. I want to understand human rights as the minimum requirements of global justice, where I conceive of justice in the Rawlsian sense of being the main virtue of social institutions (in this case of the global institutional framework, whether it be a world order constituted by largely sovereign states or some other kind of world order); ${ }^{11}$ and minimum requirements of justice refer to the requirements of justice that have to be fulfilled in order for the world to be just in broad outline, albeit not entirely. ${ }^{12}$ Content-wise, I understand human rights as, very broadly, having to do with the 
protection of the important interests of all human beings - an understanding that is, being put in this general way, a recognizable and probably quite central part of the post-World War II practice. Furthermore, seeing human rights as the minimum requirements of global justice is a recognizable part of the practice as well. Indeed, I would say that it is a recognizable part of the practice that (1) an important role of human rights is to want to offer a minimum moral ideal for the world (indeed, the main criterion that a global institutional order would have to meet); and also that (2) nothing else that human rights possibly also want to offer, no other role, should undercut this role. It is this role, and this understanding of human rights as being about the protection of everyone's very important interests, that the present book takes up. This means that this book's conception of human rights is, in the way discussed above, continuous with the post-World War II practice and that, as such, it may be said not to change the subject. At the same time, this conception of human rights is not being offered as the best interpretation - or even an interpretation - of the practice or of a part thereof. ${ }^{13}$

The further development of this conception of human rights - human rights understood first of all as offering the minimum requirements of global justice and as having something to do with the protection of all people's important interests will be undertaken in Section 2.2. It will take its main lead from existing philosophical debates about justice. ${ }^{14}$ I will discuss how, more particularly, to understand what a (moral) right is, and what a human right morally understood is (our conception, taking its lead from debates on justice, may be called moral); what a plausible list of human rights might look like; how one may think of the relation between rights and duties, and who are plausibly duty bearers; and I will again consider the weight of human rights. This will prepare the ground for discussing (in Chapter 4) how the book's conception of human rights is to deal with equality of protection among human beings, for discussing (in Chapter 5) how it is to deal with the inclusion of future people and for investigating (in Chapter 6) whether this conception in addition fulfils certain plausible motivational constraints. ${ }^{15}$

It bears emphasizing that nothing in these discussions and investigations is meant, as it stands, as a policy proposal, as direct guidance for activists or as a proposal for revising the law. Rather, what I envisage is to make a contribution to debates in what John Rawls calls the 'background culture' of a society - in universities, the media, schools, as well as in reflective discussions among diverse kinds of practitioners; it is in this sense that this book may be said to want to offer orientation for the practice. ${ }^{16}$ It is hoped that its contribution will be worthwhile for people from a wide variety of walks of life and backgrounds.

\subsection{What are the minimum requirements of global justice?}

Many questions arise if one regards human rights as the minimum requirements of global justice. This section will deal with three that are central: first, with what, more precisely, are the contents of these requirements (that is, on the 'recipient side'; I will deal both with what a moral right is and with what a plausible list of human rights would, approximately, look like); second, with 


\section{Preparing the ground}

how human rights relate to duties and with who are plausibly duty bearers regarding human rights; third, with how weighty human rights are. This section's aim is primarily to clarify (rather than defend) the conception proposed on the points where clarity is needed for Chapters 4,5 and $6 .{ }^{17}$ I will always strive, to the extent possible, to take positions that are not highly dependent on controversial theoretical commitments and that could thus be endorsed by people from a wide variety of backgrounds.

\section{Content (i): What is a human right?}

What, content-wise, are the minimum requirements of global justice about (on the 'recipient side')? I will begin by asking what a human right is, and take my lead from Henry Shue. Shue states that what he calls a moral right ${ }^{18}$ 'provides the rational basis for a justified demand that the actual enjoyment of a substance be socially guaranteed against standard threats' (italics mine). ${ }^{19}$ What I want to take from this, rather freely, is that moral rights are, at the core, about reliably protecting people's interests. ${ }^{20}$ (These interests are the 'substances'; I will come back to the notion of reliability in a moment.) Human rights, more particularly, are about reliably protecting very important interests. It is their concern with very important interests and, one may add, very important protections of them, that makes human rights so morally weighty and central. ${ }^{21}$

I want to add that, with human rights, the very important interests in question should concern broad categories of people, ${ }^{22}$ everywhere and possibly also always. ${ }^{23}$ If this were not so, and if they concerned interests that were only applicable to a small part of humanity, we would stray so far from the everyday usage of 'human rights' that we would make the notion unrecognizable. At the same time, however, interests of smaller categories of people can always also qualify as subject matters of human rights by being brought under more general headings. For example, the interest of the highly musically gifted in developing their musical capacities to some minimally adequate extent can be subsumed under the interest of people to develop their creative abilities to some minimally adequate extent. This latter interest is evidently applicable to very broad categories of people, and attending to it will, in the case of the highly musically gifted, inevitably imply that their musical abilities should be developed to some minimally adequate extent.

Shue says that a moral right is about 'guarantees'. Having a right means it shouldn't be possible that one's 'enjoyment of a substance' is taken away at will or overnight: there ought to be (well-enforced) laws or other suitable institutions (such as, in certain cases, customs) to protect the interest in question against threats. ${ }^{24}$ In my words, we are talking about reliable protection of very important interests. This is plausibly an essential part of what a right is. Equally important, meanwhile, is that the guarantee/reliable protection cannot be provided in the face of everything. According to Shue, it is against 'standard threats', which means something like predictable and prevalent threats. ${ }^{25}$ To be sure, this remains rather vague and Chapter 5 will explicitly raise the question of protection against just which threats is required as a matter of human rights. 
In sum: human rights, understood as the minimum requirements of global justice, state that certain reliable protections of very important interests ought to be provided. The interests in question concern broad categories of people everywhere and (possibly) also always. (Whether the protection of these interests should also be equal everywhere and always will be the explicit subject of the next chapter.)

But are there human rights so conceived? The answer will be affirmative, I will assume, if (1) there are very important interests, which are consequently worthy of reliable protection, and if (2) there are suitable duty bearers for protecting them. I will ask below whether (1) and (2) are indeed the case, and will conclude by revisiting the weight of human rights, in order to see as clearly as possible what is at stake in the (non-)realization of human rights.

\section{Content (ii): What human rights (if any) are there?}

Are there any interests so important that they are worth reliably protecting (and for which very important protections can be provided, otherwise it is all no use; there is, to take an extreme example, no human right to immortality)? To show that some interest, for example freedom of speech, is a very important interest, one can point to its instrumental importance for, for example, a well-functioning society - in the light of governance-related and economic considerations, etc. ${ }^{26}$ But one will also, and possibly above all, point to its intrinsic importance, which is perhaps best demonstrated by considering what happens to a human being when they have or, conversely, do not have freedom of speech (to remain with the same example): what this means for their ability to flourish, to be agents, to reach their ends, etc. In addition, one needs to consider certain objections, for example that (instrumentally) a prosperous society could be obtained without freedom of speech; or that (intrinsically), on some conceptions of the person, flourishing of the individual does not require freedom of speech; or that some forms of flourishing are not all that important in the first place.

In short, my suggestion is that the main way to establish the importance of an interest is by examining human experiences (broadly understood): by showing which will usually be through narrating, cf. also Chapter 3 below - what happens to people if these interests (to be able freely to express one's opinion, to have enough food, etc.) are, positively, reliably protected or, negatively, not reliably protected. ${ }^{27}$ If the account does not convince, the main response must be to try to show again, and now in a more compelling way, how important it is reliably to protect a certain interest. ${ }^{28}$ Thus, the same approach can be used to establish the importance of a given interest and that of a given protection. ${ }^{29}$ It will involve empirical elements (concerning what happens if certain protections are or are not in place, etc.), but also normative judgement (for example, concerning what is important enough).

Let us now ask what an adequate list of human rights would look like. ${ }^{30}$ Usually, very important interests such as the following are among the subject matters of human rights: being alive, being free from torture, being free to 
express one's views; ${ }^{31}$ freedom to engage in various forms of political participation; being able to have adequate food and work, and to be healthy. (These are, respectively, civil freedoms/rights, political freedoms/rights and socio-economic freedoms/rights; see e.g. the Universal Declaration of Human Rights [UDHR]. ${ }^{32}$ )

The main question here is not what precise list could plausibly fit with the conception of human rights developed above, nor whether this list would exactly conform to the UDHR. The question is, rather, what the broad outline of a list fitting with this book's conception would be, and how ambitious it would plausibly be. ${ }^{33}$

On the one hand, there may be serious problems with ambitious global ideals such as worldwide equality of opportunity. But these go beyond the most plausible articulations of human rights as a global ideal anyway, not least because human rights, as I understand them, only aim to articulate the main requirements of living together on a global scale. On the other hand, however, it seems unlikely that, by the criteria proposed above for there to be particular human rights (the importance of certain interests and of reliably protecting them; and the availability of suitable duty bearers, more about this shortly), the list would be very short. Both instrumentally and substantively, it is very important, not only to be safe and to be immune from torture, but also, among other things, to be able to participate in the decision-making in one's political community, to be healthy and to be able to have work; and consequently it is very important to have good protections of these interests in place.

\section{Who bears duties with regard to human rights?}

Are suitable duty bearers available for reliably protecting such interests? As indicated, I believe that, in order to make a case that there are any human rights, and more particularly that there are certain specific human rights, one needs not only to make the case that protecting the interests in question is very important, and that reliable protection of them can be provided at all; one also needs to show that certain parties have a duty to provide reliable protections of these interests. ${ }^{34}$

Are there such parties? For some duties, namely those not to actively violate human rights oneself (negative duties), the answer seems easy: everyone is a duty bearer. Now, Henry Shue distinguishes three kinds of duties that go with all human rights - if these duties did not go with them, we would have a very revisionary understanding of not only, say, the right to food (commonly called a socio-economic right), but also of such a right as that to freedom from torture (commonly called a civil right). ${ }^{35}$ First, there are, as said, duties that one respects human rights oneself (negative duties), which apply to every agent; ${ }^{36}$ second, there are duties to protect people against (potential) violations by third parties (intermediate duties); third, there are duties to ensure that human rights are more fully realized (positive duties). ${ }^{37}$

With regard to the intermediate and positive duties, there are at least three general considerations bearing on who should bear a duty. ${ }^{38}$ These considerations will be widely acceptable and do not depend on highly theoretical background 
assumptions. The first consideration is the causal contribution that an agent has made to the objectionable setbacks to an interest. ${ }^{39}$ The second is the capacity that an agent has to contribute effectively to a better protection of an interest, or even (although this may not be a necessary condition for having a duty) to contribute at little cost to themselves. ${ }^{40}$ And third - and related to the first two considerations - there must not be reasons why a certain attribution of duties can be deemed grossly unfair. To illustrate: an institutional scheme will always distribute duties in a way that may also have been different, ${ }^{41}$ but the important thing is that the attribution is defensible on the basis of considerations such as causal contribution and capacity, and that more generally it does not treat agents differently without good reason.

Now, there will, by these criteria, almost always be parties that should bear duties, also when we are talking about intermediate duties (to protect from violation by third parties) and positive duties (to ensure a fuller realization of human rights). Fulfilling these duties will provide protections, and it should be added that many parties also can and should, by the criteria just outlined, provide reliable protections - in the sense, explained above, that these protections can be counted on because they have been adequately institutionalized. ${ }^{42}$

In sum, there will be - as we have seen - several interests that are very important and worth protecting, and there will generally also be suitable duty bearers. Hence, there will be (several particular) human rights.

\section{How weighty are human rights?}

As said, I will conceive of human rights as the minimum requirements of global justice. More particularly, this means that, if human rights were fulfilled everywhere, there would only be minor injustices left in the world and no great injustices anymore. ${ }^{43}$ Human rights thus articulate what is the main part of global justice. (This is not to say that human rights are everything there is to justice. If one person has a palace and the other one has a modest house, ${ }^{44}$ this could in some cases certainly be unjust, even though there may not be any human rights problem.)

Furthermore, as explained, I follow John Rawls in thinking that justice is the 'first virtue' of social institutions: such institutions must, whatever other features they have, first and foremost be just. Thus, if human rights are such an important part of justice, they have a great deal of weight. This is so in the double sense that, first, someone who does not fulfil their human rights duties will, because of that, be very blameworthy ${ }^{45}$ and that, second, fulfilling human rights should usually get a lot of priority over other considerations. ${ }^{46}$

Can human rights really make good on this pretension of weightiness? I think they can, because, in line with what was said above, they will encompass all very important interests for which it is at all possible to provide some reliable protection. For example, they will also encompass the interests of small categories of people (for example, those who are highly gifted in some respect), and not only some small part of those interests. ${ }^{47}$ Thus, if one cares about protection of very 


\section{Preparing the ground}

important interests, one can turn to human rights to see what protections should most importantly be provided. This certainly supports the claim of human rights to weightiness.

In short: human rights, whose centre is the reliable protection of the very important interests of all humans, outline an ideal of a world with no great injustices left. Whether they can stand in the face of common relativist criticisms and criticisms that they are subject to political abuse will be the subject of the next chapter.

\section{Notes}

1 It may not be exactly clear whose understanding this colloquial understanding is. But it seems safe to suppose that many people might at least embrace something like this thin understanding, albeit perhaps also further and more specific understandings in addition.

2 The present chapter involves many relatively technical debates, more so than other chapters. Some readers will want to know where the book stands on those and, therefore, a relatively extensive footnote apparatus has been added. Those not interested in the technicalities may safely ignore it.

3 By a conception, I mean an answer to the question of what human rights are. (A concept, by contrast, would refer to the understanding of human rights that is already involved in the question 'What are human rights?'). Cf. Rawls (1999a), p. 5.

4 In a certain sense, it may be better to speak of 'broad categories of people everywhere and (possibly) also always', rather than 'all human beings'. See Section 2.2 below.

5 In thinking about the methodological matters now under discussion, I have learnt much from G. Dworkin's (1988) discussion of autonomy, specifically pp. 7-12.

6 Particularly inspiring in this regard is R. Dworkin about democracy as an ideal (Dworkin 2000, Ch. 4).

7 Griffin (2008), p. 3.

8 Years ago, I went to a talk by a well-known Dutch historian, who was going to discuss the American elections. He managed not to say a single word about them, and I left the talk with a bit of a hangover - even though some of the things he did address were worthwhile.

9 People's interest will, to be sure, not always be in this practice. For example, some philosophers and lawyers may be interested in the natural rights tradition, which goes back much further than the post-WWII practice.

10 It is a non-trivial question what the post-WWII practice of human rights is. There are several questions here: What are the boundaries of this practice? What is its most important content? What does it mean to call it a practice (or an 'emergent' practice, as it is called by Beitz 2009)? It is beyond the present scope to elaborate on all this. I will broadly understand the post-WWII practice of human rights as referring to the actions and words of policymakers, lawyers, activists, academics, etc. and citizens in general, in which the Universal Declaration of Human Rights and a number of treaties and institutions are central as points of reference. (Examples of these treaties and institutions are the International Covenant on Civil and Political Rights (1966) and the International Covenant on Economic, Social and Cultural Rights (1966), the UN High Commissioner for Human Rights, and the European, American and African regional human rights regimes with their treaties and courts.) As such, this practice is, it should be stressed, not exclusively juridical, nor perhaps even primarily. And of course, many elements of the practice are subject to contestation.

11 Rawls famously puts it as follows:

Justice is the first virtue of social institutions, as truth is of systems of thought. A theory however elegant and economical must be rejected or revised if it is untrue; 
likewise laws and institutions no matter how efficient and well-arranged must be reformed or abolished if they are unjust.

(1999a, p. 3)

Rawls (1999b) does not want to speak of global justice; but I believe that offering the minimum standards of global justice is an important role of human rights (and one they may well be good at, cf. note 14 below) and that this role can help us understand and think about other important roles of human rights, such as their being standards for governments, causes for activism, grounds for international concern and, in cases of grave violation, possible grounds for forceful intervention.

12 Underlying this idea is a sufficientarian idea of justice, which is not Rawls's. I interpret this idea as saying that there are particularly urgent reasons to provide a threshold level of goods, while the reasons change in kind and are less weighty once the threshold has been reached. Cf. Shields (2012), p. 101 and note 43 below.

13 Indeed: this book's conception is not offered even as an interpretation of a part of the practice - except that it maintains that certain elements (e.g. wanting to offer a minimal moral ideal for the world) are part of the practice and have a certain kind of importance in it; but there is no pretension of offering an exegesis even of these parts of the practice.

In not aiming to interpret the practice, my position differs from the one Charles Beitz (2009) is often held to take. But in holding that a conception of human rights has to maintain some relation with the post-WWII practice, my position may also be at variance with some - although certainly not all - 'naturalistic conceptions' of human rights (as Beitz calls them), according to which human rights are those rights that human beings have simply in virtue of being a member of the species. It is beyond the present scope to elaborate on this.

14 Many philosophers embrace, although almost always rather implicitly, the role of human rights of offering an account of the minimum requirements of global justice, e.g. Pogge (2008); Caney (2010); cf. also Nagel (2005); Miller (2007); Humphreys (2010); and this is the literature to which my account speaks and which it tries to take a step further, mainly by explicating what human rights as an account of the minimum standards of global justice could look like. I believe that human rights, if suitably developed, may provide a clearly attractive account, when compared to very minimal and very ambitious articulations of the minimum requirements of global justice. To defend this attractiveness would be a large undertaking and is not the aim of this book although the beginnings of a defence will be provided in Section 2.2.

15 Cf. note 17 below.

Ch. 3 discusses whether the ideal of minimum global justice can withstand relativist criticisms as well as the charge that it is merely a political pawn. As will become clear, the latter charge addresses itself more to human rights as they are found in the post-WWII practice than to the conception employed in the rest of the book.

16 For the notion of the 'background culture' of a society, see Rawls (2007), pp. 6-7. Relatedly, it should be noted that, if justice ideals are articulated in terms of moral rights (as I will do below), there is no presumption at all that juridical rights should directly mirror these. Buchanan (2013) rightly objects to such a 'mirroring view', as he calls it.

17 Here is why the chapters that follow require clarity about the three questions just mentioned. First, one knows too little if one only knows that human rights realization, which has something to do with the protection of the important interests of all human beings, is the content of the minimum requirements of global justice. Not until one has a clearer idea of what a human right is can one see how human rights are challenged by vast global inequalities (Ch. 4); by the need to take future people into account, including the extra claims and priority-setting problems that this entails (Ch. 5); and by possible problems of actually motivating people and arranging societies in accordance with human rights (Ch. 6). Second, one not only needs what a 
human right is to be clarified in order to know just what is being challenged; it evidently needs to be clear as well that there are any human rights at all and also, to a certain extent, what particular human rights there are. To get clear about this, one also needs to know - as will become clearer below - whether there are parties that could be suitable duty bearers with regard to human rights. Third and last, in order to know why human rights and the challenges to them matter that much at all, we need a good view of the weight of human rights.

18 One may also speak of a philosophical right, as opposed to a juridical one.

19 Shue (1996), p. 13.

20 Shue's emphasis on actual enjoyment and social protection points to his views on duties (that these are not merely negative) and duty bearers (that, on the one hand, states are not the only ones, but that, on the other hand, duty bearers do have to be able to provide guarantees). I will return to the notion of a standard threat shortly.

21 For the sake of readability, I will sometimes skip the 'very's in the rest of the book. But the idea remains that, with human rights, the interests and protections must be very important.

This is an interest conception of human rights (see e.g. Marmor 2015). Such a conception is widely prevalent in the literature. Compared with a will-conception of human rights (see e.g. Wenar 2015), it has the disadvantage, among other things, that it only partly accommodates that those having the rights should, where possible, be able to claim them themselves as autonomous agents. Meanwhile, one of its advantages is to allow more 'substances' as direct subject matters of human rights.

22 It seems unwise to demand that human rights apply to each and every member of the species. If this were demanded, it may be difficult to ground rights such as the right to political participation, and the list of human rights may become rather short. This is one way in which this book's conception of human rights generally takes distance from (what Charles Beitz calls) 'naturalistic' conceptions of human rights. Cf. footnote 13 above.

23 For 'always', see Section 3.1 below.

24 Cf. Shue (1996), p. 16.

25 The notion of a standard threat is a vital and original, but also problematic, aspect of Shue's discussion (cf. Beitz and Goodin 2009, 'Introduction').

26 For a related example, see Sen (1999), Ch. 6. Cf. also Christiano (2011), who, among other things, make an instrumental case for democracy and the rights associated with it.

27 This should happen in a way that is acceptable to people from a wide variety of backgrounds and walks of life, and which is thus compatible with a liberal social order which aims to accommodate a plurality of conceptions of a good life - as well as with many other social orders cf. also note 14 above.

28 It is also important to probe the presuppositions, coherence and consistency, and implications of what one wants to say about the importance of certain interests and of reliably protecting them. This approach has some similarities (but also differences) with Nickel (2007), pp. 61ff. The most prominent alternative approach for establishing the importance of interests is a transcendental one (e.g. Gewirth 1978, 2007), which typically explicates what a certain indubitable starting point (e.g. that I have to regard myself as an agent) already commits us (me) to. Such an approach - which I will not discuss and evaluate here - can also be used to establish that there are human rights in the first place. (It would, in doing so, typically adopt a will-conception rather than an interest-conception of human rights.)

29 Cf. Nickel (2007), Ch. 5. One element that remains somewhat problematic is the relevant baseline - usually the situation that will arise if the protection in question is not provided. It may not always be very determinate what this situation is.

30 For the spatiotemporal scope of application of such a list and for relativist doubts, see Section 3.1 below. 
31 As used here (in the articulation of the substance matters of human rights), free(dom) means that one can do or have certain things if one wants to.

32 Nickel (2007, pp. 93-95) distinguishes 'families' of human rights (which he takes from international human rights law): security rights; due process rights; liberty rights; rights of political participation; equality rights; social rights; and group rights, which may be the most controversial. A list will typically include both certain freedoms actually to do or have certain things if one wants to (e.g. to express one's opinion) and also certain actual enjoyments (e.g. to be free from torture). For a somewhat similar distinction, see Nussbaum (2000), Ch. 1, who speaks of 'capabilities' and 'functionings'.

33 It is interesting whether the length of such a list and the ambitiousness of the protections envisaged would conform to what is current in the present international practice of human rights (among other things, in the UDHR and other important documents).

A list of human rights typically indicates that protections of certain interests should be provided even considering that there are also other interests that call for protection. But for lists that are fairly generally formulated, this does not usually generate problems: if it is not exactly specified which protections should be forthcoming, there can easily be, say, both rights to certain liberties and to political participation of various sorts and various social rights. Cf. Section 3.1 below.

34 This means that I subscribe to what James Nickel (2007, pp. 28ff.) calls an 'entitlement plus' conception -the duty to not actively set back etc. an interest is co-constitutive of a right; but talk, disregarding this, continues to be of a 'duty not to violate etc. a right', and I will generally follow this usage - of human rights (cf. also Griffin 2008; pace Nussbaum 2006, p. 280). However, on this conception, some party does not need not be able to enforce that the duty bearers act as they should (see Nickel 2007; pace James 2005); if this were necessary, people in Syria may not have human rights.

35 Indeed, something like this (put even a bit more boldly than I do here, almost as a conceptual claim) could be taken to be the main point of Shue's 1996 [1980] book.

36 Pace Pogge (2008), who holds that only institutional agents can disrespect human rights. (Accordingly, I will also speak of human rights violations by e.g. individuals, although that can sound and be revisionist vis-à-vis common usage.) I lack the space to further elaborate on this point; suffice it to say that no agent, not even governments, can provide reliable protection on their own - so this is not a necessity for being a duty bearer.

37 Shue (1996), pp. 52ff.; a specific terminology ('respect, protect, fulfil') was adopted by the United Nations on account of Henry Shue's distinctions. See e.g. the Office of the United Nations High Commissioner for Human Rights (www.ohchr.org). Intermediate duties could also, among other possibilities, be of a remedial kind (cf. Shue 1996, Afterword).

38 Cf. Shue (1996), Afterword; Miller (2005). A fourth consideration may be the existence of a special relationship, such as that of co-citizenship or co-involvement in a cooperative scheme (e.g. trade). Cf. Section 4.3 below. For diverse considerations about human rights and duty-bearers (in a global context), see Kuper (2005).

39 For some complications of the notion of causality, cf. Wenar (2007). Often, talk of causality refers to making an active contribution to a situation that is morally problematic or problematic from the perspective of justice. See e.g. Pogge (2005), and for the notion of an 'active' contribution Scheffler (2001).

40 It may not be a necessary condition, but many (not all, cf. consequentialists such as Singer 1972) will deem the mere capacity to help out in a bad situation (that is, the mere capacity to do this without suffering an equal bad oneself) insufficient to generate moral duty. Cf. Philips (2007), Ch. 2.

41 Cf. Green (2005).

42 See Ch. 5 below. As Henry Shue points out, this need not always be done by the law: 'in [some] cases, well-entrenched customs, backed by taboos, might serve better than 


\section{Preparing the ground}

laws - certainly better than unenforced laws' (1996, p. 16). And, as many have pointed out to me, it need not always be done by governments; in certain contexts, other agents will provide more reliable protections (cf. O'Neill 2004). Incidentally, it seems unwise, given the reasons for attributing duties outlined above, to stipulate (as e.g. Beitz [2009] seems to do) that only states (or, in any case, primarily states, for at least the international community will also come in and it may not be entirely reducible to states) are the duty bearers of human rights - primarily each state for those on its own territory or its own citizens. If reliable protection of very important interests is at the heart of human rights, other parties could often have a role as well. (Shue's talk of 'social protection' rightly leaves the duty bearers open; 'social' only hints that the protection needs to be reliable.)

43 In other words, I think of justice in a (particular) sufficientarian way. Liam Shields characterizes sufficientarianism as follows: '[S]ufficiency principles... claim that we have weighty reasons to secure enough and that once enough is secured the nature of our reasons to secure further benefits shifts' $(2012$, p. 101). I would say that, after reaching the threshold of enough, not only do the reasons shift, they also become less weighty. Sufficientarian theories of justice have faced certain important objections, but I believe these can be answered (see Philips 2016).

The most influential sufficientarian account of minimal global justice - although it is not usually explicitly presented as such, in spite of speaking very explicitly of threshold levels - is Martha Nussbaum's (2000) version of the capability approach. Nussbaum also provides her theory, with its capabilities list, as a philosophical theory of human rights. However, she is not very clear about what, beyond intuitions, justifies her list (nor about problems of prioritization, which will be discussed in Ch. 5 below).

44 This example was made famous by Marx (1973), who uses it in a different context.

45 I have said that whether there is a particular human right will depend, among other things, on the availability of suitable duty bearers. Does not the weight (in the sense to do with blameworthiness) of such a right also depend on the weight of fulfilling such duties? My answer is that the blameworthiness of not fulfilling these duties is great, because the reasons (such as causal involvement; capacity to act at little cost) are clear and strong - regardless, incidentally, of whether one is speaking of (co-) citizens or strangers. And these reasons are all the clearer and stronger because of what is at stake: reliable protection of very important interests.

46 More about this in Ch. 5 below.

47 In this sense, I believe that human rights do accommodate every member of the species. (But they do not in another sense: not every right on a plausible list could credibly be applicable to every member of the species.) 


\title{
3 Common challenges to human rights
}

\author{
The relativist and the political \\ pawns challenge
}

This chapter deals with two further challenges to human rights, beyond those central to this book (the challenges of global inequality and of future people) and also beyond the question of motivation. These two further challenges, which I will call the relativist challenge and the political pawns challenge, are perhaps the most common 'all-out' challenges to human rights. It can be observed that they testify to a scepticism about human rights that is no longer moderate and no longer only concerns certain aspects of human rights, but that is rather pervasive and deep. The relativist challenge says that human rights have no universal validity, but only validity relative to a certain spatial or temporal (social, cultural, etc.) context; ${ }^{1}$ the political pawns challenge states that human rights are just pawns in a political power game - nice-sounding cloaks over a reality of power politics - which do not make any difference for the better and may even make things worse. ${ }^{2}$ I assume that most readers of this book are not so sceptical about human rights as to be drawn to these challenges. Still, both challenges are too important to leave them unaddressed, and too prominent in current debates (about, among other things, the end/future of human rights); ${ }^{3}$ and that is why I discuss them in this chapter. ${ }^{4}$ I shall try to outline some of the most plausible ways in which they may be construed - and answered, if (as I think) they can be. A lot has been said about these challenges, and my ambition is not, as in Chapters 4-6 below, to add to the relevant philosophical literature, but only that what I say is adequate in light of this literature. ${ }^{5}$

Importantly, if the aforementioned challenges get it right, this may well show that human rights are not fit for being the minimum standards of global justice or, in other words, for providing the most important requirements with regard to living together globally, which is the most important role that I have envisaged for them. This is not only true for the relativist challenge, in important versions of it, but also for the political pawns challenge. Furthermore, if the challenges are right, human rights may well not be fit for other important roles either, such as guiding cross-national activism and international policy, nor for - in cases of gross violation - possibly justifying forceful intervention. ${ }^{6}$ Thus, there is really something at stake when one asks whether the challenges get it right. This chapter will argue that, in the respects that matter the most, they often do not. ${ }^{7}$ 


\section{Preparing the ground}

\subsection{The relativist challenge}

I propose to understand relativism about human rights as the claim that human rights do not have universal validity, but some more restricted scope of validity relative to a culture, an historical era, a person, etc. or, more generally, a restricted spatial or temporal scope of validity. ${ }^{8}$ Relativism, so understood, is not the position on which the American Anthropological Association relied in objecting to the Universal Declaration by, among other things, asserting that 'standards and values are relative to the culture from which they derive'. ${ }^{9}$ By contrast, the relativist position that the present chapter deals with has no problems with universally valid standards, etc. as such; it simply holds that human rights claims have no universal validity. ${ }^{10}$ In fact, I think that in some ways there is something to this relativist position, as shall be explained. But it depends on the exact human rights claims that one is talking about - on their content and, relatedly, their level of generality. I begin by discussing some places where I believe relativism to be wrong, and then increasingly move to points where I believe it is right. Finally, the implications will be considered for the roles that human rights can take on. In this regard, one can say that the relativist challenge mostly gets things wrong.

One of the key features of human rights in this book's conception - and plausibly also in the post-World War II practice ${ }^{11}-$ is that they are about reliably protecting very important interests. And a second commitment involved at a fundamental level, all people matter equally, in the following sense: the important interests of all people - from everywhere and from always ${ }^{12}$ - matter a lot, and are candidates for protection. (However, as will be argued in Chapter 4, human rights do not by definition imply that the protection should in the end be equal. But often it should be.) What is the reason for accepting these two points - that reliable protection of very important interests matters a lot, and that this is so with every person's important interests? I repeat here, at greater length and explicitly with an eye to providing an answer to the relativist, some points that were already made in Chapter 2. I would say that the best case for them can be made by looking at what it implies for people if their important interests are, negatively, disregarded or, positively, attended to. ${ }^{13}$ The best way to do this is perhaps to tell stories. I am thinking of accounts that show, by narrating, what happens to people: What does it look like if people (negatively) lack safety or go hungry or, conversely (and positively), when they are safe and well-fed? Such stories can show why it matters a lot that people's, and all people's, very important interests are looked after and what goes wrong when they are not. ${ }^{14}$ And they can also show why it is important reliably to protect such interests, so that people can count on these interests being attended to: it adds something real, over and above having enough to eat now, that you can reasonably count on also having enough to eat tomorrow - and the day after tomorrow, etc. Furthermore, the stories will also make it clear what interests matter particularly and in what ways - from having enough to eat to having some control over your environment, ${ }^{15}$ to being able to make certain decisions of your own, to having a measure of respect from others. ${ }^{16}$ 
Let me offer one example of a story - Primo Levi's harrowing account of Auschwitz in If This Is a Man - which shows this importance in a negative way, by showing what happens to people if a number of their very important interests (among others, those to be treated respectfully, to be able to count on having enough to eat, to be able to take care of one's body) are flagrantly disregarded:

... my sleepiness is masked by a state of tension and anxiety of which I have not yet managed to rid myself, and so I talk and talk ... I have too many things to ask. I am hungry and when will they distribute the soup tomorrow? And will I be able to eat it without a spoon? And where will I be able to find one? ... [I] soon slip into a bitter and tense sleep. But it is not rest: I feel myself threatened, besieged, at every moment I am ready to draw myself into a spasm of defense. I dream and I seem to sleep on a road, on a bridge, across a door through which many people are passing. And now, oh, so early, the reveille sounds. The entire hut shakes to its foundations, the lights are put on, everyone near me bustles around in a sudden frantic activity. They shake the blankets raising clouds of fetid dust, they dress with feverish hurry, they run outside into the freezing air half-dressed, they rush headlong towards the latrines and washrooms. Some, bestially, urinate while they run to save time, because within five minutes begins the distribution of bread, of bread-BrotBroid-chleb-pain-lechem-keynér, of the holy grey slab which seems gigantic in your neighbour's hand, and in your own hand so small as to make you cry. It is a daily hallucination to which in the end one becomes accustomed: but at the beginning it is so irresistible that many of us, after long discussions on our own open and constant misfortune and the shameless luck of others, finally exchange our ration, at which the illusion is renewed inverted, leaving everyone discontented and frustrated....

Bread is also our only money: in the few minutes which elapse between its distribution and consumption, the Block resounds with claims, quarrels and scuffles. It is the creditors of yesterday who are claiming payment in the brief moment in which the debtor is solvent. After which a relative quiet begins and many take advantage to go to the latrines again to smoke half a cigarette, or to the washrooms to wash themselves properly.

The washroom is far from attractive. It is badly lighted, full of draughts, with the brick floor covered by a layer of mud. The water is not drinkable; it has a revolting smell and often fails for many hours.... ${ }^{17}$

If someone is not convinced by such stories, the most important reply that remains may be to tell them in a better way. ${ }^{18}$ Admittedly, for some interests, it will be very easy to tell a convincing story (as with the interest in having enough food of good enough quality) and for others it will be quite hard (as with having 'periodic holidays with pay', ${ }^{19}$ to take a common example). But what matters is that there will be a number of very important interests of which it is very plausible that their being reliably protected matters a lot, and matters a lot no matter whose interests they are. ${ }^{20}$ This is arguably so for all of the 'six families' of 
human rights (which concern having security; receiving a fair trial; having certain liberties; being able to participate politically; being equal before the law; and having one's basic material needs fulfilled) ${ }^{21}$ Moreover, the importance of reliable protections of these interests does not depend on highly theoretical or technical assumptions and may thus possibly be shared by people from widely different backgrounds.

However, the case for universal protections is not yet complete, even if one could convincingly show that certain interests matter a lot, and for broad categories of people everywhere and always. That is, the case is not yet complete if one wants to show that it is not only universally valuable for there to be reliable protections, but that there should also universally be such protections - which is what a human right asserts. To show the latter, one also needs to consider whether there are appropriate duty bearers - parties who should provide the protections in question.

What can one say about duty bearers? Here too I repeat (this time briefly) some things that were said in Chapter 2 above, now with a view to providing an answer to the relativist. To begin with, it should be relatively uncontroversial that agents must never (save perhaps in very - very! - exceptional circumstances) actively jeopardize the fulfilment of people's important interests, for instance by starving people or putting them in a position where they are much more vulnerable to being starved. ${ }^{22}$ There would be drastic implications if such a prohibition were not accepted..$^{23}$ What should one say when it comes to furthering the reliable protection of interests, and making sure, among other things, that people are protected from active disregard by third parties? Here it seems plausible that parties have duties at least when they can effectively do things at no great costs to themselves, and when no great unfairness is involved (it would be involved if, for example, it is obviously much more appropriate to assign the duty to some other party). Besides, if an agent has played a greater role in bringing about a problem with the protection of an interest (if they 'broke it'), they will plausibly also have to play a greater role in fixing it. It is important that these thoughts about appropriate duty bearers are not highly theoretical and that they are acceptable to people from very different walks of life. Frequently, they may be accepted already in virtue of reflecting on the implications if one were not to accept them.

The conditions discussed are relatively general, though, and one must take care not to jump to conclusions as to just what protections they can show to be valid across space and time. 'Everyone has the right to a standard of living adequate for the health and the well-being of himself [sic] and his [sic] family [sic]' (UDHR, Art. 25(1)) may, if 'himself/his' and 'family' are read broadly, be valid across place and time - although this will depend, among other things, on what 'adequate' means. After all, in all places and times, reliably protecting such a standard of living is important, and - by the criteria just mentioned - there may always be at least certain protections for which there are suitable duty bearers. ${ }^{24}$ However, Article 25 then goes on to mention some things where there may, in some times, be too few suitable duty bearers for providing meaningful protections (except for the more negative duties of not actively disregarding, and often also the intermediate 
ones of protecting from active disregard) such as, depending on what we mean by it, 'medical care and necessary social services', ${ }^{25}$ although one should not adopt a resigned attitude all too quickly here. If there were no appropriate duty bearers, the spatiotemporal scope of validity of this right would be more restricted, and one would have to resort to a more general - or just different - formulation to preserve universal validity. But often there will be appropriate duty bearers across time and place, and then there will be a case for the universal validity of a human right, if it can also be shown that reliable protection of the interests in question is important for wide categories of people across time and place.

Yet there may be the following complication: although certain interests are very important and there are suitable duty bearers available for protecting them, there is a price to protecting them. For instance, a society where certain freedoms to lead one's life by one's own lights are guaranteed will likely be a society where some people will lose out and become depressed or addicted to alcohol. This raises the question of whether certain protections of, say, freedom of thought and of choice of occupation, will really have to be provided at all places and times - all-things-considered. Or could it be that the protections of other interests will at certain times and places have to take priority? ${ }^{26}$

In reply to this question, it should first be observed that a large part of the interests that human rights are concerned with take the form of what Amartya Sen and Martha Nussbaum ${ }^{27}$ have called real freedoms: people should be able to eat well enough if they want to, to develop their creative capacities if they want to, etc. The freedom should, on the one hand, not be merely formal - people should really be in a position to eat well enough if they want to - but it should, on the other hand, also be a freedom: people should not be forced to eat well. ${ }^{28}$ Now the claim involved in human rights is that the stories show that it is important for broad categories of people everywhere, and also always (more about this in a moment), to have certain real freedoms - even if that results in certain kinds of social losses. So, the claim is indeed that human rights outweigh other considerations - and this is, of course, a very distinctive and non-trivial claim when made, for example, about freedom of expression, freedom of political participation and the freedom to choose one's occupation.

In short, then, the claim is that the stories, plus certain relatively uncontroversial ideas about duty bearers, show that an adequate list of human rights - which will typically, think for instance of the UDHR, be fairly abstract - can claim allthings-considered validity for all the specific rights on it. All the interests with which the list is concerned will have to receive meaningful social protections, everywhere and always.

Second, however, the more precise protections that will have to be forthcoming can vary to a certain extent between times and places. In other words, at a more specific level (where the setting of priorities among human rights will typically have to take place ${ }^{29}$ ), universal validity of human rights may be said to be less plausible - although, often, equality of protection (especially across place) will be a requirement here too (see Chapter 4 below). 
Finally, and importantly, the general/abstract level is usually the one that critics of the universal validity of human rights have in mind. Moreover, universality at this level - where I have argued it is most plausible - is what matters most for the ability of human rights to offer a framework for living together on a global scale. After all, a global charter cannot help but be relatively general.

So much, then, for an answer to the relativist. I will now consider a complication of that answer with regard to the (distant) past.

\section{Universal validity of human rights across time}

Now, someone might ask whether it is at all plausible that human rights have universal validity across time if this extends very far into the past, say back to the ancient Egyptians. (Or perhaps also: What does it even mean to say that human rights are also valid for the ancient Egyptians?) And wouldn't it be a serious problem if human rights were not so valid across time (or if we could not judge whether they are)? My answer is, again, twofold: first, there may indeed be difficulty, although one should not exaggerate, in extending the validity of human rights across time - or at least there may be doubt whether it is justified to so extend them. Second, however, these problems are not often in play in the cases we need to judge. Let me elaborate.

There seems to be no great problem in saying that for the ancient Egyptians, too, it was a very important interest reliably to have access to adequate food and that there were suitable duty bearers around for providing protections of that interest. We may feel less sure, although not so much so, when we are thinking about their ability to speak their mind. And when we are talking about a free press or their ability to vote, the most one can say is that it might have been important for them to have had institutions where such freedoms could be made sense of. But since their way of life and world is so far removed from us, it may be difficult to judge whether this statement is justified, and also what the statement could even mean - although, once more, we should not exaggerate the difficulty.

It is important, though, that, as Bernard Williams remarks, we - people now alive - need not make the choice as to what to do in this case. ${ }^{30}$ (A contemporary case we need not judge is that of an undiscovered Amazon tribe.) More important, then, is the question as to whether (certain) human rights are universally valid in cases that we can affect through action. This can involve punishing someone for alleged human rights abuses that happened 40 years ago (or, thinking of place, for making out whether human rights standards are appropriate yardsticks for judging certain practices now occurring in some faraway country). Here the situation is typically much closer to us in time or place and there are consequently many more ways to investigate whether the interests in question are important for the people concerned, and whether there are appropriate duty bearers available. It should be noted that people sometimes, also in some of the more nearby times (and places), seem to be excused because they could not reasonably have known. Yet, however this may be, one might say that human 
rights are still valid in such cases (and sometimes there will be duties on certain parties to make sure that other parties know).

Finally, things could be different for people who may live in the future: getting clear about what their important interests will be can be difficult. But it is certainly, and inevitably, within our power to take action that affects the future. So, we will have to act on the most defensible assumptions that we can make, and we will often have to focus on providing all-purpose means, which will serve future people in a very broad array of possible interests that they may have. To have adequate all-purpose means may itself be called an interest that future people will have. We may, in other words, have to focus on those interests that people will certainly (or plausibly ${ }^{31}$ ) have, regardless of what other ones they may also have; and also on interests whose fulfilment will be a precondition for meeting a wide variety of other interests.

Still, thinking about the future could give rise to a form of scepticism about the universal validity of human rights that arises less clearly when thinking about the past: human beings, or the conditions in which they live, might change in such ways that even those interests are called into question about which we (now alive) feel certain that they will be important for people living in the future; think about having enough to eat or receiving a fair trial. And the same is true for the availability of suitable duty bearers about which we may now feel certain. Perhaps the biological make-up of people far away in the future, and their institutions for living together, will change in such ways that one can doubt the importance of certain interests or the availability of appropriate duty bearers.

Yet I do not think that such a remote possibility - which, importantly, is even less likely to be applicable to people in the not so far-off future than to people in a very far-off future - should give one doubt about the universal validity of human rights. We know that the biological constitution of human beings, and the social and natural conditions of their life on earth, are always open to change just as, in certain respects similarly, our knowledge about what interests are important for human beings and about who could be suitable duty bearers is always open and provisional. This should not hold us back from going with those interests that we now, with good reason, judge to be widely important for people across time and space. Nor should it hold us back from going with the judgements that we now have good reasons to accept about appropriate duty bearers. In these cases, our present estimates surely suffice for regarding human rights as universally valid, also where the future is concerned. Human rights will thus, in so far as this depends on universal validity, be a suitable articulation of the minimum requirements of global justice, and one that is fit for the future.

\section{Concluding considerations}

So far, I have considered the universal validity (or lack thereof) of human rights if they are articulated relatively abstractly or, in other words, at a relatively high level of generality, such as that of the UDHR. (At this level of abstraction, among other things the articulation of the required protections, and sometimes 
also of the interests to be protected, has a certain vagueness.) I have argued that, considering the interests in question and the availability of suitable duty bearers, many human rights plausibly have universal validity - some meaningful protections of the interests at the centre of these rights plausibly ought to be provided at all times and places. True, when talking about their universal validity across time, one may have doubts about some human rights, but mostly this will concern cases where taking action is not in question (the far-off past). Talking about human rights in the future raises the difficult question of what assumptions to make about future people - for example about what very important interests they will have. Here it will frequently be best to go with very important interests that people will plausibly always have, no matter what other interests they may also have, as well as with interests that they will plausibly in any case need to have met as a precondition for meeting a wide variety of potential very important interests.

How are things when one is talking about a more concrete level, where it is discussed specifically which protections are in the end to be provided as a matter of human rights? Some of the most important factors here are the wealth of a society and its technological capacities. These will, at a given point in time, not easily justify inequalities in protections across and within countries, although they sometimes will. ${ }^{32}$ But they will often justify inequalities of protection across time: in a time with much greater wealth and technological capacities, more protections of important interests will, concretely speaking, be required as a matter of human rights. ${ }^{33}$ More generally, there will be more variety and less universal validity across place and especially time if one considers human rights protections at a relatively concrete level. This, however, is not typically the level that those engaged in debates about the universal validity of human rights are first of all interested in. These debates are usually above all concerned with the more abstract level (the level, broadly, of the UDHR): not with the exact protections, but with the list of interests for which some meaningful protections which will typically be only moderately specific - should be forthcoming. And there, I have argued, universal validity is often much less problematic.

\subsection{The political pawns challenge}

I will now address the second challenge: the political pawns challenge, which holds that human rights are being used as tools in political power games. Or, more precisely, human rights are supposedly a nice-sounding cloak over political realities where, really, the self-interest of states carries the day. As such, human rights may at best be useless; but the charge is that they often are something worse. Not only do they keep many people (at ministries, NGOs, etc.) occupied in useless heaps of paper and verbal exercises - people who could otherwise perhaps somewhere make a real difference for the better. But they also serve to cover up deeds and practices that are really driven by other, sometimes unsavoury, considerations. States (as well as business companies, etc.) act, so the thought goes, on the basis of political and economic interests and the like - and this will often, but not always, be alright - yet they sell it as serving human rights. ${ }^{34}$ 
This charge is naturally directed against human rights as we find them in post-World War II practice of human rights - and whether it gets things right is in large part an empirical question, something to which I will return shortly. However, the charge may end up discrediting any endeavour to take the postWorld War II practice into the future (to understand an important part of it in a possibly revisionary way, etc.), as this book has been trying to do. Relatedly, the charge is most naturally read as one that applies in non-ideal situations in our current real world; but those who make it typically go further and say that therefore because human rights function as pawns in political power games in our present world - they are broke: if we think about transforming our current world into a (more and ultimately fully) just world, human rights cannot be part of that just world; they will always be abused. More precisely, something that is in important ways related to the current practice - e.g. something concerned with reliably protecting very important interests, something trying to provide a minimum ideal of global justice - will be beyond repair and we will have to start anew in order to be able to arrive at a just place. In short: the challenge is typically about our present, unjust world and I follow it in that, for this chapter is about addressing the challenge as it is commonly made; but it has implications that go beyond these non-ideal contexts.

With this in the background, let us now for a moment assume that the political pawns charge does get things right. One reply to it could then be that it does not concern human rights themselves. The charge is rather, it might be said, about the abuse of human rights, and that is no reason to get rid of human rights in international and national practice. Yet this is not very convincing. Suppose that human rights are used to cover up dubious power politics and the like (some politics of, for example, taking influence in other societies, also forcefully) and that in many contexts there is no way to repair this. Would this really be no reason to try to get rid of human rights in the contexts concerned, if possible? What would it mean to say that in such contexts the problem is not with human rights themselves, but with how they are used?

It seems more plausible to say that human rights do have a serious problem if the charge is right. (Consider: if they irredeemably functioned as cover-ups in certain contexts, could they be plausible as specifying principles for living together in these contexts?) However, whether one should get rid of them remains dependent on the alternatives one has. These may be quite sobering. More particularly, if human rights are irredeemably used to cover up dubious affairs (and possibly serving as justifications for them), it may well seem better to have nothing - that too is an alternative - in the way of requirements for living together on a global scale, rather than having a practice of human rights.

Is this, however, a plausible picture of what has really happened or is really happening? As said, the answer to this has many empirical aspects. In theory, one may equally well think that high-sounding human rights talk serves to cover up unsavoury realities as, say, that it leads to a civilizing form of hypocrisy ${ }^{35}$ that such talk could lead people to engage in corresponding action, for example in order to avoid cognitive dissonance. ${ }^{36}$ Now, the empirical record is, as far as I 


\section{Preparing the ground}

can see, unclear. Not seldom does there seem to be a kind of stand-off between observers. On the one hand, there are those who point to instances where the paperwork and the treaties seem to have made no difference, but have only created a shadow reality or worse. ${ }^{37}$ On the other hand, others hold out hope and point to instances where appealing to human rights does seem to have contributed to making a difference for the better - in furthering minimal respect, peace, a culture of civility, equality, etc. ${ }^{38}$ Both sides can, it seems, rely on robust evidence.

To take the sides in reverse order now, on the upside, there are not only human rights activists - NGOs such as Amnesty International and Human Rights Watch are cases in point - which have in certain cases achieved freedom for prisoners of conscience and which are effective advocates for groups that are marginalized because of their political convictions, ethnicity or sexual orientation. But there are also, for example, relatively well-functioning regional human rights systems, such as the European one, which have often led to effective legal protections of the human rights of vulnerable and other groups. In addition, one may make a case that, even with such a horrendous event as the Rwandan genocide of 1994, an appeal to human rights - although, crucially and disastrously, it was not enough to bring about timely action - helped to an extent to articulate the outrage and facilitated subsequent institutional changes, such as an early-warning system for genocides and the UN adoption of the 'Responsibility to Protect'. 39

On the downside, the international prominence of human rights was, as said, not enough to stop the Rwandan genocide, and human rights did provide a nicesounding rationalization for interventions (perhaps most notoriously the one in Iraq in 2003) that really weren't justifiable by a concern for human rights, ${ }^{40}$ let alone motivated thereby. In fact, for all their prominence in international talk, human rights continue to be a relatively low foreign policy priority with, for example, Western countries. ${ }^{41}$ And the UK, for example, even continues to have a role in the trade of torture instruments. ${ }^{42}$ Thus, the picture seems mixed. Appealing to human rights has done some good, but on other occasions remains rather toothless or even a cover-up for dubious activities and policies.

Let us return, at this point, to the question of what alternatives to human rights there might be. One alternative, as indicated, is to have nothing in the way of a narrative/ideal or something similar to guide living together on a global scale. What would happen then? Presumably, power politics would often carry the day, although this need not always be so. Where it did, people would be likely to articulate their misgivings. Further, they may well try to formulate alternatives, bringing some coherence into their thoughts. And they may try to give these alternatives some teeth. They may, for instance, seek to get them reliably implemented in policy. If something like this should happen, the result would likely be very close to a set of requirements / a (minimum) ideal for living together on a global scale, with a related practice, where prominent articulations of these requirements were discussed and put to various uses.

Perhaps these requirements and the related practice would turn out to be another alternative to human rights: they could differ both from some acceptable 
interpretation of the post-World War II practice of human rights and from this book's conception (which of course holds on to some relation with the postWorld War II practice, as explained). However, there would, on reflection, at the very least be a number of important resemblances: it seems likely, if the stories (referred to above) about the importance of certain interests are convincing, that reliable protection of important interests, and of all persons' important interests, will be quite central to these new requirements - just as they are central to both the post-World War II practice and to the present book's conception of human rights.

Now, if it is right that the new requirements would in important ways resemble those that we now have (in the post-World War II practice, etc.), then why abandon those in the first place? One answer could be that the surmise that I just made is incorrect: the new requirements will in very important ways be different from the old ones after all. For instance, the list of rights could differ in a number of ways. It might put more emphasis on environmental concerns, say, or on group rights, or less emphasis on states as duty bearers. However, the differences that I would think of, such as those just mentioned, do not seem to be so fundamental that they amount to a complete overhaul. They are closer to making repairs, more or less locally (that is, as opposed to all over), in the present practice of human rights. And it should not be controversial that repairs are needed. ${ }^{43}$

Another answer may be that it does sometimes help to start all over again - or even that it may be a good idea to do so periodically - even if what you are going to build is something that, in important ways, much resembles what you had (the post-World War II practice of human rights). Then the hope is, of course, that it will resemble it in the good ways, such as sometimes succeeding in reliably protecting very important interests, and that it will not resemble it in the bad ways, such as serving as a cover-up for dubious practices. I think that the answer to this must be that, yes, sometimes it is a good idea to start all over again. But only if you have to, and if you can hope to do a better job. You would not tear your house down to build a rather similar one if you could make local repairs. And, even if you could not make local repairs, you would only build a new house if you could hope to avoid the shakiness and leakages, etc. of the old one. ${ }^{44}$

However, what about the following case? You do not have to tear the old house down because it has so many shortcomings, but you do have good reason to think you will do a much better job by building a new house. Then there may, I believe, indeed be a good case for building a new house. Importantly, though, this is still a case where (1) there are serious shortcomings in the current practice of human rights and where (2) you can reasonably expect to do much better if you start anew.

Now, while the first condition might arguably be fulfilled, I believe this is often debatable for the second: it is unlikely that many major shortcomings of the present international practice of human rights are avoided if one were to start anew (whatever exactly 'starting anew' may mean, for that matter: it is not so easy to fill that out concretely). 


\section{Preparing the ground}

True, careful institutional design, with appropriate checks and balances, etc., may avoid some problems that the current practice has, such as human rights being inappropriately appealed to in certain policy contexts, or human rights involving foreign policies being carried out without due regard for local circumstances or for what marginalized groups want. ${ }^{45}$ But there are also shortcomings that are so deeply ingrained in the biological, social, etc. features of human beings that they will not be greatly avoidable. Geopolitical considerations which, to be sure, have their legitimate place in policy - are likely to retain a great influence on the policy priority that human rights get; and human rights will continue sometimes to function as disingenuous excuses for power politics.

After this consideration of the limits of the improvements to be expected from starting anew, let's also recall that the present practice of human rights presents a mixed picture, with both favourable and unfavourable aspects. If so, I find it unclear that whatever improvements one can reasonably expect from starting anew could not in many cases also be achieved by making local repairs. ${ }^{46}$ Examples of what could be achieved - and sometimes already has been achieved - by local repairs are institutional improvements such as, for example, the Responsibility to Protect; the promotion of a name-and-shame culture; and introducing structured practices, on the part of governments that subscribe to human rights, of carefully examining local circumstances and somehow involving local people when carrying out foreign policy.

In short, then, the political pawns challenge could be answered as follows: the present practice of human rights seems a mixed bag, rather than one beyond repair and hopelessly pervaded by power and interest politics. And it seems plausible that 'starting anew' will not avoid all problems and that, arguably, necessary improvements frequently do not require starting anew. To this one may add that starting anew (whatever exactly that means) is politically probably a very bad idea in our current world; it is very dubious that a new 'house' for living together on a global scale could be constructed in the foreseeable future, let alone one that does significantly better than human rights.

\subsection{To conclude}

This chapter has considered two very common challenges to human rights, the relativist challenge and the political pawns challenge. These challenges, in the versions that one often finds and that I have discussed, are more all-out critical of human rights than the three challenges that form the centre of this book (see Chapters 4-6). Still, they are so frequent that they need to be considered. The relativist challenge, as I have understood it, denies that human rights can claim universal validity. As a consequence, they are not deemed fit for playing such roles as providing the most important requirements for living together globally (as well as, among other things, guiding transnational activism and, sometimes, in cases of grave disrespect, potentially justifying forceful intervention). In reply, I have argued that one should distinguish between different human rights claims with, among other things, different contents and levels of generality. The 
scope of validity of such claims can vary. At the same time, one can draw on the importance of certain interests, and that they are important for everyone, and also on broadly acceptable thoughts about when agents have to bear duties. On this basis, many human rights claims - typically relatively general, but not empty ones, think of civil, political and socio-economic rights such as those mentioned in the UDHR - will plausibly have wide validity across place, and relatively wide validity across time. This will be enough to make human rights suitable for providing the main requirements for living together on a global scale and for playing a number of other important roles.

I want to emphasize that one must remain cautious with regard to what this means in practice. Suppose that certain agents plausibly bear duties to protect some people's access to food (say, that of English citizens) against certain threats. May they then impose these protections on the people in question? Sometimes this will be so, but they have to take great care that they know the context in which they operate very well. And it is also an important interest for these people to decide themselves about things that greatly matter for their lives. This interest might sometimes justifiably be overruled, but surely not very easily.

The concerns just raised already point in the direction of the second challenge discussed in this chapter: that human rights may be complicit in political power plays, etc. This challenge mainly concerns our present (highly non-ideal) world, but it may have wider implications - human rights may in general seem so much beyond repair that they cannot even be shaped into something just. The way in which human rights may be complicit in political power games would, according to the challenge, for example be that they cover up these games in nice talk, or that they keep critics of such games silenced in useless paperwork. Such things do happen, but equally there is evidence that human rights play positive roles in guiding activism, governmental policy, etc. I have argued that we should only let go of human rights if there are serious shortcomings in them that we can avoid by having an alternative. It is dubious that this is indeed the case. Especially, it is not evident that we can do much better by turning to an alternative for human rights. However, continuous vigilance remains needed, as well as continuous 'local repairs' and improvements - which should also, emphatically, include learning from relatively disenfranchized groups. We should aim to get an ever better view of where human rights coincide with power interests, and keep improving the institutional framework of checks and balances for preventing undesirable instrumentalization of human rights.

In short, then, it can be admitted that it is too simple unqualifiedly to say that human rights are valid across time and space, and similarly to hold that the occasional or even widespread abuses of human rights are the abusers' problem, rather than a problem for human rights as a practice. On the contrary, one will have to take on board quite a few concerns expressed by the relativist and political pawns challenges. Yet in the end, it will often be possible to answer these challenges, or so I have argued.

Against this background, we now turn to other challenges and questions that remain for human rights, starting with the challenge of global inequality. 


\section{Preparing the ground}

\section{Notes}

1 Some important and current references about relativism and human rights are: Donnelly (2013); Nickel (2014, 2007, Ch. 11); Williams (2003); and Ibhawoh (2001) and Sen (1999), also on Asian values, with which this chapter will not explicitly engage. See also e.g. Bauer and Bell (1999). Furthermore, all the literature that tries to argue for the existence of human rights (e.g. Gewirth 1978, Beitz 2009: see Ch. 2) deals, at least implicitly, with questions of relativism and human rights.

2 For some contributions that emphasize and detail - sometimes under the heading of debating the future or even end of human rights - the political abuse of human rights, see Bob (2019); Douzinas (2007); Hopgood (2013); Kennedy (2004); Posner (2014). (To be sure, these authors do not always go so far as to say that human rights make no difference for the better or actually make things worse.) This literature is usually not philosophical - not explicitly at least - but it is highly relevant to the political pawns challenge, which I take to have clear philosophical aspects, speaking as this challenge does of 'making a difference for the better' or 'making things worse' (better/worse in terms of, among other things, the protection of important interests).

3 See note 1 and 2 above.

4 Thus, the reason for discussing them in the same chapter is not that they would have something substantive in common.

5 Or, to be more precise, that it is adequate in light of the philosophical - or philosophically highly relevant - literature on the subjects. As far as I can see, the answers that I propose in this chapter have, in large part, not been proposed in this literature, nor have they been invalidated by observations made in this literature.

6 Cf. Ch. 2, note 11 and 14.

7 If readers are convinced by my answers to the relativist and the political pawns challenges, the issues with which Chs. 4-6 deal still remain important and unanswered. Alternatively, if my answers to the relativist and/or political pawns challenge should be unconvincing, the issues addressed in Chs. 4-6 can be taken to examine whether there are important additional grounds for scepticism about human rights.

8 Cf. Nickel (2007), p. 168.

9 Quoted after Nickel (2007), p. 169. Relativism, in the present chapter's sense, is not either what Bernard Williams calls 'standard relativism', where each party (e.g. culture, JP) is right 'for itself' (Williams 2003, p. 68). For, as Williams convincingly points out, this position is much too simple when it comes to delineating the scope of validity of outlooks, etc. Williams says:

For standard relativism, one may say, it is always too early or too late. It is too early when the parties have no contact with each other, and neither can think of itself as 'we' and the other as 'they'. It is too late, when they have encountered one another: the moment that they have done so, there is a new 'we' to be negotiated.

10 One motivation for this position may be, as James Nickel observes (2007, Ch. 11), a noble concern for the plurality of human ways of life. But, as he also observes (ibid.), it is doubtful whether relativism, as understood here, is the best way to do justice to this concern.

11 However, as pointed out in Section 2.1 above, I am not concerned with interpreting that practice, only with providing a (potentially revisionist) conception of an important part of that practice - its wish to offer a minimum ideal of global justice.

12 Cf. Section 2.2 above, and below in this section.

13 In what follows, I will not address possible instrumental ways to make the case for the importance of certain interests. See Section 2.2 above.

14 If someone is, in the end, not convinced by such stories, it may be hard to think of what to say to her (as to Napoleon when, according to one anecdote, a soldier protested 
that he would die if Napoleon were to send him out of the army and into the Russian winter; whereupon Napoleon allegedly replied: 'What's that to me?' I am unable to find the reference of this story). At the same time, an emphasis on stories should be supplemented with a method - some would call it 'reflective equilibrium' (Rawls 1999a), but it can be given a less controversial name - which, in addition to critically investigating the narrative at hand, probes the implications, presuppositions and coherence of saying that certain interests are particularly important for broad categories of people everywhere and always. (For a discussion of 'broad categories of people everywhere and always', see Section 2.2 above.) The key 'extra', compared with this method, that the emphasis on narratives offers is that it moves beyond a simple reference to intuitions: it tries to show (both negatively and positively) why certain interests should be regarded as particularly important. Probing the implications, presuppositions and coherence of so regarding them can then follow afterwards.

15 Cf. Nussbaum (2000), pp. 78-80.

16 What about someone saying that people (and sometimes collectives of people) in certain cultures, etc. (say, the Dutch) should decide for themselves which protections are important for them? One should reply, I think, that yes it is an important interest for people to be able to decide for themselves; and yes, also politically, it is often appropriate that outsiders show a fair deal of restraint in meddling (in ways that are possibly paternalistic) with people deciding for themselves (where surely the appropriate delineation of who are the people will often remain an issue). Despite all this, the decisions that people themselves make are not always a good guide to the interests that are genuinely important for them (as testified by e.g. the well-known problems of adaptive preferences) - although they are perhaps often more so than the views of outsiders.

17 Levi (1987 [1958]), pp. 44-45. I am aware that one should be somewhat cautious with regard to the conclusions that can be drawn from this very extreme account. Some further examples of relevant stories can be found in e.g. Scheper-Hughes (1992), Ferréz (2000), Hermens (1999). Generally, one may draw on anthropological studies or also fictional accounts that offer convincing interpretations of what goes on in real-life situations (what convinces would of course be a matter for further investigation). Note that these stories have a certain 'objective' thrust in that what they show can diverge from how people themselves perceive their situation. It is always important to take people's own perspective very seriously; but this doesn't settle the question of whether an interest is universally important. At the same time, if an interest is universally important, that doesn't tell one immediately what policies etc. are justified.

18 And cf. note 14. For transcendental accounts, cf. Section 2.2 above.

19 UDHR, Art. 24.

20 In other words, the stories can show why it matters that a person is adequately fed regardless of the age, sex, position in society etc. of that person.

21 For these families, see Nickel (2007), p. 181. He adds group rights, which may be more controversial.

22 Things are already more difficult when it comes to actively reducing reliable protections (see Ch. 5 below), although this cannot in all cases be sharply distinguished from examples such as those mentioned in the text.

23 Referring to drastic implications may be in line with a reflective equilibrium approach to moral justification. But it may also be cast less controversially as approximating a reductio ad absurdum.

24 I take a right to an adequate standard of living, just as a right to health, to mean that certain protections of it must be provided - not that the achievement of an adequate standard of living, or of health, must be 100 per cent guaranteed. See Chs. 2 and 5.

25 I am thinking of sensible curative care, and of social services whose content would depend on medical and scientific know-how that did not exist in certain societies.

26 Compatibly with such priority, there may also be a pro tanto case for providing, at all times and places, the protections concerned of freedom of thought and choice of 
occupation; but such a pro tanto case is weaker than what is often meant when such a right is claimed to have universal validity.

27 E.g. Sen (1999); Nussbaum (2000).

28 In line with Sen and Nussbaum, there are certain exceptions. For example, the freedom to have an environment free of infectious diseases can only be brought about by in fact realizing such an environment, which means that it will be kind of forced upon many people.

29 See Ch. 5 below.

30 Williams (2003), p. 67.

31 See Section 5.3 below.

32 This will be argued in Ch. 4 below.

33 Conversely, in a time with less wealth and fewer technological capacities, fewer protections will be required. Cf. Mulgan (2011). These judgements depend on the idea that human rights should consume a substantial part of a society's wealth and technological resources, but by no means all. See Ch. 5 .

34 Cf. Hopgood (2013), Stephen Humphreys, personal communication (2012; Humphreys doesn't say he subscribes to this analysis). For further recent contributions broadly in this spirit, see note 2 above and note 37 below.

35 Jon Elster (1998, p. 111), in the context of democratic theory, uses the expression of the 'civilizing force of hypocrisy'.

36 In a similar vein, it may be doubted whether (for instance) the naked power politics of a George W. Bush, who often felt no need even verbally to pay homage to human rights ideals, was really an improvement.

37 Some authors broadly in this spirit (although also making other and more specific claims) are Bob (2019); Douzinas (2007); Hopgood (2013); Kennedy (2004); Koskenniemi (2011); Posner (2014); and, to a certain, limited extent Gearty (2006); Moyn (2012); Malcontent (2015); and Humphreys (personal communication, 2012).

38 Some authors broadly in this spirit are Buyse (2015); Goldschmidt (2012); Nickel (2007); Sikkink (2011, 2017), and also Beitz (2009); Gilabert (2009); Shue (1996). Goodale (ed., 2014) discusses both strong and more problematic aspects of human rights.

39 See www.responsibilitytoprotect.org/index.php/component/content/article/35-r2pcstopics/5356-african-arguments-how-did-rwandas-genocide-change-our-world- (consulted 30 December 2019).

40 Few people would now say otherwise for the intervention in Iraq in 2003, but more generally speaking, grounds for debate about human rights and intervention remain. In any case, and just to be sure: I do not think that a concern for realizing human rights can by itself justify forceful intervention. Additional conditions should always be met (cf. the jus ad bellum of the just war tradition, e.g. Orend 2005).

41 For the UK as an example, see 'The Guardian view on human rights and foreign policy: do the right thing, not the easy one', Editorial, the Guardian, 5 April 2016; and more generally, see e.g. Klaas (2016).

42 See www.amnesty.org.nz/tools-torture (consulted 30 December 2019).

43 I have already assumed as much when saying that the present book's conception of human rights, as articulating the minimum requirements of global justice, is likely to be to a certain extent revisionist vis-à-vis the post-WWII practice of human rights (although there are various reasons for the revisionism); cf. Ch. 2 above.

44 It may be objected that human rights are not really 'our house', or rather, the 'global house': that human rights are not yet the overwhelmingly influential international practice that articulates, among other things, the main requirements for living together globally - and that, then, also guides activism, in certain cases justifies forceful intervention, etc. But, for better or worse, human rights do often seem to do these things and I do not see any other principles for living together on a global scale that are nearly as influential internationally. 
45 Besides, 'starting anew' might ameliorate some shortcomings (such as the omission of environmental concerns from the UDHR) that arose because of historical contingencies and often stayed around thereafter.

46 What exactly is a major and minor repair, or what counts as starting anew, would need further discussion. So does, of course, the question of exactly what can(not) be achieved by repairs as opposed to starting anew. All this must await a future occasion. The general suggestion for now is that, if something is not totally broken, more or less local fixes can be tried. 


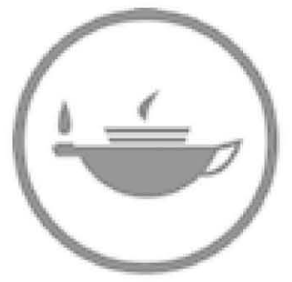

Taylor \& Francis Taylor \& Francis Group

http://taylorandfrancis.com 


\section{Part II}

Novel challenges to human rights 


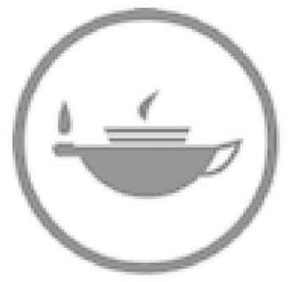

Taylor \& Francis Taylor \& Francis Group

http://taylorandfrancis.com 


\section{The challenge of global inequality}

This chapter will be concerned with the question of whether (and if so how) a non-hypocritical commitment to human rights can be achieved in a world of great global inequalities in human rights protection; and where (many of) those inequalities seem to be brought about by features of that world that we would often seek to uphold, notably by the central place of states in that world. I will call this the challenge of global inequality; it could, as will become clear, also have been called the challenge of (non-)hypocrisy.

It is obvious that we - myself and the readers of this book - want to be committed to human rights non-hypocritically (in a way to be explained precisely in a moment). Otherwise, how could we really embrace human rights as a vision of minimal justice for the world and sincerely try to ensure that human rights are ever more realized? Hence the importance of providing a satisfactory answer to the challenge that this chapter is about.

But why would it be problematic in the first place to achieve a non-hypocritical commitment to human rights in a world of great inequalities? Three steps are needed to explain this.

First of all, many of us are committed to a world made up of largely sovereign states, that is, of states which commonly make the ultimate decisions about what happens within their borders and which are in a number of ways equals in international affairs. This is of course a very rough approximation: there could (for instance) be, as there is in our present world, an elaborate system of international law and supranational institutions, as well as huge power imbalances between states. Yet the broad picture could still be one of a world of largely sovereign states, and most of us are not willing - more about this shortly - to abandon it in favour of a world state or some other kind of mainly supranational system where states only play a minor role.

Second, we are, at the same time, also committed to human rights, which profess, and this is one of their most central features, that all human beings are fundamentally equal - however exactly one may want to put this: in terms of equality of status, equality of dignity, equality of rights, etc. ${ }^{1}$ This must, I take it, at least mean that the important interests of all human beings matter a lot ('equality'), and that reliably protecting the interests ('rights') of all humans matters a lot ('equality' again). Typically, the idea of equality takes the following 
stronger form: when one is talking about those protections of very important interests that are a matter of human rights there is the equality constraint that people must receive the same protections whenever their need for protection is the same. It is this stronger idea (an example follows below and further development of the notion in Section 4.1) that I will, in this chapter, always be referring to when talking about equality of protection. ${ }^{2}$

Yet, third and last, states will in a largely state-based system always come to differ greatly in their wealth and in the quality of institutional - legal, etc. protections provided (of course this needs to be, and will be, argued for); so there will foreseeably be large and large-scale differences between countries with regard to the protections that people receive of their important interests, even where one is dealing with interests and protections that are so important that they qualify - even given alternative claims on limited resources - as a matter of human rights. Put differently, there is no equal protection in the sense explained above. To visualize this lack of equal protection by way of an example from the present world: in Sweden, everyone who needs renal dialysis will likely get it, and this seems a matter of human rights. At the same time, it is unlikely that everyone who needs renal dialysis will get it in Zambia. ${ }^{3}$ One could also give examples of receiving protections of having enough and good enough food or examples that concern getting a fair trial, etc. Moreover, these inequalities of protection between countries are often great as well as large-scale; and they are not only foreseeable, but even structurally engendered by a world order importantly consisting of largely sovereign states. Against this background, it seems to be hard to be committed both to human rights, with their demands of equality of protection, and to a world order that foreseeably and structurally engenders great and large-scale inequalities of protection.

Yet suppose that we remain committed to a largely state-based world order, and act accordingly. Then this may invite the charge of hypocrisy when it comes to our commitment to human rights, if we do not act equally much on this commitment. Hypocrisy is meant here in the sense of not putting one's deeds where one's words are: we pay lip-service to human rights, but our actions mainly help to uphold a world order - and may even be intended to do that ${ }^{4}-$ which is in important respects in tension with human rights. ${ }^{5}$

This chapter's aim is to investigate how, if at all, a non-hypocritical commitment to human rights can be achieved. It is, as will be defended below, not so easy to let go of a commitment to a largely state-based world order and to advocate, say, a world state instead. ${ }^{6}$ It is also not easy to abandon the idea that human rights demand some robust form of equality of all humans as typically expressed in the idea of equality of protection - that, if certain protections are important enough to qualify, also given alternative claims on limited resources, as a matter of human rights, then this should be so for all human beings in all countries. Thus, both commitments seem hard to abandon; that is what makes this chapter's undertaking of interest. ${ }^{7}$

The chapter will proceed as follows. First, it will be explained in detail just why and when a largely state-based world order provides a problem for equality 
of protection (Section 4.1). Second, the chapter will discuss what the solution should be: get away from such a world order, get away from equal protection and thus from human rights? - or a particular mixture? (Section 4.2) I will indeed defend a particular mixed solution and then, thirdly, consider and answer some important objections to it (Section 4.3). For example, the mixed solution sometimes loosens the requirement of equal protection of very important interests, and even regards doing so as compatible with human rights. But in doing so, doesn't it unjustifiably leave people out in the cold whose interests are most vulnerable to threats? Finally, the chapter's conclusion summarizes its findings and outlines how a non-hypocritical commitment to human rights is, in the end, possible. It also indicates some points to be taken up in future research.

\subsection{A largely state-based world order and equal human rights protection: a tension?}

Equal protection in the sense of receiving the same protection of very important interests if one's need for protection is the same (for example, in the case of two persons who equally need renal dialysis or access to a fair trial) is the sense of equal protection that many people - for example, many activists, policymakers and academics such as philosophers - often have in mind when thinking of the equality that human rights require. This chapter will focus specifically on equal protection between countries, that is, on one specific form of equal protection in the sense just indicated. ${ }^{8}$ This specific form also seems, as operating in the background of the idea of progressive realization, to be part of the post-World War II practice of human rights (which, to interpret, however, is not this book's intention ${ }^{9}$ ). The idea of progressive realization is found most prominently in the International Covenant on Social, Economic and Cultural Rights, which says that each state should:

... take steps, individually and through international assistance and co-operation, especially economic and technical, to the maximum of its available resources, with a view to achieving progressively the full realization of the rights recognized in the present Covenant....

(Art. 2)

The idea seems to be that there is, in principle, a clear idea of what a right to food, to health or to work requires in the way of protections against threats and that everyone in need of these protections should get them. Less protection may only be provided for a short period of time, where there is a lack of resources. (Tellingly, the idea of progressive realization is absent in the International Covenant on Civil and Political Rights, presumably because these rights are very dubiously ${ }^{10}$ - thought to be less dependent on the availability of resources. However, most important in the present context, the idea in this Covenant is again one of equal protection in the sense indicated above: everyone in the same need should get the same protections/guarantees of getting a fair trial, having freedom of expression, etc.) 
It may already be noted that the idea of equal protection in the sense of people getting the same protection of their important interests when their need for protection is the same is stronger than the idea that the protection of all people's interests matters a lot, regardless of whose interests they are. Of this latter idea of equality, I said that it is in any case a central feature of human rights. The divergence between the two ideas indicates that there may be some room to relax the stronger idea - the requirement of equal protection in the sense indicated without falling out with human rights. (Indeed, this is exactly what the idea of progressive realization suggests for certain non-ideal circumstances.)

However, before investigating, in Section 4.2 below, whether such relaxation could or should indeed be undertaken (and if so, when) I want first to further examine the tension between equal protection and a largely state-based world order. I want to argue that there is indeed a tension and I will do this by outlining one central type of case where equal human rights protection seems unachievable. ${ }^{11}$ This case has the following characteristics:

1. States are largely sovereign, which means most importantly that they usually have the final word about what happens on their own territory, with forceful outside interference being the exception rather than the rule (this is one sense in which states are "equals" ${ }^{12}$ ). This also means that a large part of the duties for fulfilling the human rights of those on their territory (or perhaps for their citizens ${ }^{13}$ ) will fall to states. ${ }^{14}$

2. A situation of largely sovereign states will - this is the second characteristic of the case - inevitably lead to differences in human rights protection. Some states will maintain the rule of law better and more effectively than others; some states will grow richer and have more resources for human rights realization at their disposal than others. It is important that to say all this is not to assume that a country's institutional structure and wealth are entirely shaped by domestic factors, such as a country's political culture, work ethic, etc.; also if international factors have a considerable influence and if the international structure is just (which it now notoriously is not ${ }^{15}$ ), differences in human rights realization will still arise. They will arise as long as domestic factors have a clear influence, too; and it is very probable that they do. ${ }^{16}$

3. A third characteristic is that assistance by outside states or other outside agents cannot make up for all the differences in human rights protection between states. Is it plausible that they cannot? As Mathias Risse observes, it is often very hard to determine just what outside assistance can and cannot do. ${ }^{17}$ But it is very unlikely that it can erase all differences in human rights protection, all the more so if (as must be demanded) it is done with due respect for a country and its people and if (as we have been assuming) the state that receives it remains largely sovereign.

4. Given 1-3, it would still be possible to achieve equality of protection of human rights by providing people in all countries with equally little protection. Even the least well-functioning, least prosperous state could provide protection if the level required was extremely low. Obviously, however, 
such 'levelling down' is unacceptable; achieving equality by offering everyone hardly any protection at all is a twisted idea of justice. ${ }^{18}$

Now the case just outlined not only looks much like our current world, but it may apply even to the most just world order. To explain: the most just world order, it is usually thought, will, in any case, be no world state; it is even likely, many think, to hold on to largely sovereign states. The question is whether that is correct and, depending on how that turns out, how to continue with our commitment to human rights. These are the matters to which we will now turn.

\subsection{A largely state-based world order and human rights: reconsidering our commitments}

Suppose that, as suggested in the previous section, there is indeed a degree of incompatibility between a world order of largely sovereign states and equality of protection received as a matter of human rights (equality of protection in the sense that, without levelling down, two people who similarly stand in need of a certain protection of an important interest do receive the same protection). We can then (1) revise our commitment to a world order importantly based on largely sovereign states; or (2) revise our commitment to human rights or to the idea that human rights call for equal protection; or (3) we can, in a sense that needs to be explained further, do a bit of both. ${ }^{19}$ I will discuss these three options in turn and argue, perhaps not very surprisingly, that the third route should be taken and also, more particularly, how. However, it is important to stress from the outset that the tension between a state-based world order and equal human rights protection is not everywhere: as will be argued below, in a just international world, the differences in human rights protection between states will only go so far, and outside assistance will also be able to achieve a lot.

Option 1) Revising our commitment to a world order of largely sovereign states. One could continue emphatically to endorse the idea that, whenever people stand in equal need of protection of an important interest of theirs, the protection provided should be equal. If it is correct that a largely state-based world order cannot always provide such equal protection, one could then advocate a different world order, and any charge of hypocrisy could perhaps disappear. I see four alternative world orders (all to be explained further): a world state; a world order based on subsidiarity; world governance; and anarchy. I will discuss the first two in detail and end up dismissing them (although for subsidiarity only to an important extent) and I will then dismiss the third and fourth alternative almost immediately. The next section will then, among other things, reconsider whether a largely state-based world order could not be compatible with equal protection of important interests after all. As elsewhere in the book, I will be talking about ideal theory, that is, about a world where people have been ideally socialized and where, more generally, institutions are the best that can be achieved with the kind of beings that humans are. ${ }^{20}$ Thus, the discussion is not about whether it is a good idea immediately to institute a world state (to take just 
this example) and also not primarily about the question of how a transformation from our current world order to a world state could and should be effected although some things will be said about transformation as well.

I imagine a world state to look like a state as we know it now. It would generally have the last say over things happening within its territory and be able to employ forceful sanctions to enforce that things go its way. (But of course, the idea of a state being equal to other states would fall away for a world state.) This idea of a world state has met with a lot of philosophical criticism, part of which is so well-known that it is by now a cliché: the Kantian/Rawlsian idea that a world state would be either powerless or a dictatorship; ${ }^{21}$ the idea that a world state would be a threat to cultural diversity; and the idea that there is nothing outside a world state, so that, if things go wrong with it, they go wrong everywhere. But the most important objection, to my mind, is one that I take from Mathias Risse and will call the terra incognita objection. ${ }^{22}$ Risse states that we do not know enough about what a world state would look like and what its morally relevant advantages and disadvantages would be to be able to advocate it - even as an ideal gradually to be approximated and to be fully realized only in the long run. Appearances are deceptive here, says Risse: if one models a world state after states as one knows them, one might think that one understands well what such an institutional arrangement would involve. In fact, however, the differences with the largely state-based world order that we do know are vast; a world state would blow such a world order apart and we cannot really imagine with any certainty what the new world order would look like. So, we cannot with any reasonable assurance endorse it as an institutional ideal after all.

I accept this point. ${ }^{23}$ Yet there is an important objection, which Risse himself raises, but which he deals with very unsatisfactorily. ${ }^{24}$ Basically, the problem is whether his reasoning should not also have led people before the French Revolution, or before the abolition of slavery, to oppose any very large institutional changes that would lead the social world as it then was into a terra incognita. Risse says that we cannot sufficiently imagine a 'world without countries' to advocate it as an ideal, ${ }^{25}$ but that, still, people in the past were right to seek the demise of the Ancien Régime and the abolition of slavery. He also suggests that we do not know what exactly the differences are between changes that should and changes that should not be tried.

But a better answer is surely required here, since, presumably, for many people living under the Ancien Régime and possibly also for many people in slaveholding societies, certain social changes were in good faith, and sometimes with good reason, seen as a leap in the dark. My own answer would go in the direction that, first, the case for change is greater the more inhuman, degrading or horrible the prevailing situation is for at least certain categories of people, such as slaves in societies with slavery. Second, there still also needs to be some reasonable assurance that the changes advocated are not going to make matters even worse. The more inhumane, etc. - or also connected with imminence of greatly inhumane situations, and the larger-scale - the practices are that stand to be changed, the less sure one needs to be about the alternatives; but one still 
needs to pick an alternative that seems (also in the longer run) least risky in terms of harm, etc. Genocide and rampant murder need to be stopped fast and almost no matter what. Some other horrible situations prevalent in the current world order are not so far removed from this and also need to be changed almost no matter what. One may, for example, think of widespread destitution, violence in war zones or exploitation in modern-day slavery. ${ }^{26}$ However, it seems to me that in order to halt such horrors, one needs no world state, but that a more modest reshaping of the world order could be enough. ${ }^{27}$ If so, Risse's terra incognita objection could still stand for a world state.

A second alternative for a world of largely sovereign states would be a world order based on subsidiarity, by which I mean a world order where everything is done at the lowest possible level where it can still be done in a just way. ${ }^{28}$ 'Just', in this context, is to be understood with human rights as an articulation of the minimum standards of global justice. When speaking of a 'level', I am thinking of national, provincial and local levels, etc. A rather close real-world approximation of such an order of subsidiarity may be found in the example of federal states, such as in the USA or Germany - or, also, in certain ways, in a complicated institutional set-up such as the EU. ${ }^{29}$ In federal states, a lot of things are done at a state (or Bundesland, etc.) level, but also a lot at the federal level.

Someone might argue that certain commonly mentioned disadvantages of a world state (for example, that it is too powerful or else has no effective power at all; or that, if things go wrong, they go wrong everywhere) would be avoided or at least mitigated in a world organized on the basis of subsidiarity. And also, that a subsidiarity-based world order could preserve some alleged advantages of a world state (which have not been addressed at all yet), for example that it might effectively overcome certain coordination problems that remain in a largely state-based world order. Or, which is of course particularly important in the present context, that a world state might eliminate differences in the reliable protection of important interests that would arise in a largely state-based world order ${ }^{30} \mathrm{~A}$ world order based on subsidiarity could preserve such advantages because, in this world order, problems that need to be solved on a higher level will be delegated to that level. So, if solving coordination problems or realizing human rights protection requires moving beyond the national level or even 'going global', this is - unless there are strong countervailing reasons - what will be done. One could think, in short, that a subsidiarity-based world order may be defended as offering both the advantages of a world state vis-à-vis a world order of largely sovereign states and the advantages of a state-based world order vis-à-vis a world state. However, this way of putting it cannot stand if the terra incognita objection holds for a world state. But one can still point to certain advantages of a subsidiarity-based world order vis-à-vis one based on largely sovereign states; and one can point out that a subsidiarity-based world order avoids certain problems, such as a too great concentration of power.

Yet a number of questions arise about a world order based on subsidiarity. Is it possible to find an appropriate level for everything that needs to be done? Or will it frequently be unclear what the appropriate level could be? Is it clear how 
the different levels should interact and work together, and why? And will not very many things in the end be assigned to a very high (world state-like) level, so that in practice we get something close to a world state after all? In addition, there are political questions: ${ }^{31}$ who decides about the level at which something should be done? How, and with what checks and balances, does decision making at the various levels function exactly? Etc. And more important than the problems to which these questions may point is the problem that Risse's terra incognita point may, on reflection, apply to a world order based on subsidiarity as well, albeit perhaps less than to a world state. Such a world order, too, takes us quite some distance from the institutional arrangements that we know, so that it is very difficult to grasp with any reasonable assurance what its advantages and disadvantages could be. It is true that we do know federal states, and these are much closer to a subsidiarity-based world order than to a world state. But the leap is still great, inasmuch as federal states do, among other things, of course not comprise the entire world. On the other hand, if one is effectively to solve certain urgent problems of coordination and collective action - think of current examples such as mitigating climate change, preventing economic crises, etc. - one does need to take some significant steps away from a largely statebased world order. Weak legal, etc. supranational arrangements (think of the Kyoto and Paris treaties) are not going to be enough. If so, this will mitigate the force of the terra incognita objection; but it will retain some force nonetheless as, sometimes, institutional arrangements that are considerably closer to the ones that (have) exist(ed) - for example, strengthened existing international institutions could be used to solve urgent problems. ${ }^{32}$

Other arrangements besides a world state and a world order based on subsidiarity are sometimes advocated, and I want to consider two - world governance and anarchy. ${ }^{33}$ The former refers to a network-like structure of distributed responsibilities that are then coordinated in various ways, not only vertically but also more horizontally. This is my rendition of what world governance is rather than someone else's, and if it is somewhat or considerably vague that is because, as far as I can see, the idea of world governance $i$ s vague. It is simply not very clear who should do what and how it is all to fit together in one coordinated whole. Now, it is a laudable endeavour to want to involve agents other than states and supranational structures that somehow look much like states; and this is an attraction of world governance. ${ }^{34}$ Still, the notion as it stands seems too vague to be very useful.

As for the idea of anarchy, it is not so vague as to be indefensible for that reason. Anarchy is understood here as the absence of any power - be it a 'conventional' state, a world state, a subsidiarity-based order or some other entity - which can, in a relatively well-defined way, effectively impose its will over some territory or substantive domain. A long argument would surely be needed to actually show that anarchy in this sense is indefensible, but this is beyond the present context. In any case, though, enough of Hobbes's bleak diagnosis ${ }^{35}$ survives to think that coordination problems often cannot be solved effectively without some clear authority, and that, although in certain circumstances more 
bottom-up arrangements such as shared norms or customs can substitute for more top-down state-like arrangements, ${ }^{36}$ this will certainly not always be the case.

The upshot of the discussion so far is that the search for alternatives to a statebased world order has to a great extent remained fruitless, with only a subsidiaritybased alternative holding some promise. Thus, a largely state-based world order may well have to remain around. Let us, then, consider a second way to resolve the tension between a state-based world order and human rights.

Option 2) This second way is to give up our commitment to human rights or to the idea that human rights require some ambitious form of equal protection. Giving up one's commitment to human rights altogether would obviously dissolve the tension. However, the aim of the present inquiry is exactly to find out whether there can be other ways of resolving it. Therefore, the more promising way to go in the present context would be to find out whether, or to what extent, one can have a sincere commitment to human rights without also being committed to equal protection, or while being committed to equal protection only in some qualified way. I think it is implausible to deny that human rights in any case require that one subscribes to (what may be called) the fundamental equality, equal dignity or equal moral status of all human beings, understood (all three synonymously) as meaning that the important interests of all human beings and the protection of those interests matter a lot, regardless of whose interests they are.$^{37}$ Now, the question is whether subscribing to fundamental equality in the sense just indicated requires that one also subscribes to equal protection in the above sense, that is to say, to the notion that people's important interests are to receive the same protection whenever their need for protection is the same. ${ }^{38}$

My answer is negative. One can subscribe to fundamental equality and still agree with equal protection sometimes being withheld - there may be sufficiently good reasons to withhold it. Yet in the absence of such reasons, equal protection must be provided, if one takes fundamental equality seriously at all; and the burden of proof will be on the party that favours unequal protection (where I always assume that she, too, is committed to fundamental equality).

An example can make all this clearer. Imagine a mother who cares equally about all her children. ${ }^{39}$ They, and the protection of their important interests, all matter equally to her. However, there may still be reasons to provide more protection to one child than another, even if their need for protection is the same. The most obvious reason may be that the mother can only provide equal protection of her children's interests by providing them all with equally little protection. Then unequal protection may be better.

Very importantly, however, the mother does need such reasons. If she provides more protection to one child than to another without having good reasons, one must doubt that she really cares equally about her children. In other words, fundamental equality does imply equal protection unless there are really good reasons to the contrary. This, in effect, puts the burden of proof - the allocation of which is always important and tricky - on those who want to say that fundamental equality and unequal protection can in a particular case go together. The 
example of the mother shows why this allocation of the burden of proof is justified.

Thus, in certain cases, a non-hypocritical commitment to human rights may be maintained while abandoning equal protection. For in certain cases there will be good reasons, or it may even be necessary, not to provide equal protection, however much one would like to. Here is an important example: if there are good reasons for advocating a largely state-based world order and if, in such an order, equal protection can sometimes not be provided without levelling down (or engaging in highly morally problematic foreign intervention), then that constitutes a case for sometimes abandoning equal protection. However, this is not, to my mind, a case of abandoning a commitment to human rights. One upholds both a commitment to the fundamental equality of all human beings and to equal protection, generally speaking.

Option 3) A third way? In the end, then, it seems that possibilities come into sight of resolving the tension that do not involve abandoning either commitment that to a world order of states and that to human rights. Or it may be better to say that what we are beginning to see is a mixed solution, a third way that does a bit of both, inasmuch as a world order of largely sovereign states with the concomitant inequalities of protection will not in all instances be accepted, but sometimes elements of a subsidiarity-based world order are to be embraced - where, in the present context, this most importantly means that certain things should be done at a supranational level. When, more precisely, should this be the case? In line with what was said above, this would be in cases where two conditions are met (and sometimes already when only the first one is met): (1) There are urgent problems, often concerning the protection of very many people's very important interests (think of climate change mitigation, averting economic crises ${ }^{40}$ ) and serious coordination - or other issues will arise if those problems are not dealt with at a higher level than the national level. (2) There are good reasons to think that there are supranational solutions to these problems - solutions that to a considerable degree draw on institutions that are in line with the ideal of subsidiarity and that are also not so far from existing institutions (think, for example, of solutions found in federal states of which there is good reason to suppose that they could work globally as well) so that the terra incognita objection has little force. $^{41}$

Now, if a world order is advocated where some things are done at or near the global level - such as a subsidiarity-based world order - this may well benefit equality of protection. For instance, everyone will benefit where climate change mitigation action is effectively realized internationally. And since many are equally threatened by climate change, this will often mean equality of protection in the sense that, across countries, people who need the same protection will receive it. ${ }^{42}$ By contrast, there will continue to be quite some inequalities of protection when, as should often be the case, things are left to sovereign states one may, for example, think of measures to secure food provision. For states will not function equally adequately everywhere and there is only so much that outside assistance can do. 


\subsection{Some objections}

I have argued that, in cases with certain specific characteristics, one may have very good reasons to withhold equal protection - in the sense of different people, in different countries, receiving the same protection of their important interests whenever their need for protection is the same. This would fit the above example of the mother who is committed to the fundamental equality of all her children (in the sense that, with all of them, protecting their important interests matters a lot) and for whom this does translate into equal protection in the above sense - unless there are good enough reasons not to provide such equal protection. To recall, the cases considered have the following characteristics:

1) there are good reasons to stick to a world order of largely sovereign states; and

2) this inevitably leads to certain inequalities in protection of human rights between states; and

3) these cannot be entirely eliminated by (duly respectful etc.) external assistance

4) unless a very low level of protection were to be provided for everyone; but there are good reasons to deem this impermissible.

Characteristic 1 was already extensively examined above. I will now examine characteristics 2,3 and 4 once more and see what objections they may give rise to.

Concerning Characteristic 2, couldn't we assume that, in an ideal world, political cultures, the work ethic, etc. would be rather similar everywhere? If so, differences in wealth and institutional quality would be minimal (and outside assistance might also be able permissibly to achieve more if political cultures, etc. were rather similar everywhere; but I will not pursue this here). To evaluate this thought, we would have to estimate how great the diversity of societies and cultures would be in an ideal world, at least at points that lead to differences in wealth and in the protection of very important interests. This is hard - but there is a fair chance that, in a world of largely sovereign states, people's free use of their thinking and judgement abilities will lead to a considerable and permanent pluralism of social and cultural orders and of ways of life, ${ }^{43}$ also in respects that will influence wealth, etc. ${ }^{44}$ Thus, social and cultural diversity may well be there to stay, and then a largely state-based global order and equal human rights protection remain in tension.

Characteristic 3: One may also reconsider what foreign assistance could do (within the bounds, of course, of what is permissible); and if, on renewed inspection, this is virtually everything - as an objector might suggest - then there will in ideal circumstances be virtually no scope for inequality of protection in the above sense. Now there are indeed many things that outside assistance may permissibly do. It is perhaps sometimes conceivable, for example, that almost all arrangements that a country would need to adapt to climate change 
could be put in place and maintained by foreigners. But in other cases, there will be limits: even if foreigners could run a country's entire education system, in perpetuity, this is unlikely to be permissible as it undercuts that country's selfdetermination, in the sense of its people being able to determine their own course into the future. ${ }^{45}$ Or it may also, for example, be impermissible because it encourages certain parties (such as the government of the country in question) to shirk what are plausibly their duties, and this may, among other things, lead to much worse outcomes in the longer run. Here, too, it is hard to say how many things exactly outside assistance can and cannot permissibly do; but there will, in any case, remain some limited scope for inequalities of protection.

There is an additional consideration: perhaps countries are sometimes morally allowed to withhold assistance they could permissibly provide - e.g. financial assistance with setting up a better healthcare system in a foreign country. Withholding such permissible assistance might be allowed because governments may arguably to a certain extent be partial to their own citizens. Many would even go so far as to say that a government may permissibly give precedence to non-human rights concerns of citizens over realizing human rights for foreigners. However, I want to suggest that it is very well possible that - at least in ideal circumstances all global inequalities of human rights protection that can permissibly be remedied through foreign assistance should indeed be remedied.

Let me explain why that would be so. Realizing human rights for a country's own citizens will always only take up a limited part of a country's wealth and of its technological and institutional resources; a society that spends all of its means on protecting important interests is an unlivable society, with no place for somewhat less important or more frivolous things. To be sure, it $i s$ very plausible that a society should spend a considerable part of its resources (financial, technological, institutional, etc. ${ }^{46}$ ) on protecting important interests; but this part should, although considerable, nonetheless be limited and there should be ample free space and breathing room left. ${ }^{47}$ In other words, a lot of room will remain for other concerns. A consequence of this is that, even if a rich and institutionally well-functioning country provides some meaningful foreign assistance, it will still be able to attend to many non-human rights interests of its citizens. It can incidentally be noted that - although there should, as said, also be room for less important or even frivolous matters - many of these non-human rights interests are quite important. One may, for instance, think of providing very expensive cancer medicines - something which may, because the medicines are so costly, well fall out of human rights, but which often still remains (literally) vitally important. However, a cause such as providing these medicines is not to be regarded as being in competition with providing meaningful foreign assistance. For, in a rich and institutionally well-functioning country, many important (but non-human rights) interests of citizens can be attended to compatibly with providing such assistance. To be sure, if one rich country alone would have to provide all the foreign assistance that is permissible, the important interests of its citizens and that assistance would conflict. But in ideal circumstances, all rich countries will likely do their fair share. If so, it is 
well possible that, in ideal circumstances at least, all the foreign assistance that may permissibly be provided ought also to be provided. ${ }^{48}$

Now, someone might argue that the case that a rich country should provide meaningful foreign assistance still falls away because the resources concerned could always be spent for the benefit of that country's own citizens instead. However, to regard this by itself as a good enough reason would surely take partiality towards citizens too far. ${ }^{49}$

Characteristic 4: I have just talked about countries that are sufficiently rich and that are institutionally well-functioning enough - and, one may also add, technologically advanced enough - to realize human rights for those within their borders. This raises the question of what level of protection should be required as a matter of human rights. This level must not, I argued above, be so low as to be amply affordable by countries with the least resources (financial, technological, institutional). That would be 'levelling down' to the lowest common denominator. But someone might ask whether this would really be morally problematic. More generally, what reasons are there, in the end, to set the requirements of human rights protection at one level rather than another?

There are, I believe, at least three levels at which human rights protections may not defensibly be set, and there is one at which they may be set, when we think of a world where there are considerable wealth disparities (and technological and institutional disparities ${ }^{50}$ ) between countries. One indefensible level, as said, is a very low level across the board: it would not be acceptable that, also in very rich countries, only a very minimal level of protections (say, of a decent standard of living or of receiving a fair trial) would count as a matter of human rights. This would be a paradigm case of achieving equal treatment by treating everyone equally badly, which is morally problematic inasmuch as it makes a mockery of the idea that it matters to protect very important interests. It is a mockery because too often very important interests may, as far as human rights are concerned, go unprotected that could very easily be protected.

Second, it would be indefensible to set the requirements of human rights protection at a different level for rich countries than for poor countries. This would be tantamount to stating that unequal protection is justifiable. But one needs arguments for this; and if one starts out by setting a differential level of protection, one assumes it. It is, therefore, better to start out with a globally uniform level and subsequently to consider whether there are good enough reasons to depart from it in certain situations.

Third, it is also indefensible to set the (initially globally uniform) required level of human rights protection so high that, given the global wealth - and other relevant resources such as technology - aggregately available in the world, it could not possibly be realized everywhere in the world. Then the level is clearly set too high.

The level that is acceptable will be one that is quite close to a level that would be set in a rich country if one were to consider that country on its own. At least, this level will be acceptable as long as its provision in the whole world is amply affordable given the wealth, and also technological resources, aggregately 
available on earth. (To clarify, it could be that, for example, there is so much wealth in the USA or North-Western Europe that, in so far as it depends on the wealth, it would be sufficient for realizing a near-rich-country level of human rights protection everywhere in the world.) That something like this level is the acceptable one follows from the unacceptability of the three levels just discussed. Just how close this level would come to a rich-country level is a moot point and largely an empirical matter. I believe that it may come quite close if it is correct that, as some say, a small percentage of the global GDP spent on overseas assistance would already suffice, as far as money is concerned, to eradicate global poverty; so it seems that one can already get rather far with limited financial resources. ${ }^{51}$

The same may well be true for technological resources. But, if one were also to take the institutional capacities available for everywhere as a reference point, the baseline of protection would have to be lowered drastically. I think that this would come too close to protecting everyone equally by protecting everyone equally badly; and therefore, what institutional capacities are available for everywhere should not be incorporated into the baseline (of what protections are required as a matter of human rights). Leaving institutional capacities out will lead to a rather high baseline and it paves the way for inequalities of protection sometimes being permissible. That is a price that should be accepted - although some may make different judgements here. ${ }^{52}$

\subsection{To conclude}

In the end, the chapter's initial thesis remains standing: there will, even in an ideal world, be some scope for inequalities in the protection of human rights because:

1) there would be likely to remain largely sovereign states, and they will be providing many of the human rights protections;

2) there will remain differences among these states regarding their wealth, state of technology and institutional capacities to provide effective protections;

3) these differences cannot be entirely eliminated by outside assistance;

4) unless the protection required as a matter of human rights were reduced to a very low level across the board, which would, however, be impermissible.

If one takes all this together, providing unequal protections will in certain cases be allowed even if one is committed to the fundamental equality of all human beings and also to the provision of equal protection in general. This dissolves the hypocrisy charge. For, to be sure, and as argued above, a sincere commitment to human rights does imply a commitment to the fundamental equality of all human beings, in the sense that the protection of their important interests matters a lot regardless of whose interests they are. It also, as the example of the mother and her children shows, implies a commitment to providing equal protection in the sense 
that people receive the same protection of their important interests whenever their need for protection is the same. ${ }^{53}$ That is, such a commitment to equal protection is implied unless there are very good reasons not to provide equal protection. Now, the four points just mentioned do, in conjunction, provide just such reasons. Thus, accepting unequal protection in cases where it is necessary based on this conjunction is compatible with a sincere commitment to human rights. It is not a matter of having a commitment to human rights while one's actions are guided by something else.

To say that very good reasons - indeed very good reasons - are needed to deviate from equal protection is to say that the burden of proof is on those who want to deviate from it. ${ }^{54}$ If two persons, one in Sweden and one in Zambia, are both equally direly in need of renal dialysis, and one were to accept without very good reasons that human rights require that it be provided in Sweden while in Zambia provision is not required, it may really be doubted that one has a sincere commitment to the fundamental equality of all human beings and thus to human rights.

Finally, couldn't the hypocrisy point have been dissolved much more quickly? Is it not immediately clear that human rights only demand equal protection in this chapter's sense - if there aren't very good reasons to deviate from such protection? And, is it not equally clear that sometimes there are indeed such reasons, most importantly perhaps that there are good reasons to embrace a world order of largely sovereign states, and that such a world order and the realization of equal protection are sometimes incompatible? If so, it is immediately clear that one is not hypocritical if one is committed to human rights and also to a world order of largely sovereign states.

My answer to this objection is straightforward: it is not immediately clear that human rights do demand equal protection unless there are very good reasons to deviate from it - it is not even clear what exactly equal protection might mean. Similarly, it is not immediately clear that a world order based on largely sovereign states, even if it is reasonably clear what such a world order looks like, is frequently to be embraced, nor is it clear right away that such a world order sometimes makes the provision of equal protection impossible. In other words, this chapter's central claims do need argument, as well as frequent clarification at a conceptual level, and the chapter has aimed to provide just that.

Now, some have told me that it does not empower vulnerable people very much to say that inequality of protection under human rights may be justified where there are very - indeed very - good reasons. But it certainly does not empower them very much either to ignore commitments that pull in different directions. (Ignoring these is not very empowering even if one holds, as many activists, lawyers and academics do, that human rights self-evidently require equal protection in this chapter's sense. ${ }^{55}$ Even then, overlooking structural obstacles to actually realizing equal protection surely cannot be all that empowering.) I much prefer to say that sometimes, compatibly with a sincere commitment to human rights, equal protection may be withheld - but only if there are very good reasons. The emphasis should be on the need for very good reasons and 
that will hopefully help a lot to ensure that vulnerable people are not left out in the cold.

This chapter has engaged with ideal circumstances. If, by contrast, one considers our present, non-ideal world, one may say that many inequalities of protection found there are simply not justified (or, perhaps, only justified to some extent or for the limited timespan in which it is really impossible to change them). Such inequalities of protection may, for instance, be tied to global injustices such as rapacious regimes being propped up by foreign countries and the international community - that we (often citizens of affluent countries, and the governments and NGOs, etc. we can influence) should make considerable efforts to change very soon.

As for the argument in ideal theory, one important task for future research will be to investigate more precisely what a world order based on subsidiarity could look like, and to what extent it can be clearly grasped, rather than remaining largely unknown territory. ${ }^{56}$ What would its justice-relevant advantages and disadvantages be? And would there, in such a world order, really be fewer very good reasons, compared with a state-based world order, to deviate from protecting human rights equally for all human beings? For such equal protection evidently remains what one would want.

\section{Notes}

1 For a recent author who has stressed this, see Buchanan (2013).

2 Rather than of equal protection, one might also speak of equivalent protection, in order to explicitly indicate that different ways of providing protection could be more or less equally good (although, looking in very much detail, they will all have advantages and disadvantages of their own). Equal protection is, thus, not about the absence of contextual differences (cf. Chs. 3 and 5) but of structural inequalities. 'Protection' generically refers here to all the human rights duties specified in Section 2.2 above negative, positive and intermediate.

Also, the notion of equal protection may evidently be understood in different ways. One may, for instance, think of providing extra protections for those whose important interests are particularly threatened. In addition, one may think of equality of protection (if it is understood as it is in the text: people receiving the same protection whenever their need for protection is the same) not only globally, but also within countries and small-scale (between two specific persons). I will return to these different understandings in note 53 below.

3 This example is taken freely from Albie Sachs (2009, pp. 161ff.) who uses a somewhat similar example in the context, not of human rights, but of constitutional rights in South Africa.

4 A commitment will typically consist of both words and deeds (and dispositions etc.), where parts of the deeds (and also words) will be very consciously aimed at. This will be so, for example, when someone does things to help realize human rights and to stop violations of them. These deeds may thus be called intentional, but other deeds and words will be less so.

5 If our commitments, in words and deeds, pull both ways, we may speak of doublemindedness rather than hypocrisy. Incidentally, hypocrisy is thus not meant, in this chapter, as reproaching somebody else for doing something that one also does oneself. 
6 As indicated in Ch. 1, the present chapter (as well as the book as a whole) will mainly be engaging in ideal theory. Obviously, however, the chapter has a number of implications for our actual world with its great inequalities with regard to the protection of important interests.

7 The academic debates to which this chapter primarily speaks are in global justice. In these debates, human rights are often regarded as minimum requirements of global justice (see Ch. 2, note 14) and it is often regarded as evident, even by those authors who do not endorse ambitious global requirements of justice or morality, that equal human rights protection, more or less in the sense in which I have understood it, is a global moral requirement (e.g. Nagel 2005; Miller 2007). At the same time, a world state is almost universally rejected (see Section 4.2 below), and very often a largely state-based world order is endorsed (see e.g. Nagel and Miller, as well as Nussbaum 2000). The tension between being committed to human rights and also to a largely state-based world order is scarcely addressed in this literature, nor are, therefore, the problems of hypocrisy to which this tension may give rise.

8 For some points about equal protection in different senses, see note 53.

9 See Ch. 2.

10 See Section 2.2 above.

11 There will, to be sure, be different sets of characteristics that could also lead to inequality of protection under human rights that may turn out to be permissible; but the set mentioned in the text constitutes a central type of case and I will restrict my analysis to it.

12 There are a number of other aspects in which they are equals, but these are less relevant here.

13 I will not further pursue the question of whether 'those on their territory' or 'citizens' is the better option.

14 That is, according to the account of duties outlined in Ch. 2.

15 See Pogge (2004), (2005), (2008); R. Miller (2010).

16 Cf. Risse (2005). Cf. Sen (1999), Chs. 5-7.

17 Risse (2005); Risse (2012), Ch. 7.

18 Cf. Parfit (1997).

19 Or perhaps there is yet another way out of the tension that I fail to see at present.

20 I take this notion of ideal theory, somewhat freely, from Rawls (1999b), pp. 4ff.

21 Rawls (1999b), p. 36. For the other objections, see Lu (2006).

22 Risse (2012), Ch. 3, esp. pp. 83-85.

23 This point also implies it is hard to evaluate the correctness of other alleged disadvantages and advantages of a world state.

24 Risse (2012), p. 84.

25 Ibid.

26 Such things would have hardly any place in an ideal world, although possibly conflict and hunger would not be entirely eradicated even there.

27 I lack the space here to develop this point further.

28 I do not aim to defend this conception of subsidiarity against alternatives (which could e.g. emphasize some form of effectiveness rather than justice); I only outline one conception that seems plausible and relevant. For various understandings of subsidiarity, see e.g. Follesdal (2014); also cf. Pogge (1992).

29 The EU is complicated, among other things because matters of EU-wide concern are in certain cases decided by EU institutions (such as the European Parliament, the European Commission) and sometimes by the EU's states together (e.g. Council of the European Union; European Council). See e.g. Buonanno and Nugent (2013).

30 Incidentally, I am assuming here that a word state need not be very poor or ineffective. If it were, equal protection of important interests as a world state could provide it, would be equally bad protection for everyone.

31 Cf. Fraser (2008). 
32 For problems of transition, which are beyond the present scope, one could in a number of cases envisage gradual institutional change away from the current world order. While making the transition, our views of what is ideally possible will gradually come to change. For now, states remain in the picture there.

This chapter's discussion illustrates that our grasp of ideal situations is not easy to get and will always be partial (and shifting). Yet ideal theory is not, as such, to be considered an 'unknown land' and (pace Sen 2009) is important to form ideas as best we can of where we'd want to go - while always being as explicit as possible about what we do not know, how things may shift, etc.

33 Cf. (although rather for exposition than advocacy) Lu (2006) and Risse (2012), Ch.3, respectively.

34 Although roles for such agents will often also be envisaged in a world order of largely sovereign states or one based on subsidiarity.

35 In Leviathan, Ch. 13ff.

36 Cf. Ostrom (1990); (2005), esp. Ch. 9.

37 And not 'twice a lot' for anyone. I am not concerned here with surveying the possible meanings of 'fundamental equality', 'equal dignity' and 'equal moral status' (expressions that, as said, I used interchangeably), nor with clarifying the role that such concepts may have for human rights (e.g. they could function, in a certain sense, as the foundation of human rights); for very good discussions of human dignity see e.g. Düwell et al. (2014); Riley (2016); McCrudden (2017); Göbel (2019). For the present purposes, only one possible important meaning of fundamental equality etc. is proposed.

38 Providing equal protection should, some will say, be regarded as a conceptual requirement of human rights. But this needs argument; otherwise, too much would be decided by mere stipulation. One line of argument may be that one is no longer talking about human rights if one allows unequal protection, because there would then no longer be universally valid rights, equal for everyone everywhere. My answer is that there can be a universally valid list of rights, even if one allows for unequal protection in certain cases. For such a list of rights can be relatively general (think e.g. of the UDHR), stipulating only what interests are to be protected and roughly what kind of protections are to be provided. By contrast, considerations about (in)equality of protection are very often situated at a much more concrete level. See Chs. 3 and 5.

39 Of course, I could equally well have spoken of a father. This interpersonal example will certainly have differences with human rights cases, which among other things have many institutional aspects. And, importantly, a number of reasons will be relevant in the mother case that have no relevance in human rights cases. But the example of the mother can still illustrate how fundamental equality may be compatible with unequal protection.

40 These are problems that will still need attention even in an ideally just world.

41 For, obviously, this objection should not be driven to the point of making all institutional change impossible.

Why are inequalities of protection between countries themselves not a good reason to move to subsidiarity-based solutions, if it can be done in accordance with (2)? I imagine these inequalities, regardless of exactly how (in)frequent they would be, to be pervasive instead of local, so that in effect nothing would be left of a largely statebased world order and the terra incognita objection kicks in with full force after all. Perhaps certain specific inequalities of protection between countries could be singled out and addressed without things becoming pervasive; and perhaps addressing other problems - such as, possibly, climate change, but it would be a large discussion exactly which problems - will lead to pervasiveness as well. But that is beyond the present scope.

42 However, inequality of protection in different senses, e.g. in the sense that people with a greater need for protection should receive (some meaningfully) greater protection, 
will not necessarily be realized where coordination problems are solved through supranational arrangements.

43 This is a guiding theme in Rawls's (1999b) account of the international order and how it should be shaped (my formulations are also very Rawlsian). Cf. also, to some extent similarly, Rawls (1993), pp. 55-56 for an abiding plurality of conceptions of the good in one liberal-democratic society.

44 And, if it did, there would be limits to what outside interference could permissibly do to reduce that pluralism. Cf. under characteristic 3, below.

45 Of course, the exact meaning and normative weight of self-determination would require a long discussion. It is true that this weight may be dubious because of, among other things, historical contingencies (e.g. concerning who are a country's inhabitants and who are outsiders). Still, I assume that self-determination will normally have a certain normative weight (cf. also note 49 below) and that the case for this can be made without making very outspoken liberal assumptions.

46 In what follows I will confine the discussion to wealth and technology (on the one hand) and to institutional resources (on the other hand), but this short list remains open to further elaboration.

47 For more on this, see Ch. 5 .

48 In order to see that rich countries may well not be overwhelmed in ideal circumstances, it should also be noted that human rights realization stands out inasmuch as it includes all important interests that can be socially protected (see Ch. 2). In other words, there are not many - indeed, I'd say no - other causes for foreign assistance that are on a par with human rights realization.

49 Nor does providing foreign assistance - even if a community would morally have to do it and could not decide the matter as it wanted - plausibly get in the way of political and cultural self-determination of a relevant group. Reasons of political and cultural self-determination stress the importance of a political or cultural group being able to chart its own political course and to shape its own culture. This is often thought to be important for individuals to be able to choose and carry out their own conceptions of a good life (see e.g. Kymlicka 2000, Ch. 8; but also cf. note 45 above). But even if such self-determination is important (and must concern a much smaller political community than the entire world), the point is that providing meaningful foreign assistance doesn't seem to jeopardize it.

50 In what follows, it will be generally presupposed that a society's resources do not only concern its wealth, but also how advanced its technologies are and its institutional capacities (its 'organizing-related' resources for realizing human rights effectively and acceptably, e.g. with the required respect for people and with the required checks and balances to ensure reliable protection). Which resources are relevant for setting the baseline is, of course, very important, but the discussion in the text must remain very brief.

51 See e.g. Pogge (2008), p. 211. The rich-country level is one where there are, in the country concerned, ample resources left for non-human rights concerns.

52 The underlying methodology here might be called 'reflective equilibrium', although to say this is not to say very much. Besides, part of my judgement is also based on the idea that institutional factors are in a way less hard-and-fast than financial and technological ones. However, I cannot pursue this point here.

Concerning non-ideal situations, inequalities of protection there will sometimes be due to factors that, although they would not be present in ideal situations, cannot be changed until $\mathrm{t}=\mathrm{t}$. It is then a moot point whether one should say that these inequalities are permissible until $\mathrm{t}=\mathrm{t}$, or that they are impermissible, but unavoidable until $\mathrm{t}=\mathrm{t}$. Nothing of substance may hinge on which of these two possibilities one chooses. At the same time, one emphatically has to keep in mind that, often, inequalities cannot be called permissible because of certain factors by the agents who can change those factors. For example, certain states, business companies, strongmen, etc. commonly 


\section{Novel challenges to human rights}

cannot take their own (mis)behaviour as a given - even if it is just that, a given, for many third parties who cannot change it. Cf. Cohen (2000), Ch. 9; Frick (2016).

53 There are, of course, other important meanings of (un)equal protection than the one this chapter has dealt with. First off, one could say that there is only equal protection if people whose very important interests stand in much greater need of protection than those of others receive at least some meaningful extra protection. For example, people who are unable to walk need much more protection of their important interests concerning mobility, among other things in the way of the environment not throwing up certain kinds of obstacles and providing certain kinds of facilitation. This sense of equality of protection is inspired by the capability approach (see Sen 1992, 1999; Nussbaum 2000; Robeyns 2005, 2017; for human rights and disability, see e.g. Harnacke 2012 and Anderson and Philips 2012); and I have specified here a rather minimal form of it - at least some meaningful extra protection - so that it is extremely plausible that this much will mostly have to be provided as a matter of human rights.

Second, equality of protection as understood in this chapter could also be expanded to within-country cases. Within countries, very good reasons will be needed for allowing inequalities of protection (in the present chapter's sense) between two individuals or groups. In any case, the reasons given in the present chapter for allowing such inequalities globally in certain cases do not apply within one country.

54 The allocation of the burden of proof - which typically has a very large influence on the outcome of an argument - can easily become a trick. But in the context of the present chapter, the example of the mother shows why it is justified to put it on those who wish to deviate from equality of protection.

55 I have argued, of course, that human rights do not self-evidently, let alone conceptually, require equal protection.

56 As it does in e.g. Pogge (1992), Follesdal (2014). 


\section{The challenge of future people}

If human rights are to remain plausible and relevant as an ideal of minimum justice at a global scale, it is necessary that governments and people can be committed to them in a non-hypocritical way. But not only that; human rights must also be able duly to include the interests of future people and the reliable protection of those interests. How human rights can do this constitutes what I call the challenge of future people.

Some say that people who are not there yet cannot have anything, so they also cannot have interests, let alone rights. ${ }^{1}$ However, we must accept in any case that there will, in the future, very likely be people who have not been born yet. They will be human beings and they will have important interests; and once they have been born, their interests will matter a lot, just as those of other humans do. This, at least, is what one will say if one is committed to the fundamental equality of all human beings. And one will be committed to this if one is committed to human rights - or so I have argued in the previous chapter. Furthermore, if one abides by the usual criteria for attributing human rights duties, such as the capacity to solve a human rights problem or causal involvement in its coming to exist, people now alive could well be duty bearers for protecting the (future) important interests of future people. ${ }^{2}$

If so, this raises a number of important questions. For instance, with how many future people should one reckon? And what assumptions should one make about what the important interests of future people will be, and about where on earth they should be able to live? $?^{3}$ Furthermore, there is also the problem, which is central to this chapter and also particularly important in times of climate change, as to when the future should get precedence and when the present. Not that there is always a conflict, of course. Taking measures against climate change, for example, will often also be favourable for current generations (and sometimes even more so for the global poor), especially for the young among them. But in other cases, there will be conflicts. For example, caring for future people by mitigating climate change might require the curtailment of certain freedoms for those presently alive and will, at the very least, require that they voluntarily change their lifestyles.

In two cases, it will at any rate be clear how to set priorities in relation to human rights, and the task of this chapter will be to begin developing a framework that is 
relevant for other, more difficult cases as well. The first clear case is one where very important interests of very many future people are at stake and where there is a respectable account - typically a scientific one - that this is so. One may think of a scenario where severe climate change ${ }^{4}$ is likely to occur and where, according to a respectable (scientific) account, this may lead to widespread food insecurity, water shortages, extreme weather events such as heatwaves and flooding, and a severe loss of biodiversity. At the same time, present people in this scenario only have to give up trivialities (heating unneeded rooms in their houses, buying disposable consumer items, etc.) to prevent these future horrors from happening. This case may have some, but limited, real-life relevance: although often present people may well have to give up more than trivialities in order to prevent dangerous climate change, giving up trivialities could already help somewhat. Yet very importantly, this case does not in the end really concern prioritizing among human rights.

The second clear case is one where, on a respectable account, the protection of very important interests of very many future people is at stake; but where the only way to protect these interests is by compromising the protection of very many people's very important interests now. I think, for instance, of a case where, in order to prevent serious climate change, very many people in the present would have to be left to starve. It is vital to keep in mind that such dilemmas are often spurious and that such tragic choices are luckily rare: there are usually third ways available. But in a case where this is really the choice to be made, it is - in my view - clear that one should go for the present - even if the number of people in the present is, although large, possibly considerably smaller than that in the future. The reason is mainly, as will be explained below, that the threats to present people are imminent.

Other cases are less clear than these two, and this chapter's aim, as said, is to begin to develop a framework that can help us to deal with them. I will start by specifying what claims can, on first consideration, qualify as human rights claims, and subsequently develop principles as to which of these claims ought to be honoured, all things considered. Accordingly, the chapter will take the following steps. ${ }^{5}$ First, I will give an account of the characteristics that claims will need to have in order to count, on first consideration, as human rights claims. I will defend that, in order to do so, claims will have to concern very important interests, very important protections and there has to be a good (for example, scientific) account that these interests are indeed threatened and can indeed be protected (Section 5.1). Second, I briefly consider the priority of human rights as a whole and spurious conflicts among human rights, and then develop and defend a formal framework for setting priorities among human rights, that is, among the claims that are human rights claims on first consideration. This framework will include such factors as the number of people threatened, the severity of the threats and how certain the threats and the efficacy of the protections are (Section 5.2). Third, Section 5.3 will, given the chapter's particular interest in setting priorities between the present and the future, more extensively discuss uncertainties of various kinds. ${ }^{6}$ This section will also discuss what assumptions should be made about the number of future people and the 
important interests that they will have. Assumptions about this are needed in order to decide how to prioritize among human rights. Section 5.4 concludes.

There is not much literature on priority-setting among human rights. ${ }^{7}$ In fact, lawyers and activists often say that there are no priorities. ${ }^{8}$ This, however, is unlikely to be the case; and lawyers and activists do, indeed, generally speak of 'balancing' human rights, which may practically not be all that different - but I will come back to this shortly - from what I mean by priority-setting. ${ }^{9}$ And one should not take too simple a view of what priority-setting may involve. It may not only concern one right (such as the right to a decent standard of living) versus another (such as the right to security), but also certain protections offered under one right versus other protections that could be offered under it, or under another right. Or it may concern one group of recipients versus another - which will, to be sure, often be constrained by demands for equality of protection (among other things).

But are priority-setting and balancing so close after all? I do think that there may be a great difference of view between, on the one hand, those who are willing to think in terms of priority-setting and, on the other hand, those who say that there are no priorities, although they may speak in terms of balancing. The former group tends to strive for principled priority-setting (my term), understood as an approach to priority-setting that seeks to develop general principles that in the end aim to cover, as closely as possible in a deductive fashion, ${ }^{10}$ every conceivable conflict among human rights. The latter group, by contrast, advocates a case-by-case approach where every instance of conflict among human rights is to be dealt with by looking at the particularities of the case at hand. This, too, will in due course yield relatively general principles, which can also be applied to new cases. But this, the defenders of the case-by-case approach will say, will never even come close to a deductive enterprise, given the number, variety and complexity of the considerations bearing on each particular case. The defenders of a case-by-case approach may be right here, I would say; but one may still try to develop an informative account consisting of relatively general principles, and just see how far one gets. ${ }^{11}$ Whenever one fails, so be it, yet there is no reason to think that relatively general principles and considerations nowhere and never get one anywhere. ${ }^{12}$

Thus, this chapter will try to make the beginnings of a principled account of priority-setting among human rights, with an eye especially to prioritizing between the human rights claims of people presently alive and those of future people (and with climate change as the leading example throughout). As with other observations made in this book, I refrain from discussing whether this beginning account of priority-setting should aspire to some prominent place in a public practice of human rights. ${ }^{13}$

\subsection{Which claims can qualify as human rights claims?}

Not all claims can, even at first sight, plausibly qualify as matters of human rights - for example, only those can (I will argue) which concern important 
interests and important protections of those interests. This section will, thus, as the first step of the priority-setting exercise, discuss a number of conditions - I will call them entrance conditions - that claims have to meet in order to qualify as matters of human rights at all. Thereafter, the next section will, as a second step, propose a beginning framework for how priorities among the qualifying claims should be set. Throughout, the place of the claims of future people will receive particular attention.

The claims with which this section deals typically state that reliable protection $\mathrm{P}$ of interest A should be provided. For example, food provision for people who are now threatened by famine in Yemen should receive protection $\mathrm{P}$. This means that we are talking at a much more concrete level than that at which many human rights declarations, etc. (such as the UDHR) articulate their claims. There, usually only some very general idea of the protections to be provided is articulated. ${ }^{14}$ To be sure, such a more abstract level, too, is needed if human rights are to provide an ideal of minimum global justice - which is the main role that has been envisaged for them above - because it is at this abstract level that one can frequently most plausibly say of a set of human rights that they are universally valid while, importantly, still having content. ${ }^{15}$ But when we are thinking about priority-setting, we need a more concrete level where, among other things, the protections that qualify as matters of human rights have to come into view much more precisely. So, one must conceive of human rights as being on two different levels at least: a more abstract level needed for universal validity and a more concrete level needed for priority-setting. ${ }^{16}$

Which conditions, then, do claims have to meet to qualify as matters of human rights at all ('entrance conditions' in my terminology)? Two main entrance conditions - which were already briefly mentioned - plausibly are that the claims to protection should concern very important interests ${ }^{17}$ and also very important protections against very important threats. Thus, if we imagine starting with all claims saying that certain interests should be protected, a whole lot of these fall away immediately: they could never be matters of human rights because they are not concerned with matters of sufficient importance. Protecting the ability of people to, say, have a fashionable wardrobe is not sufficiently important; and a protection against floods by building a dyke that immediately gives way is not sufficiently helpful.

Here are two further plausible entrance conditions: it should not be farfetched or mere guesswork - call this a non-contrivance entrance condition that, on the one hand, there are indeed very important threats to very important interests and that, on the other hand, the proposed protections are effective. Rather, there should be a good account that these two things are indeed the case. One cannot even begin to consider a certain protection as possibly a matter of human rights if the existence of the relevant threats or the efficacy of the protections in question were far-fetched or mere guesswork. When are they not? One possibility is that there is a good scientific underpinning available that serious threats, etc. exist. ${ }^{18}$ For some cases, this may be made more precise by saying that one should 'understand the mechanism' of the threat and have an idea as to 
when 'the conditions that lead the mechanism to function' ${ }^{19}$ begin to be fulfilled and similarly for the envisaged protection. In other cases, a different specification may be appropriate. In yet other cases, one might not make any reference to science, but rather hold (say) that things are a matter of judgement - an example of this being a case of a dictator who threatens to kill very many people, as Muammar Gaddafi did when he threatened the inhabitants of Benghazi in 2011. Whether the threat was real, rather than merely far-fetched, could in this case only be determined through thorough knowledge of the relevant socio-political context and its historical backgrounds. To be sure, the condition that a threat and the effectiveness of a protection must not be far-fetched or mere guesswork is vague as it stands. But it is not easy to say more in general terms. For all its vagueness, this condition could still be difficult to meet when we are dealing with threats and protections that concern future people - although not only then. This, however, is no reason to omit the condition. For, if it were omitted, too many unsubstantiated things (to make the idea vivid: even things featuring aliens...?) could qualify as a matter of human rights.

\subsection{How to prioritize among human rights claims - including between the present and the future}

Suppose it has become clear which claims can, because they meet the relevant entrance conditions, qualify as human rights claims at first sight. One could then also say that they 'initially qualify' (or are 'initial' human rights claims), for there remains a question of how to set priorities among these claims. Only after settling this will it be clear which claims to protection ought all-things-considered to be granted as a matter of human rights. This is the way human rights are usually spoken of: if you have a human right that, for example, your freedom of expression is protected in certain ways against threats by third parties, it is normally presupposed that your and other people's other claims have already been taken into account. They cannot justifiably get in the way of the protections of your freedom of expression. In other words, your claim to these protections is not understood as being pro tanto, but as being all-things-considered.

The question of how to set priorities among human rights (that is to say, among initial human rights claims) is important, for human rights claims are usually taken to be weighty, in the sense that it is a grave moral fault not to fulfil the duties associated with them; and also in the sense that human rights claims often ought to get precedence over non-human rights claims when there is a conflict. ${ }^{20}$ But their weightiness would be hard to sustain if there were no good account of how to resolve conflicts among human rights. How could human rights be weighty if we have no idea of whether, where there is a conflict, to give priority to protecting the food provision of individuals A1-An in way $\mathrm{X}$ or to protecting the freedom of speech of individuals B1-Bn in way Y ? $^{21}$ (There should also, for that matter, be a good account of what priority human rights should have vis-à-vis other claims, for example how many financial or technological resources they may or should consume; more about this in a moment.) One 
could of course say that a coin ought to be tossed or that we can do both with equal justification; but this is one way of setting priorities. The point is that some answer has to be given and that one should have good arguments for it. If protecting very important interests matters a lot, one cannot simply shrug one's shoulders in cases of conflict and have nothing to say.

There are, broadly, two kinds of conflicts between initial human rights claims: conflicts that are due to lack of resources and conflicts that are not. The former kind already exists simply because resources (financial, technological, etc.) are not unlimited, but it becomes more frequent because human rights may not plausibly consume all or nearly all resources. To be sure, it is plausible that human rights may and should consume a sizeable part of financial and technological resources given that these rights - in this book's conception - deal with all very important interests for which it is at all possible to provide social protection. $^{22}$ But they must not nearly consume all resources, for there is more to life than protecting very important interests, however weighty these may be. As for conflicts of the latter kind, that is, conflicts which are not due to limited resources, one may for example think of some possible conflict between protecting security and protecting privacy, assuming - as is plausible - that at least certain protections of privacy, too, would qualify as, on first consideration, a matter of human rights (such as important protections against having one's house randomly searched and one's letters opened at will). Such a conflict would at least in part remain no matter how many resources a society could spend on protecting human rights.

Before proposing a beginning framework for priority-setting among human rights, it should be noted that alleged conflicts between initial human rights claims can, for various reasons, be spurious. Where this is so, it is obviously wrong to pit the two claims against one another; one should instead deny that there is a conflict. In addition, it is generally wrong to say that there is a choice between 'providing protection $\mathrm{X}$ ' or 'providing protection $\mathrm{Y}$ '. This is the wrong way to think about priority-setting among human rights; rather, we should consider all initial human rights claims together and then consider them in light of the framework to be proposed, which asks - as will become clear - a number of questions, such as: Just how important are the interests and protections concerned? How many people are involved? And how vulnerable are these people?

Specifically, there are several ways in which a purported conflict between human rights claims can be spurious. I mention three, without any pretension of completeness. First, one of the claims could, on reflection, turn out to be not even initially a claim of human rights. For example, with one of the claims, a necessary entrance condition could on further consideration turn out not to be met: the interest in question might, say, not really be very important, as has rightly or wrongly often been said of having 'periodic holidays with pay'. ${ }^{23}$ Second, it could be that human rights as a whole should receive more resources and that, once they do, two conflicting claims ought clearly both to be accommodated. ${ }^{24}$ Or, third, it might be that two initial human rights claims should clearly both be granted all-things-considered, at the expense of other initial 
human rights claims. For example, it may be that food provision for certain people should be protected in way $\mathrm{X}$ and that freedom from torture for some other people should be protected in way $\mathrm{Y}$.

Having said this, however, it remains the case that not all conflicts between human rights claims will be spurious. How, then, to set priorities when there is a genuine conflict? A beginning framework will now be outlined for such cases. My aim will not be to develop a full account of general principles for covering all possible cases of conflict among human rights, but only to propose relatively formal considerations. The exposition that follows will have a negative and a positive part, although the distinction between the two is not always sharp (some points could be formulated both negatively and positively). Negatively, it will be considered what kinds of priority-setting have to remain off limits. Positively, certain formal principles will be proposed for setting priorities among human rights. After this, I will specifically discuss some aspects that are especially relevant for priority-setting between claims of present and future people: how to deal with uncertainties when setting priorities, and what assumptions to make about the number of future people and about what interests they will have (Section 5.3).

\section{A) Ways to set priorities that should remain off limits}

In what ways should priorities among human rights not be set? I will formulate some (relatively general) ideas about this. Their background goes in two almost opposed directions: that human rights are, on the one hand, about providing reliable protections, and exhibit a resistance to always doing what provides the best outcome overall. Yet, on the other hand, the protection that human rights are about does leave a place for arguably relatively mundane matters such as quantitative considerations. ${ }^{25}$ To elaborate somewhat: on the one hand, human rights are not just about providing very important protections of very important interests, but about providing reliable protections. One should be able to count on having the interests protected and it should not be possible that the protection of an interest is taken away at will by some party or overnight. This implies, first, the necessity of certain kinds of safeguards - formal or informal institutionalization, with appropriate checks and balances and the like - and articulating such safeguards is, when we are talking at a concrete level, part of what it is to articulate a right. ${ }^{26}$ Second, to be able to count on protection, it must also be the case that a 'utilitarianism of rights ${ }^{27}$ is avoided, where my protection X of a very important interest of mine is taken away whenever more protection of interests overall can be provided by doing so. ${ }^{28}$ On the other hand, I will assume that the expectation that very many people will benefit from some protection rather than another for instance, from some protection of secure food provision rather than (say) some protection of health through certain health-care provisions - can sometimes be a good reason to provide one protection rather than another. And, somewhat similarly, the efficacy of a certain protection can be a good reason to provide this protection rather than another protection that is less efficacious. 
Thus, I will not conceive of priority-setting among human rights as a strictly deontological exercise in the sense of one which says that one ought (not) to do certain things regardless of, for example, the numbers of people involved or the effectiveness of the protections. Rather, I will adopt a more 'flexible' approach, which also takes quantitative considerations and effectiveness, and also uncertainties, etc., into account. The approach that policymakers, etc. will actually employ will do this anyway (which does not, of course, in itself mean that doing so is justified); and it will probably do so all the more if the claims of future people, with all their attendant uncertainties, need to get a place in human rights. One will have to take quantitative, etc. considerations into account also if one professes to take a strictly deontological approach, and consequently professing to take such an approach could evoke the charge of hypocrisy once more (hypocrisy in the sense of one's not actually acting on one's moral ideals; cf. Chapter 4 above).

Still, certain ways of setting priorities among human rights should remain off limits. In this regard, I will now argue for three points. ${ }^{29}$ First, all individuals must receive consideration and, second, so must all important interests. Third, active violation of human rights is always to be avoided. ${ }^{30}$

Let me discuss the first and the second point together: that one must not neglect certain individuals $\mathrm{s}^{31}$ to the favour of (even all) others; ${ }^{32}$ and that one must not neglect certain interests to the favour of (even all) others. What exactly these points entail will be different in different cases. Generally put, they are distributive concerns, which require the relevant duty bearers always to consider whether a defensible balance between different beneficiaries and different interests has been struck. If this much is no longer the case, one gets a situation where some may lose everything or where some interests may lose out entirely.

But why is this a problem for human rights, as long as it makes for the most protection of interests overall? I see two main reasons. The first and foremost reason is this: can one really rightly regard certain interests as very weighty and arguably more importantly - can one really regard the interests of all individuals as very weighty if one is prepared to let some lose out completely? A consequentialist philosopher might say that one can: one may, indeed should, let certain individuals or interests lose out completely if it makes for the most protection of interests overall. However, the right thing to do, I would say, is to balance (1) a concern for a lot of protection overall with (2) a concern for not letting certain individuals and interests lose out entirely. The former concern was taken care of by human rights' sensitivity to, among other things, quantitative considerations and uncertainties; and to insist on the overall maximization of protection of interests is to refuse any balance with the latter concern. ${ }^{33}$

The second reason why it is a problem to abandon the requirement of striking a defensible balance is - following up on what was said above - whether there is a way to conceive of reliable protection if there is no requirement of striking a defensible balance between different beneficiaries and also interests. For a protection to be reliable, it must at least not be liable to overnight change; it must not be possible for some party to change it at will; and it must stay away 
from a utilitarianism of rights, where (say) a protection that I have has to be taken away whenever by doing so a similar protection can be provided for three others. Abandoning the requirement of striking a defensible balance between beneficiaries, and also between interests, might well get one much closer to a utilitarianism of rights as well as - if the abandonment got an institutional translation - to overnight changes of protection. To be sure, that one might well get much closer is not a logical necessity, but an empirical possibility; ${ }^{34}$ but even as such it is worrisome enough.

However, while it will be rather evident why no individuals may lose out altogether, why is this also the case for interests $?^{35}$ The background idea is that the interests involved - all of them very important - are not interchangeable. If one calls an interest non-interchangeable, one will usually do so for more intrinsic, as well as for certain more instrumental, reasons (which will vary from case to case) ${ }^{36}$ for both kinds of reasons, one cannot do without the interest being attended to. ${ }^{37}$ For example, an intrinsic reason for valuing freedom of expression has to do with what happens to people if they can no longer express their thoughts and opinions and discuss them with others. Moreover, if freedom of expression is absent (or not guaranteed), they often cannot even express their thoughts to themselves (or it is not guaranteed that they can), in cases where doing so requires writing these thoughts down, say, or speaking them out loud. This would have grave consequences for, among other things, these people's opportunities to be practically rational and to develop their cognitive capacities to some minimum extent. Instrumentally, reliably protecting the interest in freedom of expression is important for reliably protecting many other important interests. ${ }^{38}$ For example, freedom of expression allows people to draw attention to how the protection of other important interests fares, and this often helps with improving that protection.

Finally, there is a third point as to how interests may and may not be protected when we are talking about human rights - in addition to the points that it is unacceptable entirely to disregard, first, any individual and, second, any interest. This third point is that active disrespect for rights, by any agent, should normally be ruled out; to deny this would have very undesirable implications. That such disrespect should be ruled out is obvious if we think of political regimes, such as many dictatorships, that murder or starve a country's people. However, disregarding these extreme examples, someone might still object that putting active disrespect off limits in a sense privileges the status quo. For it makes certain ways impermissible in which this status quo may be changed in order to protect certain interests that are currently unprotected. Active disrespect is not generally meant here in the sense of taking away, perhaps typically by reallocating, a certain protection of an interest from someone - although there, too, very good reasons are needed indeed - but in the sense of actively (and considerably) setting back an interest: torturing, starving, etc. are common albeit extreme examples. However, such active disrespect should indeed, even if the stakes are improving a very bad or unjust status quo, be off limits - this is a bullet I would bite. The paradigmatic example perhaps remains this: I may not 
come and take your organs from you, even if this is the only way to save five others. It is generally the same for actively setting back other very important interests of yours. ${ }^{39}$ It is more difficult where the (allegedly) active violation is due to a combination of different agents, as is often the case in our complex, globalized world (call this 'joint violation' or 'joint disrespect'). I think that, here, the appropriate thing to say would typically be that, when our focus is one particular agent involved in joint disrespect, their actions lie somewhere between actively violating human rights and failing to further realize them. ${ }^{40}$ It is not so clear that, like actively setting back someone's important interests, contributing to such 'joint disrespect', however objectionable it often is, should always, by way of an absolute constraint, be off limits for an agent; it will depend on the details of the case. ${ }^{41}$ At least sometimes, it would be better to focus, not so much on avoiding implication in joint disrespect, but on how to change structural settings. ${ }^{42}$ What is crystal clear, meanwhile, is that an agent cannot treat joint disrespect simply as she does failures of assistance: she must not relate to cases of joint disrespect in which she is implicated as if she were merely an outsider, a passive onlooker, and, more generally, she must not let herself off the hook easily. Yet further discussion of such cases is beyond the present scope. The point here is merely that human rights must not be actively set back, ${ }^{43}$ save perhaps in very extraordinary circumstances. ${ }^{44}$

This concludes my brief discussion of three ways in which priorities among human rights must not be set - there must be no neglect of any beneficiaries of human rights, of any very important interests and active violation of human rights must not occur in any case. (As said before, some of these points may be put positively instead of negatively. But that does not matter for their content and they still read like constraints.) All three points seem important with regard to future people and their interests. Future people as beneficiaries should not be disregarded, nor should their interests (which may also be different from the interests of people presently alive; cf. Section 5.3 below), and certainly not actively so - as may, arguably, be nearly the case when environmental damage is quite directly inflicted by some agent, as where rainforests are destroyed or river deltas polluted. And cases of failing to halt climate change, while typically a matter of joint disrespect and as such serious enough, may sometimes be, rather, very nearly direct, for example when a powerful agent starts a strong lobby to prevent a meaningful mitigation regime.

\section{B) Principles for setting priorities among human rights}

I now turn to the beginnings of a positive account of how priorities among initial human rights claims should be set. This will consist of relatively formal principles that can apply to many conflicts between human rights considerations, often regardless of whether the conflicts are due to scarcity of resources or not. Such principles are not so substantively specific as to say, for example, that in the case of a conflict between providing protection $\mathrm{P}$ of freedom of religion and protection $\mathrm{Q}$ of non-discrimination, such and such is what should be done - including, 
possibly, a specification of the agent who should do it. Within the scope of this chapter, it would be much too ambitious to develop such substantive and specific principles, and I will confine myself to more formal considerations. ${ }^{45}$ First of all, (i) several factors will be outlined which should be considered when setting priorities among human rights; then (ii) I will discuss some further formal principles; and finally, (iii) some formal considerations to do with equality of protection will be discussed. This section will end with a brief discussion of how these considerations apply to future people and to setting priorities between the present and the future when there is a conflict. Section 5.3 will then further go into how to deal with uncertainties in the priority-setting-exercise, which is particularly important for duly including future people. And Section 5.3 will also ask what assumptions should be made about the number and interests of future people.

But let us now first discuss the positive account of how to set priorities among human rights, which consists of three parts.

(i) The following factors (a)-(g) should be taken into account when setting priorities among initial human rights claims (claims which all meet suitable entrance conditions):

(a) how important the interest is that stands to be reliably protected;

(b) how serious the threat to that interest is;

(c) how much the envisaged protection contributes to averting the threat;

(d) how (un)certain the threat is and the efficacy of the protection;

(e) how many people stand to be protected;

(f) what the cost is of providing the protections, in such terms as the wealth of a society and its technological resources; and

(g) whether there are suitable duty bearers available.

Just to focus thoughts: one could think of a conflict between, on the one hand, providing certain protections of the freedom of expression for certain people (possibly presently alive) and, on the other hand, providing certain protections of a decent standard of living for certain others (possibly future people), and one could consider factors (a)-(g) to see whether a clear picture emerges. It is important, though, that such a conflict is stylized and that one should consider all the possible protections that meet the appropriate entrance conditions together. An isolated comparison of two conflicting claims by looking at factors (a) - (g) will often have to leave open the possibility that both ought to be honoured except where this is by definition impossible - at the expense of other initial claims, as well as the possibility that neither of the claims ought to be honoured, to the benefit of other initial claims.

To clarify further, I do not think of considerations (a)-(g) as exhaustive, nor do I think it is plausible that they can neatly be combined into what Samuel Scheffler calls a 'mechanical decision procedure', ${ }^{46}$ where, given inputs on (a)-(g), the right decision will follow without any further need for judgment or sensitivity to context. Rather, (a)-(g) are no more and no less than factors that 
need to be considered in determining how priorities should, in a given spatiotemporal context, be set among protections that meet suitable entrance conditions. Factors (a), (b), (c) and (d) follow straightforwardly from a focus on providing very important protections of very important interests. Concerning factor (a), the case for the importance of an interest can be made by pointing to its intrinsic and instrumental importance, as was discussed above in the example of having freedom of expression. The seriousness of the threat and usefulness of the protection - factors (b) and (c) - may be clear enough as they stand. Factor (d), how to deal with uncertainties, will be discussed in Section 5.3 below. With factor (e), it should be remembered that, on the one hand, no individuals and interests may be entirely neglected, but that, on the other hand, the number of people involved in a protection remains relevant as well. Some defensible balance has to be struck between, on the one hand, doing justice to everyone and to every very important interest and, on the other hand, doing justice to many. It may be hard to say more than this without considering particular cases. As for factor (f), this - although it is already largely implicit in the other factors - bears explicating inasmuch as there are many protections that meet suitable entrance conditions. Consequently, the 'opportunity costs' of providing certain protections need to be taken into account. And factor (g) needs to be included if (as has been argued in Section 2.2) certain conditions must be fulfilled in order for some agent to be rightly regarded as a duty bearer for providing protections. For example, they must in any case have the capacity to provide protections and it must not be grossly unfair to ask them to do so.

Before I add some further principles for priority-setting among human rights, let me first make some remarks that begin to show the above framework at work. Suppose that a choice must be made between providing a particular protection of very many people's food supply and the provision of some quite important form or element of education (for example, one working towards elementary literacy) for even many more people. I assume that this is a choice that must be made rather than - as it will often be in practice - a false dilemma. Also, as said earlier, a priority-setting exercise based on the above framework needs to consider all initial human rights claims together rather than make isolated comparisons. Still, let us go with the example. Food provision, it may be thought, is more important than education, ${ }^{47}$ so, unless perhaps the number of people whose education is threatened is very much larger, it ought to get precedence. But, then again, this will surely also depend on how large the threat to it is and to what extent that threat can be staved off. If there is a great difference in favour of the education here, it may have to get priority after all, especially if it is very much less costly to provide the education or if a suitable duty bearer is much more easily found, for instance one who clearly has the capacity to provide the protection of the interest (education) and of whom it does not seem grossly unfair to ask it.

This example also goes to show that one will always have to know a lot of details about the case at hand. This is beyond the present scope; but let us look at a somewhat different example, where the interests involved are arguably not 
of clearly different importance: say the freedom of expression, to express and share one's views, versus the freedom of work in the sense of having the liberty, within certain limits, to engage in and withdraw from economic activity. ${ }^{48}$ In this example, one will need to look more closely into the intrinsic and instrumental importance of these interests; and beyond that - again sticking with the stylized example of an isolated case where there is really a conflict - many considerations will follow similarly as in the previous case. One will consider the size of the threat and the extent to which it can be staved off, as well as the cost of providing the respective protections and the availability of suitable duty bearers. Especially where different considerations pull in different directions, the details of the case will matter a lot. In a case where one protection relates to future people whereas the other one concerns people presently alive, things will be much the same again - although clarity will be required, in particular, about the relevant assumptions to be made about future people and about uncertainties concerning the protection of their important interests (even though there are of course also uncertainties relating to people presently alive).

Finally, and more generally, I have said that thinking in terms of isolated pairs of conflicting claims is misleading. It is, therefore, better to consider several alternative configurations of protections provided as a matter of human rights, and test these against both the negative constraints and the positive framework that were proposed above. And these configurations should also be tested against some further formal principles, which will now be discussed.

(ii) These formal principles are as follows (I will use positive formulations). First, following up on the idea that each person is owed consideration, one may formulate a principle to the effect that there should be particularly careful attention for exceptionally vulnerable right-holders, for example the physically or mentally disabled or the world's poor, and that they are owed a careful explanation if their claims lose out. ${ }^{49}$ Second, also following up on the idea that no person - or interest - may lose out entirely, a principle concerning imminence may be formulated: ${ }^{50}$ failure to protect against imminent serious threats to important interests should receive especially careful justification, all the more so if the failure is larger in the sense that one can do more to protect the interests, or in the sense that the interests are exceedingly important, etc. The rationale behind such a principle is that, with imminent threats, protecting the interests concerned may be a case of now or never. ${ }^{51}$ As examples, one may think of imminent threats to receiving a fair trial, to having security or a decent standard of living. A third formal principle has to do with cases of priority-setting where several considerations point in the same direction: if some protection concerns 1) an extraordinarily important interest (for example, life), 2) many people and 3 ) is efficacious against serious threats, then frequently that protection should receive precedence vis-à-vis protections that score significantly less on all these dimensions. And this will be so more often yet, if even more of the factors (a)-(g) mentioned above point in the same direction. It may be against this background, I surmise, that activists and lawyers who generally deny that there are priorities among human rights, still recognize certain rights as absolute, that is, 
as not allowing of any exceptions - the right not to be subjected to genocide would be an example. In such important cases, the answer to the question of how to set priorities among human rights involves so many considerations that point in the same direction that things will not be controversial. ${ }^{52}$

(iii) Finally, as a third part of the positive account of priority-setting among human rights, certain principles to do with equality of protection will also have to be observed. Some negative constraints discussed above - that every individual and every very important interest should receive attention - already articulate very minimal senses of equality of protection. By contrast, Chapter 4 has specifically discussed one more ambitious form of equality of protection: that persons receive the same protection of a very important interest whenever their need for protection is the same. I have argued that deviations from this form of equal protection are, even in an ideal world, sometimes justified; but that good reasons are indeed needed. The reasons that I have explored have to do with the circumstance that a world order made up of largely sovereign states will in many ways likely be desirable; and then, differences in the protection of very important interests will result and it will be limited what external assistance can do about them.

Assuming, in light of what was said in line with this, that it will often be states that carry out the setting of priorities among human rights - although the framework outlined above should be thought of more broadly and generally we can note that the reasons just mentioned for sometimes allowing global inequalities of protection do not apply within one country. So, one needs different reasons if one is to maintain that two people for whom a very important interest is in equal need of protection may still receive protection that is not the same. Such reasons, I have suggested, will usually be hard to come by. If so, within a country, equality of protection - in the sense of two persons receiving the same protection when their need for protection is the same - will generally be a constraint on how priorities among human rights may permissibly be set. Furthermore, in Chapter 4 it has also been defended that those right-holders whose interests are especially vulnerable should at least receive some meaningful extra protection. ${ }^{53}$ This, too, will constrain how priorities among human rights may permissibly be set.

\subsection{Priority-setting among human rights: uncertainties, and assumptions, concerning future people}

Let us now discuss two aspects of priority-setting among human rights that require special attention when one is considering future people. The first aspect concerns the uncertainties associated with the threats to, and protections of, future people's interests - notably, what exactly these threats will look like and whether certain protections will be efficacious. To be sure, such uncertainties can also be present with regard to people who are alive now, but with future people they are particularly conspicuous. A second aspect that needs particular discussion is what assumptions should be made about future people - about how 
many they will be and about what their interests will be. I will consider these two aspects in turn.

\section{Uncertainties}

The cases of uncertainty that are of special interest here, and for which it is a particularly difficult question how to take them into account when setting priorities among human rights, concern uncertainty in the technical sense, meaning that no probabilities of a given outcome are approximately known - but that there is good evidence (it is not contrived) that some particular outcome could occur if a certain course of action is followed; that outcome is, so to speak, 'on the menu' of outcomes. ${ }^{54}$ In other words, a suitable entrance condition is fulfilled, which I have called a 'non-contrivance' entrance condition. Cases of uncertainty, so understood, are to be distinguished from cases of risk, where approximate probabilities of outcomes are known, and also from cases of ignorance, where it is not even clear, on good evidence, what the outcomes of a given course of action may be - what the 'menu of outcomes' is. In cases of risk, one should generally draw the probabilities into the priority-setting exercise which will, to be sure, be a non-utilitarian and non-mechanical exercise, but even so the known probabilities should clearly be part of what is on the table. ${ }^{55}$ Cases of ignorance ('if course of action A is performed, no idea what might happen in regard R ...') are hard to deal with and it seems that in any case they will not figure among initial human rights considerations. For they will not meet the entrance condition that a good scientific account, or something similar, must be available about the threats and about the efficacy of the protections if they are to merit consideration. In what follows, I will put cases of ignorance to one side, and for the most part cases of risk as well. The focus will be on cases of uncertainty, which one encounters particularly often when dealing with climate change.

My ambitions are limited: to criticize one prominent approach and propose what I believe to be a better alternative. The approach to be criticized is the one that leading climate ethicists Stephen Gardiner and Henry Shue have defended. It is sometimes called a precautionary approach, but I take it that hardly anything depends on this label. It essentially says that, when certain conditions are met, the uncertainties associated with a threat (and with the efficacy of a protection) should be disregarded entirely. This approach is, it will be argued, hardly ever helpful in setting priorities among human rights. ${ }^{56} \mathrm{I}$ will defend an alternative approach of which it is a part to visualize uncertainties (in a sense to be explained).

Let me first explain the way in which Stephen Gardiner and Henry Shue deal with uncertainties - which is, although different in some details, similar in many respects. ${ }^{57}$ I will paraphrase the main points. Both Gardiner and Shue are concerned with outcomes that are uncertain in the above sense ${ }^{58}-$ no probabilities are even approximately known - and which we would want very much to avoid, such as severe climate change with all its possible adverse effects in the way of extreme weather events, problems of water and food provision, reduced biodiversity, etc. Both authors add an entrance condition (as I have called it) that 
the outcome in question should not be contrived (my words again). More particularly, Gardiner holds - but he does not elaborate on this very much - that there should be a respectable scientific account about the outcome in question. ${ }^{59}$ Shue thinks explicitly of climate change when he says that '(a) we understand the mechanism by which the [massive losses] are likely to occur and (b) we have begun to create the conditions that lead the mechanism to function' ${ }^{60}$

Gardiner says that, if two conditions are fulfilled (in addition to the entrance condition just formulated), we should avoid acting in such a way that a particular (worst) outcome becomes possible. These conditions are, first, that we care greatly about avoiding that outcome; and second, that we care relatively less about what we lose by avoiding that outcome. ${ }^{61}$ Shue mentions very similar conditions with regard to climate change: ${ }^{.62}$ we ought to avoid 'massive losses ${ }^{963}$ if, in addition to an appropriate 'non-contrivance entrance condition' (my expression) being met, what we have to give up in order to avoid those losses is relatively less important (the cost is "not excessive ${ }^{964}$ ). Then, Shue argues, we ought to act so as to avoid these losses even if they are uncertain.

I have rendered one of Gardiner's and also Shue's conditions as saying that we care relatively less about what we give up compared to what we gain. ${ }^{65}$ In fact, what they say is more ambiguous than this and, although they do not say so explicitly, we could either go with the relative interpretation just given, or with a more absolute interpretation saying that we do not care that much at all about what we give up. ${ }^{66}$

And this is where my criticism of Gardiner's and Shue's accounts sets in: it is very plausible that 'massive losses' or very bad outcomes should be avoided if the cost of doing so is only small (or perhaps moderate), where obviously what concretely is 'small' (or moderate) requires further interpretation and discussion. Suppose, by contrast, that cost is understood in a relative way: we care less ${ }^{67}$ about what we give up than about what we avoid by doing so (the very bad outcome or the massive losses). Then, I submit, it is at least not evident that we should always do the giving up when (1) there is indeed a very bad outcome or massive loss at stake and when (2) a plausible non-contrivance entrance condition is met. To accept that we should always avoid the very bad outcome or massive loss under these conditions would, it is true, not be all-out consequentialism in the sense of always being required to realize the best overall outcome. But it would be very close to it: basically, always realize the best outcome to the extent that this is about the avoidance of massive losses, which might be called a particular form of negative consequentialism. It is hardly self-evident that one should adopt this position, and many would resist it. I will come back to this.

Let us now provisionally read Gardiner and Shue in an absolute way: they speak to cases where we care only little/moderately about what we give up; and they say that, in such cases, very bad outcomes/massive losses ought to be avoided in any case, also if they are uncertain, as long as they meet a suitable noncontrivance entrance condition. This seems plausible to me. But the trouble is that, on this reading, Gardiner's and Shue's accounts have a much too narrow scope of application: when setting priorities among human rights, we are always 
dealing with very important protections of very important interests, and we are thinking about which of those to provide and not to provide. If so, there will almost always be great (opportunity) costs involved in avoiding massive losses/ very bad outcomes. ${ }^{68}$

It may be that one should avoid them nonetheless, but that needs argument. ${ }^{69}$ Also, and to follow up on the beginning criticism of the relative reading of Gardiner's and Shue's accounts, it is doubtful whether the potential duty bearers would still have to take action (perhaps just because of their ability to do so), even if the costs to themselves are (very) great - as such a relative reading would suggest. That would be a very demanding morality. Such a morality may be more plausible in cases where the duty is not merely based on capacity, but on being involved in a problem in a way that is considerably causal; but even this much is hardly self-evident. ${ }^{70}$

Furthermore, what is even less self-evident, and what I actually believe to be incorrect, is that one could rightly be asked to bear (very) great costs for the sake of preventing even greater costs, while at the same time the uncertainties concerning these greater costs/massive losses could justifiably be left out of the picture - as long as a plausible non-contrivance entrance condition is met. I concentrate now on a relative reading of Gardiner's and Shue's accounts, where people presently alive could (in theory but also in practice ${ }^{71}$ ) be asked to bear costs/losses that are (reasonably) certain, and which may be only moderately (or perhaps, in some cases, even slightly) less bad/massive than the uncertain outcomes/ losses for whose sake they are borne. In such cases, there is so much at stake for present people that - I submit - one may not only take the uncertainties into account in the priority-setting exercise, but one should do so.

Yet how should they be taken into account? To recall, uncertainties, as understood here, are distinguished from risks in that approximately precise probabilities are not known; and by approximately precise probabilities, I mean that the probability range is quite narrow. ${ }^{72}$ Furthermore, I assume we are dealing with uncertainties of which there is a respectable scientific account (or alternatively where, for example, as Shue says, we understand the mechanism and whether the conditions are fulfilled for setting it in motion). With this in the background, how should uncertainties regarding, in particular, future people be taken into account when setting priorities among human rights, especially when deciding whether to give priority to those presently alive or to future people in cases of conflict? The cases of which I am thinking involve uncertainties concerning threats: Will the earth warm up with a certain number of degrees? Will a certain amount of warming lead to problem P for food provision, etc.? And there may also be uncertainties concerning protections, for example: Will doing X limit global warming to maximally 1.5 degrees Celsius? I propose that, in such cases, one should generally, on the one hand, avoid thinking too 'lowly' of the uncertain outcomes. For, even though they are uncertain, they meet a suitable noncontrivance entrance condition. That global warming by a certain number of degrees, and certain consequent problems of food provision, extreme weather events, etc., are uncertain if we pursue course of action A, only means that we 
cannot attach remotely precise probabilities to these occurrences. But they are 'on the menu' if we pursue course of action A. Similarly for the realization of a protection such as limiting global warming to 1.5 degrees Celsius (or avoiding certain problems with food provision), if we pursue course of action B: a protection whose realization is uncertain is still 'on the menu'. On the other hand, uncertain outcomes of the kind just mentioned should not be thought of too 'highly' either; they should not simply be put on a par with adverse effects or protections that are certain.

However, is it possible to put matters positively and say what should be done rather than what should not be done? As indicated above, I believe that the way to go is to strive for a detailed picture of all sides of the 'equation': ${ }^{73}$ the importance of the interests in play, the number of people concerned, the severity of the threats, the efficacy of the protections, etc. Whether there are uncertainties (concerning threats or the efficacy of protections) is one part of this. This is the general answer; I now add some detailed remarks about the uncertainties specifically.

About uncertain threats (etc.) we can say that, while (obviously) they are not certain, there is a chance of their realization that is, depending on the cases at hand, non-miniscule, or decent, or reasonable, or small but non-negligible, etc. this is how their being non-contrived/'on the menu' may be put differently. In light of this, my (cautious) suggestion is that, in deciding how to deal with uncertainties when setting priorities among human rights, it would help to try to visualize them by - paradoxically - quantifying them, while always looking carefully at what is adequate for the cases at hand. Let me explain by taking an example that concerns climate change. Suppose that someone sketches five scenarios (sets of outcomes) that may occur when a particular amount of greenhouse gases is emitted. The assumptions that these scenarios are based on all might be correct and not far-fetched; yet, if a knowledgeable scientist is pressed, she cannot name - even very roughly - the probabilities of these scenarios being realized (if she could, we would have a case of risk). This is, then, a case where one could say that the chances of these outcomes, if that particular amount of greenhouse gases is indeed emitted, are not negligible, but where any remotely precise probabilities cannot be assigned to that outcome.

Yet what I now want to propose seems directly in tension with this: that, in a priority-setting exercise, we can think of such cases of uncertainty in terms of a probability range nonetheless, and that it may be a good idea to do so. Suppose say, in the climate change example - that the odds of a certain outcome occurring are not negligible. Then one would not want to think of the likelihood of that outcome happening as miniscule - nor, of course, as all but 100 per cent. (In other cases, one might prefer to say: the odds are reasonable; small, but noteworthy; considerable; or use yet other and perhaps more informative characterizations; and such variations may influence how we want to think of the likelihood of that outcome, as somewhat greater or smaller, or being in a certain range of magnitude rather than another. ${ }^{74}$ ) When does one start to think of the probability of an outcome as miniscule? For some outcomes, this will be when one thinks of it as having a chance of less than 10 per cent; for others, a chance 
of less than 1 per cent; for others, of still less. ${ }^{75}$ One can ask the same question at the other side of the spectrum: when does one start thinking about a certain outcome as virtually certain? For some outcomes, if its chance is 90 per cent or more, for others if it is 99.9 per cent or more.

Now, if one is going to use the resulting (very broad) probability ranges in a priority-setting exercise, it is essential to keep two things in mind. First, one should never forget what function these probabilities have, namely to avoid thinking of the probability of a threat as miniscule on the one hand and virtually certain on the other - or something similar in certain other cases. It is in light of this role that the probabilities were picked. Second, the priority-setting exercise that I have in mind is not mechanical, but essentially involves judging various relevant factors so as to arrive at an overall judgment concerning which protections of important interests ought in the end to be provided. One cannot use quantifications of broad probability ranges simply as input in multiplications (of the size of the good or bad in question and its chance: its magnitude multiplied by its probability).

However, why would one want to work with such broad probability ranges in the first place? I'd say: because if one does not do it, and instead just keeps thinking of the threat of massive losses as 'not negligible' or some such thing, one runs the risk (in line with what was argued at the beginning of this section) of ending up thinking of it either too lowly, and then one risks concluding rather quickly that the present will have to get priority: that what are certainly serious threats to important interests in the present will have to get precedence. Or if, on the contrary, one jumps at the threatening undertones of 'not negligible', one risks thinking of the threat too highly and one may want to avoid these massive losses at just about any cost. Against these risks, the probability range potentially gives us a bit of a grip.

Yet, one might object, cases of genuine uncertainty are defined by our not knowing any remotely precise probabilities. We do know, of course, that the outcome in question is not certain; we also know that it is not contrived (that is, there is, for example, a respectable scientific account associated with it). And in some cases, we might know a bit more as well: the chance of the outcome seems reasonable, or rather large, or small but non-negligible, etc. - but whatever we might know more cannot be translated in any remotely precise probability ranges. Are we really justified, then, in introducing broad probability ranges? The reply can simply be this: we do know that the outcome in question is clearly not certain, but that it is also not contrived and, as such, to be taken seriously; and working with probability ranges could help to make sure that all this is adequately put on the map in the priority-setting exercise.

Let me give an example of how this may work concretely. Consider a case where one could avoid uncertain widespread hunger in the future by giving up some quite important freedoms today - giving up these freedoms is, let us suppose, necessary to reduce greenhouse gas emissions sufficiently (one may think of economic freedoms to purchase certain things or to travel across the globe for certain reasons). If one simply thinks of the possibility of widespread 
hunger as 'not negligible', without associating a probability range with it, one may easily be torn between two contrasting reactions. The first reaction zooms in on the possibility of widespread hunger: we must go to great lengths to prevent that from happening! This reaction, however, risks going too quickly and considering as not weighty enough important freedoms in the present; and there may be a related risk of not going to great enough pains to look for more acceptable alternatives. A second possibility is to say: yes, there is some chance of things going wrong, but let us not be too pessimistic and give up important freedoms too easily. But this reaction, obviously, risks neglecting the interests of future people.

How are things when probability ranges are employed? I may then well start thinking of the chance of widespread future famine as miniscule if I think of it as having, say, a probability lower than 1 per cent. ${ }^{76}$ However, I ought to avoid thinking of the famine as having a miniscule probability because, by hypothesis, there is a plausible scientific scenario that it may occur if we emit more than a certain amount of greenhouse gases (but one cannot give probabilities). For this reason, it is arguably a good idea to think of the widespread future hunger as having a probability of at least 1 per cent. In the face of this visualization, it will clearly be inappropriate to say: 'This is merely a vague possibility and we are not going to give up important freedoms for the sake of that!' On the other hand, through this visualization, we now also see clearly that the occurrence of the widespread famine is far from certain. It therefore becomes very urgent to find out whether there are ways to avoid the famine without sacrificing important freedoms. If not, further scientific questions will arise: Is the scientific scenario really plausible? Are there different scenarios? Just how widespread would the famine be? Could there still be ways to avert it, once it was directly imminent? Are the freedoms that we stand to lose all that important after all? Could new freedoms be gained? Etc.

In short, I suggest that introducing quantitative elements, more precisely an appropriate probability range, may make for a much more thorough investigation of what can and should be done, inasmuch as the dilemmatic aspects of the priority-setting problem may become much more vivid.

Again, someone may say that the minimum probabilities chosen (as well as the maximum probabilities) are completely without base. But, as I have emphasized, they are merely meant to bring more vividly before our mind that the probability in question is not miniscule (nor almost approaching certainty), and the probabilities should be chosen to convey this adequately in the case at hand. ${ }^{77}$

Now, that it is a good idea to visualize uncertainties is to a considerable extent an empirical hypothesis. The aim for which it is done and the context in which it is to function largely aren't empirical, but whether it functions as envisaged (that is, whether visualizing an uncertainty in a certain situation as, for example, 0.1 per cent conveys that its chance is non-negligible) is. Besides, and as discussed before, other factors have of course to be considered as well when setting priorities among human rights considerations, such as the importance of the interests involved, the number of people involved and the availability of suitable duty bearers. All I want to propose here is that an appropriate visualization of uncertainties could be an important element of the priority-setting exercise. ${ }^{78}$ 
I want to consider now what assumptions about future people ought to be made in such an exercise. Finally, in the chapter's conclusion, I will come back to the question of whether the framework that has been developed in this chapter can really help with setting priorities among human rights, particularly where there is a conflict between protecting very important interests of people now alive and of future people.

\section{Assumptions concerning number and interests of future people}

What assumptions should one make about the number and about the important interests of future people? How many people should in perpetuity be able to live on earth? Where should they be able to live? What important interests ${ }^{79}$ should we assume they will have? The answer to these questions can obviously make a difference for what we (now alive) should do. To take an extreme example (which Stephen Gardiner mentions ${ }^{80}$ ): if we only need to make sure that a small number of people can in the future live in an underground dome, we probably have to do very much less now than if we are morally required to make sure that very many people can live widely across the earth. (If the dome scenario were acceptable, there would be no problem with, for example, whole regions of the world becoming too hot to live in, as may, because of climate change, be happening with the Middle East.) Or, to take a less far-fetched example: it may make a difference if we should morally make sure that 15 billion people, rather than five billion, can in perpetuity live on earth. If we prepare for the five billion, when we should have prepared for the 15 billion, the level of protection of very important interests that can be provided may be drastically lower as a result. And that may be morally blameworthy if we should have prepared for more people, indeed very blameworthy because we are speaking of very important interests.

I want to defend that the assumptions made should not be very 'minimal', such as that only a fairly small number of people should in perpetuity be able to live on earth, and merely at very limited places. But we should not go with 'maximal' assumptions either - say, that 100 billion people should at all times be able to live everywhere on earth. ${ }^{81}$ More particularly, I want to defend the following:

1. As for the number of people that should in perpetuity be able to live on the face of the earth, we (people now alive) should make sure that the number that will be alive according to high-growth projections (say, 20-25 billion at the top point in time ${ }^{82}$ ) is used in a priority-setting exercise concerning the protection of very important interests. This is somewhere between a very low number (e.g. one billion) and an extremely high number (e.g. 100 billion), while preferring to err on the high side - the side of safety.

2. As for the very important interests of future people that qualify for reliable protection, those interests should not be restricted to what are (almost) certainly their very important interests, but also include what will plausibly, 
although not certainly, be their very important interests. ${ }^{83}$ Similarly, reliable protections should not be restricted to what will (almost) certainly be preconditions for meeting these interests, but also include what will plausibly be preconditions. (Sometimes, very important interests and preconditions may coincide, as in the case of having enough food and freedom of movement, which will almost certainly be among future people's very important interests, while at the same time being preconditions for other very important interests of theirs to be met.) Examples of very important interests that they will plausibly have may be interests in being able to enjoy certain kinds of learning or culture (say, Latin or 20th-century architecture) and plausible preconditions may include being able to use certain rare earth metals (potentially useful for a variety of technologies) and having certain marine ecosystems intact. Thus, a fairly wide array of interests should be accommodated - but not a virtually boundless one. For example, we may assume from the outset that old buildings of cultural value may sometimes be demolished and probably also - which relates instrumentally to people's interest in being able to have enough food and other resources - that people should be able to live in coastal regions, but not in all of them.

I am aware that much more remains to be said by way of articulation of what a 'middle road' would be, when it comes to assumptions about the number and interests of future people. ${ }^{84}$ However, I want to leave this for now and ask what the arguments are for taking such a middle road. It is important to keep in mind that the assumptions presently under discussion would come out of the first step of the exercise of setting priorities among human rights, that is to say, the step where a first selection of interests and protections is made: important interests, important protections, of which a non-contrived account is available that they are indeed important. These will then be the interests and protections among which priorities are set in a second step so as to decide which protections of which interests are all-things-considered to be provided as a matter of human rights (see above). In the case of interests of present people, this is usually done by showing what goes well for someone if these interests are adequately attended to and protected, and what goes badly for them if they are not. ${ }^{85}$ If only very few interests are admitted into the priority-setting exercise in this first step - I am still thinking of interests of people now alive - this will be inadequate to what is actually important to them. ${ }^{86}$ By contrast, if very many interests are admitted, it will make the priority-setting exercise rather unmanageable ${ }^{87}$ - the most important interests may well suffer, although this need not be so if the priority-setting exercise is carried out well. ${ }^{88}$ It is the same for the interests of future people: including very few interests may well be inadequate to what is actually important to them, including very many may make priority-setting unmanageable and may make very important interests lose out.

Concerning population size: it may well be that the number of people figuring in the projections (' 20 billion people in 2100 ') will indeed be alive then; and, if the population size should morally have been smaller (say, not larger than 15 billion), 
it is not the fault of the people who will be alive in, for example, $2100{ }^{89}$ So, we' $d$ better, in the first step of the priority-setting exercise, reckon with the number of people figuring in the most plausible (high) projections. But not a number even much larger than that; for then the exercise may well become unmanageable or present people may well lose out unduly - although, again, it may still be that they win out in the second step of the priority-setting exercise.

These arguments, it may be said critically, have a somewhat circular aspect to them: one already has to know how much one weighs the present and future and use that as input into the arguments, rather than as their outcome. However, I would say that these arguments can at least help to explicate and clarify what we find acceptable, and that the modicum of circularity in them does not make them useless.

Suppose now that it is possible to accommodate even many more interests of future people, or a much greater population, and to do so at hardly any cost to the present. I am not sure how often this will be so: there are certainly win-win situations, but at the same time, many things in a priority-setting exercise come at a price in terms of at least opportunity costs - of other things that might have been done instead. Yet sometimes this will hardly be the case: restricting climate change to two degrees Celsius, say, may make the earth inhabitable in perpetuity for 20 billion people, but also for many more, and doing so may lead to the protection of a moderate range of important interests of theirs, but possibly of a much broader range as well. However, if there are additional costs to achieving more, then one should go with the moderate assumptions as to interests and population size.

\subsection{To conclude}

This chapter has proposed a formal framework for setting priorities among human rights. According to this framework, it has to be made sure that claims meet a number of (what I have called) entrance conditions: that they concern very important interests, very important protections of those interests, and that the threat to the interest and efficacy of the protection meet a plausible 'noncontrivance' condition (my term). Second, in setting priorities among the claims that meet the appropriate entry conditions, a number of factors have to be considered, such as: how important the threatened interest is, the number of people involved, the magnitude and certainty of the threat, how certain it is that the protection will be effective, whether suitable duty bearers are available and whether certain appropriate constraints - such as that interests should not be actively attacked - have been met.

In particular, I have suggested that the framework proposed in this chapter could, in cases of genuine conflict, help to decide whether to give priority to protecting interests of future people or of people now alive. Two kinds of cases were already clear at the beginning of the chapter. First, that interests of future people ought to be protected where very important interests of very many future people are greatly jeopardized and where protections can be provided at 
little cost to people in the present. (For problems related to climate change extreme weather events, threats to food and water provision, loss of biodiversity, etc. - which have provided the leading examples throughout the chapter, there will only sometimes be 'little cost'.) A second clear example is one where protecting very important interests of future people inevitably - emphatically inevitably implies that the very important interests of very many people now go unmet. Then, I have argued, the present should typically be prioritized, even if many more people are concerned in the future. An example may be preventing imminent famine in the present versus protecting food provision for future people - for example, in the light of climate change - in a number of ways.

The beginning framework outlined in this chapter can, I believe, help to decide additional cases, beyond the clear ones just mentioned. First (as indicated in Section 5.2), there are cases that are overdetermined - where both the number of people involved, the importance of the interests, the certainty of the efficacy of the protection, etc. are more on one side of the equation than on the other. Yet these overdetermined cases may not be so interesting inasmuch as they will have been relatively clear from the beginning. Whether to provide, where there is a conflict, a very certain protection of food provision for many future people or a very moderate protection of the freedom to work for a few people now, is not a hard choice. Still, the framework helps to see why the choice is clear.

The harder cases are ones like this: suppose that, in order to prevent dangerous climate change (with the extreme weather events and the problems of water and food provision, etc. it entails), certain freedoms - freedoms of movement, of choice of occupation, etc. - need to be curtailed in the present; and these freedoms perhaps even need to be (close to) actively limited - and in any case provided with less protection. ${ }^{90}$ Should this be done? I'd argue that reflection about the certainty of the problems (with the visualization of them proposed above, with a percentage of, for example, 1 per cent or 0.1 per cent where appropriate), about the number of future people to be counted with, about who are suitable potential duty bearers and so on - that all this does potentially help to get more clarity about the problem. Sometimes the conclusion may be that the choice at hand is a tragic one and that one should look especially hard to find third ways of avoiding the dilemma and preserving both sides, for example freedom of movement in the present and food provision in the future. Or, alternatively, it may on reflection be overwhelmingly clear that, given what is at stake in the future, certain curtailments of freedoms in the present simply ought to be accepted. And a third possibility is that, on the contrary, some problems in the future - say, certain extreme weather events - concern limited numbers of people and remain very uncertain, so that solutions should be found that do not weigh very heavily on the present.

I am not saying that the framework will always make clear which of these three options (or other ones still ${ }^{91}$ ) should be chosen in a given case. But it does generally have the potential to facilitate and improve reflection on specific cases as to how priorities among human rights ought to be set. ${ }^{92}$

But can people and societies really be moved to act in accordance with human rights? This is what the next chapter will investigate. 


\section{Notes}

1 In the philosophical literature, this is called the 'non-existence problem', see e.g. Meyer (2015).

2 For the criteria for attributing human rights duties, see Ch. 2 above.

3 Some will say that future people can have no complaints against environmentally harmful behaviour of earlier generations in cases where these people owe their existence to such harmful behaviour; in such cases, they are - at least if they still have lives worth living - not justified in complaining, even if many of their important interests are badly protected. The problem involved here is the so-called 'non-identity problem' (made famous by Parfit 1984; see also Hurka 2001; Meyer 2015). It has received more than its fair share of attention in the philosophical literature, so I will leave it aside here and simply assume that it can be solved. The literature concerned has, among other things, investigated the assumptions on which the problem depends (it assumes, for instance, a certain conception of identity, and that something can only be bad if it is bad for someone). I would favour a solution explaining why people can still have weighty moral reasons for demanding protection of their important interests, even though they would not have existed if there had not been certain lacks of protection (e.g. they would not have existed if long-distance flights had been banished). Parfit's own sympathies go in a somewhat similar - a so-called 'impersonal' direction (1984, e.g. Ch. 16).

4 Climate change will be my central case throughout the chapter, mostly explicitly, but sometimes also implicitly - for example often when I speak about the food provision of future people. Yet there may also be other problems (of pollution, depletion of natural resources, etc.) that raise quite similar ethical issues.

5 Both steps work with more concrete human rights claims than those found in, for example, the UDHR, where it is often not very clear which protections ought to be provided and for whom. Cf. Sections 5.1 below and 3.1 above.

6 For example, it is common to distinguish between risks (where approximate probabilities are known), uncertainties (where they are not known) and situations of ignorance (where it is not even known what might happen).

7 I am then thinking of the philosophical literature. Exceptions include Nickel (2007, 2008, 2010) and Gilabert (2009, 2010), cf. also Philips (2012, 2014). And there is, of course, literature that is indirectly relevant. For example, the entire justice literature deals with scarcity and hence, it might be said, with priority-setting, but it seldom does so explicitly when considering human rights. I am not aware of any discussions of priority-setting and human rights that explicitly include future people or uncertainties; for example, the discussions of precaution referenced in Section 5.2 do not deal explicitly with human rights. Philosophical discussions of assumptions to be made about the interests and number of future people are, for all I can see, usually rather implicit; Caney (2009) seems a typical example.

Some will say that, considering such issues as those to do with priority-setting, we are talking at such a concrete level that it is no longer part of human rights. I doubt it; but, however this may be, the really important thing is to think about this level - it is far too important to leave it unthematized.

8 Cf. Goldschmidt (2012). See Section 5.2 below (the discussion of interdependence among human rights in note 36 ).

9 Importantly, I am thinking about human rights claims at a concrete level here - see below for elaboration. Furthermore, I will leave aside the respective rhetorical merits of talk of balancing and priority-setting.

10 That is to say, as majors of a syllogism which, combined with quite straightforward minors, yield definite conclusions about all concrete cases of conflicts among human rights considerations.

11 Cf. Mulgan (2001), p. 19. 
12 It is not, in other words, a fact beyond dispute that human rights are so multifaceted, etc. as to make the quest for general principles of priority-setting clearly hopeless from the start.

13 See note 92 below.

14 Take, for example, the right to freedom of expression: 'Everyone has the right to freedom of opinion and expression; this right includes freedom to hold opinions without interference and to seek, receive and impart information and ideas through any media and regardless of frontiers'. (Art. 19, UDHR). This Article mentions (albeit somewhat implicitly) a negative duty ('without interference') and it is clear throughout the Declaration that governments - primarily each government for its own people - are regarded as the main duty bearers of human rights. But whether the government also has intermediate duties (to protect the freedom of expression from interference by third parties) and positive duties (to make sure that people can actually express their opinion) is left unclear. (Of course, in law, such things often do get clarified, e.g. in additional treaties.)

15 Cf. Section 3.1 above.

16 This is the general thrust and it is not to say that certain matters of priority-setting cannot be dealt with at a more general level (indeed, principled priority-setting is relatively general), and certain issues concerning universality at a more specific level.

17 These will often be interests of broad categories of people across place (and frequently also time, see Section 3.1); but I would not list this as a separate entrance condition because interests of smaller categories should also be included by subsuming them under more general headings. See Section 2.2 above. With protections, it only matters that they are about interests that qualify, and are very important protections of those interests; they need not concern broad categories of people.

18 Cf. Gardiner (2006), n. 61.

19 Shue (2010), p. 155, although Shue is talking here, not about human rights, but about the action required in the face of climate change.

20 See Section 2.2 above.

21 Cf. Düwell (2012); the argument I give in the text is different from Düwell's.

22 See Section 2.2 above.

23 UDHR, Art. 24.

24 It may be said that resolution of this second case, as well as of the third one below, already indicates an outcome of the second step of priority-setting - and that in that sense the conflicts are not spurious. This may be so; but the point is that the outcomes are already clear from the outset.

25 These remarks may be read as a further development of the book's conception of human rights outlined in Ch. 2 above.

26 Just how concrete or detailed the articulation of the safeguards needs to be will depend on how concrete an articulation of the right in question is intended.

27 The term has influentially been used by Robert Nozick (1974, p. 28).

28 This is one sense in which (human) rights confer what Thomas Nagel has called 'a status' on someone. See Nagel (1991), pp. 148-149.

29 The first and second point take inspiration from what Samuel Scheffler (1988, pp. 1ff.) regards as one standard criticism of consequentialism, understood as the view that one must morally always do what, on expectation, produces the best outcome overall: its negligence of distributive issues. The third point broadly resembles a second standard criticism: that consequentialism (not only allows, but even) requires that agents sometimes do horrible things. A third prominent criticism, consequentialism's being too demanding, is not discussed here.

30 Below, I will use 'realizing/protecting a right' in a broad way, as covering everything that has (inspired by Henry Shue) been referred to as 'respecting, protecting and fulfilling' a right: not actively violating (assaulting the interests, e.g. in having enough to 
eat), preventing violations by others and providing additional protections of an interest (cf. Shue 1996). See Section 2.2 above.

31 I assume that group interests ultimately matter because they matter to individuals. Given their importance to individuals, some way must be found to incorporate them, without letting certain individuals fall victim to doing so (cf. Kymlicka 2002, pp. $327 \mathrm{ff}$.).

32 Cf. Goldschmidt (2012), p. 59.

33 Indeed, earlier (and below again) I moved (and will move) much beyond the rather minimal constraint that no individual may lose out altogether, and defend that there should be, in the absence of very good reasons to the contrary, equality of protection among individuals. So, the constraint as formulated here is really very minimal.

34 And, one that will not be plausible in all contexts; in some cases, there could, at any rate, be a very entrenched and 'stable' neglect of certain beneficiaries and/or interests. Conversely, however, an arrangement that attends to all persons and interests may be surmised to be relatively stable - relatively isolated from quick and arbitrary changes.

35 By 'all interests', I mean all interests as found with individuals, e.g. one particular individual's freedom to speak her mind, her freedom to have enough to eat.

36 However, one generally cannot say that human rights are in some very strong way interdependent, so that that would be a reason why one needs to attend to the protection of all important interests. See Nickel (2008). Interdependence of two human rights claims would mean that (for conceptual, empirical, etc. reasons) one cannot have one human rights claim fulfilled without the other and vice versa. Nickel argues that it is often not plausible that there is such interdependence (especially not at lower levels of realization of human rights). He also argues that indivisibility of human rights, understood as all human rights being strongly interdependent ('systemwide', as Nickel calls it), is not plausible at all.

It is useful to elaborate on indivisibility a bit: some lawyers and activists defend that human rights are indivisible and that, therefore, principled priority-setting among human rights is not appropriate. But if they were indivisible, we could not even balance them on a case-by-case level: one could not have one human rights claim fulfilled (or have a certain level of fulfilment of it) without also having that level of fulfilment for all other human rights claims. But the lawyers and activists concerned do often find case-by-case balancing between human rights possible as well as appropriate (see e.g. Goldschmidt, 2012). It follows, I think, that they cannot really be committed to the indivisibility of human rights. Probably, they are rather committed to the normative claim that no human right is, as such, more important than any other. Saying this is certainly compatible with case-by-case balancing; it is even compatible, I would say, with principled priority-setting among human rights.

37 The observations that now follow in the text are not, by themselves, enough to show that one cannot compensate for having few protections of freedom of expression by (say) having a lot of protections of security. To show that such compensation is impossible, one must go into the intrinsic and instrumental importance of all the interests whose protection initially qualifies as a matter of human rights. I cannot do that here, but take the examples of security and freedom of expression. Imagine a state that wishes to protect security so thoroughly that it subjects all expressed thoughts of its citizens to scrutiny, and will even use lie detectors, etc. where it deems this useful. It is plain, I believe, that this is a rather indefensible situation, given what the lives of people in such a situation look like: they are severely hampered in articulating their thoughts, discussing them with others and, thus, in steering their lives. One has every reason to prefer having a very substantial degree of freedom of expression and, if that is the price, to an extent a less stringent protection of security. Moreover, it is very doubtful whether security can really be improved by such a strict surveillance of all expressions - in such a situation, the party doing the surveillance 


\section{Novel challenges to human rights}

has so much power that this puts people's security in great jeopardy; that party can probably take their security away at will. Relatedly, people having meaningful freedom of expression would also help the realization of their right to security as well as of many of their other rights, as people could then better scrutinize how well or badly their security is being protected.

38 Where this is so, it might be called some kind of interdependence, albeit it will sometimes be only one-way (as well as sometimes only moderate).

39 The organ example only works for actively setting back someone's important interests; it clearly no longer works if we say: I can either give my organs to save your life or I can save the life of five others with them. It would perhaps not even work if I took away (albeit, as always, not at will or overnight) a protection that you enjoy against having your organs taken by certain third parties, in order to provide three others with a similar protection.

Importantly, for some very important interests, such as freedom of movement and freedom of occupation, setting them back actively should in certain contexts remain under discussion - but very good reasons are needed. The constraint against actively setting back interests could, thus, also be called a very strong presumption; it will always continue to require judgement.

40 Thomas Pogge $(2008,2004,2005)$ has tried to assimilate the behaviour of certain parties, such as governments of rich countries, with a violation of negative duties. Sometimes it is; but cases where, as in one of his examples, the persistence of severe poverty is due to the contribution of both such governments and local dictators (and where, let us assume, neither of them alone would be sufficient) are not, in my view, to be completely assimilated to violating a negative duty - although, as emphasized in the text, they do certainly and clearly not merely involve a failure to fulfil a positive duty either.

41 Discussion of this point should countenance various complexities and uncertainties, including epistemic ones. However, this is not to deny that there are particular examples of joint disrespect for which an absolute constraint against being implied in it, is plausible.

42 See e.g. Iris Marion Young's (2011) 'social connection model'.

43 To be sure, in certain special circumstances, omissions to do certain (good) things strike us as morally as problematic as doing certain (bad) things (cf. Scheffler 2001, p. 39). Or, for the present context, failings to realize human rights strike us as morally as problematic as active disrespect. But it is beyond this chapter's scope to examine in which cases this would be so.

44 These will be very exceptional indeed. For example, even for conduct in war, there seems a very good case that an agent may hardly ever (except arguably in certain extreme cases of so-called pre-emption, but not prevention) actively disrespect human rights.

45 As James Nickel (2008) shows, the number and variety of conflicts that are possible within human rights are quite daunting.

46 Scheffler (1992), pp. 39ff.; he discusses such a procedure in a very critical vein (in a very different context than the present chapter's).

47 Cf. also Shue (1996) on basic rights.

48 Cf. UDHR, Art. 19; Art. 23(1). It is not my concern here what exactly the plausible content of these freedoms is.

49 What concerns me here is not the need to provide particularly vulnerable right-holders with extra protections: whether that should happen I regard as a (particular) question regarding equality of protection. The point here is, rather, that certain right-holders cannot stand up for themselves as well as others can, to see to it that they even get the same protections as everyone else.

50 Factor (d) above already to some extent gestures in this direction. It is beyond the present scope to elaborate on the notion of imminence. 
51 I do not say, of course, that what is imminent must always win out over longer-term protections. That would - in the face of, for instance, problems of climate change be highly problematic.

52 Of course, these activists and lawyers might also simply recognize - without further grounding - certain constraints, e.g. against ever violating certain negative duties. But arguably, the absoluteness of rights sometimes goes beyond negative duties.

53 In Ch. 4, note 53. Furthermore, it may be noted that equality of protection in the sense of people receiving the same protection of an important interest when their need for protection is the same, is best understood as equivalent protection (see Ch. 4, note 2). A rather broad and systemic notion of equivalence will globally be needed when different countries have different priority-setting exercises. But as said, the framework outlined in this chapter is first of all to be understood, not as being for practical use by countries, etc., but as broad and general - as a contribution to reflection in the background culture (see Ch. 2, note 16).

54 Talk of something being 'on the menu' remains somewhat coarse, but I take it that it is a good enough approximation of reality. To see whether it is justified in a particular case, there may be no alternative but to look closely at the (scientific) evidence at hand.

55 It will shortly be discussed how to visualize uncertainties in the priority-setting exercise. For (approximately) known probabilities, too, it might be that sometimes a visualization should be chosen which differs from what they actually are. See below.

56 For some recent literature on precaution, see e.g. Hartzell-Nichols (2017); Meyer et al. (2018); Pissarskoi (2018). All stress that great risks, as well as catastrophic outcomes that are in some sense realistic, require special attention in decision making, etc. Furthermore, all emphasize that catastrophes, etc. cannot simply be avoided no matter what, but that we need a complex decision-making framework, which takes into account a variety of factors. What little relatively hard guidelines are offered, e.g. (by Pissarskoi in his commendable essay) to avoid options that could set in motion an uncontrollable causal chain (cf. Pissarskoi 2018, p. 202) may, in practice, often be relatively helpless: when such options can be avoided?

57 They are proposed in Gardiner (2006) and Shue (2010 [=2014, pp. 263-286]). Shue explicitly refers to Gardiner, but is not concerned with clarifying exactly how their approaches are similar or different (but cf. Shue 2010, p. 159, note 9).

58 More precisely, Gardiner and Shue mainly focus on uncertainties associated with threats (the warming and, more particularly, the adverse effects generated by it), but much of what they say also applies to the efficacy of protections.

59 Gardiner (2006), p. 51, n. 61.

60 Shue (2010), p. 155. Shue allows that there may be other possible ways to specify the 'entrance condition' (my term).

61 Gardiner (2006), pp. 46-47 and pp. 51ff. (my rephrasing). Gardiner speaks of a 'core precautionary principle' and also adds the following condition: we either (1) do not know probabilities or (2) we have good reason to disregard them. I am talking about the first case and take it, with regard to the second case, that one should usually in some way take known probabilities into account in the priority-setting exercise; but I will come back to exactly how.

The conditions mentioned in the text are sufficient, but not necessary, Gardiner cautions. In other words, it may be that we also ought to avoid a particular worst outcome under different conditions.

62 See Shue (2010), p. 148, my paraphrase. Shue also stresses very much that one should avoid actively imposing these losses on future people. To do so is very different, he says, from merely passively failing to prevent the losses from occurring. I would say that, where the imposition of losses is in effect a direct, active violation of a human right, it ought never to be done (see above). Where (as will frequently be the case) it is not that, but there is a certain active involvement and it is not merely a 


\section{Novel challenges to human rights}

matter of 'letting happen' either, this will sometimes influence, among other things, who is the most suitable bearer of certain duties.

63 Avoiding massive losses could again be labelled the 'precautionary' way of acting (but hardly anything depends on the label), although Shue does not use this term.

64 Ibid.: 'the costs of prevention are not excessive, (a) in light of the magnitude of the possible losses, and (b) even considering the other important demands on our resources'.

65 Emphasis mine.

66 Or, as Shue says, we do not care so much that the cost is excessive. This, too, is vague; but it is clear, in any case, that if we act only as long as the cost to ourselves remains small, we will do less than if we act until the cost to ourselves is 'excessive'. This enlarges the scope of the absolute interpretation in Shue's case: it will be applicable more often. But in many cases it will still be inapplicable.

67 Or the precise formulation should actually be less subjective: we have good reason to care less. 'We' is those who do the giving up, e.g. people now alive.

68 Only when this avoidance does not come instead of other significant protections that could potentially have been provided (e.g. with the same resources) will there not be great (opportunity) costs.

69 In fact, the priority-setting framework will, at least at the background, always be involved, also where we care only moderately or little about what we give up. But there its outcome will be clear.

70 But I'd hesitate to omit 'may': Philips (2007), Chs. 2-4. Moreover, as for human rights, they may plausibly only consume part of a society's resources.

71 In practice if, for example, the 'heat' of climate change gets up very much and one is considering societies that are not so rich and need to adjust away from fossil fuels.

72 To indirectly give some feel for what this means, let me mention one case that I would already tend to regard as one of risk rather than uncertainty. Someone who knew the Libyan context in 2011 on the ground could perhaps have said that, if the international community were to do nothing, the chance was very considerable that Gaddafi would murder many inhabitants of Benghazi. Given Gaddafi's behaviour in the past, and given that the person making this judgement was, let us assume, intimately familiar with Libya's history and its political and social realities, she might have had good reason for saying that the chance of widespread murdering was considerably higher than 50-50 - although it was not a certainty. Of course, a probability range from 'considerably higher than 50 per cent' to 'by no means certain' is still very broad, approximately from $p=0.6$ to $p=0.9$. Still, I would not call this a case of uncertainty, but one of risk. In cases of uncertainty, in other words, we do not even have this much to go by.

73 Or: of both sides of the equation, if one were to think - but this is generally too simple - in terms of a conflict between present and future people.

74 For example, suppose that the likelihood seems considerable in the sense (drawing on Shue) that one understands the mechanism of a threat (of flooding etc.) and that the conditions for its operation are beginning to be fulfilled. Then, one may want to put a higher number on the lower end of the likelihood (e.g. not 1 per cent, but more) in order to visualize it adequately.

75 It may also depend on the person. Sometimes, you read in the newspapers that behaving this or that way will increase your chance of contracting a certain disease by 1 per cent. My hunch is that many people will regard this as a very small increase; but some may regard it as one that is huge.

Sometimes, even very small chances matter greatly. If having a nuclear power plant would bring with it a 0.0001 per cent chance of a disaster that would wipe out humanity, I would personally find that far too big a chance. This example may point to a problem for my suggestion in the text: suppose this were a case of uncertainty and one only knows that there is a 'non-negligible' probability that operating the 
nuclear power plant will wipe out humanity. Are we going to put the probability of this happening at, say, 1 per cent then? My reply is negative. First off, mostly the nuclear power plant case will not be one of uncertainty, but one will know more precise probability ranges. Second, 1 per cent is not an adequate translation of 'nonnegligible' in this case. In some cases, I would propose probabilities of 1 per cent or even 10 per cent because, otherwise, one will regard the probability as miniscule. In the nuclear power plant case, by contrast, one can have a far smaller probability and one will still not think of it as miniscule. Indeed, I would rate a probability of 1 per cent that humanity will be wiped out as 'beyond huge'.

76 Again, some may prefer 0.1 per cent or 5 per cent: this is a matter of dispute and will also vary across cases. See the previous footnote.

77 How are we to deal with uncertainties concerning a protection against threats? If we do not know any remotely precise chances, we cannot say that, if a certain course of action is chosen, the chance of a massive loss is 'significantly lower'. But we may say, for example, that if a certain course of action is chosen (e.g. to realize a certain greater reduction of greenhouse gases rather than another), the chance shifts from 'reasonable' to 'miniscule', or that it goes off the menu altogether; yet we cannot translate that into remotely precise probabilities.

78 As briefly indicated before (see note 55), but this bears repeating, the importance of visualization could also lead to introducing risk (i.e. known or approximately known probabilities) being introduced in the priority-setting exercise differently than as what the actual probability is. This should, following the reasoning in the text, in principle be done whenever the actual probability visualizes the chance incorrectly. For example, it actually is 0.001 per cent, but should be regarded as non-negligible, and that would not happen if the actual probability is used.

79 Alternatively, one may call them needs. But the important thing is what content they should be given, and not much, if anything, may depend on whether they are called interests or needs. See below.

80 Gardiner (2011), p. 43; Gardiner obviously doesn't argue that it would be enough to prepare for such a scenario.

81 I mean this 'should' as input in the priority-setting exercise about the protection of very important interests. This is also the case for the two points below.

Of course, the addition 'in perpetuity'/'at all times' means that the total number of future people that we should count with is very much larger.

82 This is an estimate that some make; but it may be high, compare e.g. https://esa. un.org/unpd/wpp/publications/files/wpp.2017_keyfindings.pdf. It is beyond the present scope to discuss in detail what the best estimate would be.

83 Cf. also Section 3.1. 'Plausibly' refers to a substantive judgment, based on a reasonable standard of evidence (which would need further discussion), about what will be good or important for people; a judgement that something is 'certainly' the case is based on a higher standard of evidence, e.g. an appropriate scientific account.

84 Furthermore, one would also need to make assumptions about what kind of threats there will be to the relevant interests and what kind of protections could be helpful, what duty bearers may be around, etc. In these regards, the future will sometimes plausibly be rather like the present, but not always.

85 See Chs. 2 and 3 above.

86 By this, I don't necessarily mean what they find important. There may also, for example, be an objective account of what is actually important to them.

87 Indeed, one could say that making the exercise manageable - keeping the weighty interests and threats adequately on the map - is the point of having a first step in the first place. Further discussion of the notion of 'manageability' must await another occasion.

88 But there will always be a temptation to give at least some attention to all the interests and protections included in the exercise (even if the constraints I have defended 


\section{Novel challenges to human rights}

above as part of a second step are not yet on the table). Better then, probably, not to include certain interests and protections in the first place.

89 Someone might say: it is the fault of some people now alive, those who have too many children. Let us assume that this is so - although it is quite dubious that the argument can be made. If so, it may be unfair to the others now alive to have to reckon with a rather larger world population in the future. But it is also unfair to people in the future if they are not reckoned with.

90 Cf. note 39 above. Freedom of movement may be an ironic example inasmuch as currently so many people worldwide lack it to an important extent. The very important freedoms/interests associated with economic development in the global South provide examples of particularly hard cases, if there are genuine conflicts with other important freedoms/interests.

91 Perhaps solutions saying that the problem is in some important way misstated.

92 This, in turn, may lead to a refinement of the framework, which clearly remains a beginning one. As for the role of the framework, and of the considerations in the present chapter at large: I regard this chapter, as well as the rest of the book, as a contribution to discussions among academics, activists, policymakers and citizens in general or in John Rawls's words (2007, pp. 6-7), as a contribution made in the 'background culture' of a society, and I leave it open whether it could also be more than that. 


\section{Part III}

\section{Getting to realization}




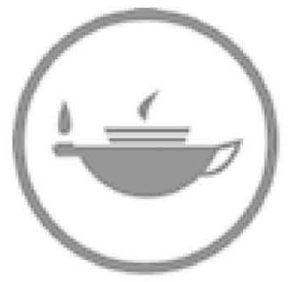

Taylor \& Francis Taylor \& Francis Group

http://taylorandfrancis.com 


\section{The question of motivation Can people be motivated as needed for realizing human rights?}

Can human rights be effectively realized in societies worldwide? In other words, can societies across the world effectively function in accordance with human rights? ${ }^{1}$ If human rights are to make sense as the minimum requirements of global justice - that is how I have understood them - they must, at least in ideal circumstances, be able effectively to be realized in societies worldwide. By ideal circumstances I mean, after John Rawls, ${ }^{2}$ circumstances where institutions (laws and other arrangements in society) are optimal, given human beings as they are. It is of course a large question how human beings are, but one may at least say: neither saints nor devils (I will come back to this). More precisely, in ideal circumstances, societies should be capable of being guided by human rights not only effectively, but also acceptably (that is, through morally acceptable means) and across generations. ${ }^{3}$ Are they indeed capable of this? This is what I will call the question of motivation or, synonymously, the motivational question.

This question is real because, on the one hand, it is not evidently impossible to provide an answer to it; if that were the case, we would be done immediately. On the other hand, it is also not clear how and even if it can be answered. For it is safe to say that the world as a whole has never been guided by human rights effectively, acceptably and across generations. To be sure, there have been cases where human rights have, for quite a long time, been rather effectively realized in societies. These cases will be investigated below, but I will argue that their relevance for the present chapter's purposes is, in the end, limited. But let me first explain some central notions, and also what the chapter's structure and ambitions are.

Humans being motivated (having motivation) to act in accordance with human rights refers, in this chapter, not to people having the intention to act in accordance with human rights (which is how many psychologists would understand motivation), but to people actually acting - actually moving - in accordance with human rights. ${ }^{4}$ Effective guidance means that the guidance is not just in letter, but in fact: human rights should in fact be realized in societies worldwide. ${ }^{5}$ This means something like the following: that there are no official violations of human rights, that is, cases of active disregard for human rights by the government or by officials. It also means that the violations that exceptionally occur by individual members of a society are effectively prosecuted. Finally, it means that the intermediate and positive duties are also effectively taken up 
and receive sufficient resources (think, for example, of maintaining an adequate educational system). ${ }^{6}$ And guidance that is acceptable does not come at an unacceptable price, not in terms of human rights themselves (but then, societies would not really be effectively guided by human rights after all), nor in terms of more ambitious ideals of justice, ${ }^{7}$ nor in certain terms (partly) different from this. For instance, people behaving in accordance with human rights must not be incompatible with them seeing themselves as acting for reasons. To take a straightforward example from an environmental context, if individuals are made to behave so as to reduce their greenhouse gas emissions, the methods by which they are brought to do so (prohibitions, financial incentives, nudging, etc.) must be in line with them being agents who can choose their own courses of action, and these methods must in an appropriate way involve the capacities of individuals to reason and choose. This will often mean that something like the following condition must be fulfilled: that people can at all times understand themselves as acting for reasons or, at least, that they can judge after the actions concerned that there were good reasons for these actions, and that they can in some sense understand themselves as having acted for those reasons. ${ }^{8}$ Obviously, much more could be said about this, but that would go too far here. The important thing in the present context is that, if some condition such as the one just stated is not fulfilled, getting people to behave in accordance with human rights will come at the price of disrespecting them as agents and will therefore generally be unacceptable - as well as frequently not being in accordance with human rights after all.

Finally, guidance across generations indicates that societies should not only be effectively and acceptably guided by human rights at present, but that this should also remain so across time ('generations' does not mean more than this and should not be taken too literally). Note, incidentally, that there is another intergenerational dimension that one must not confuse with this one: that human rights should adequately include claims of future generations.

The chapter will be structured as follows. First (in the first part of Section 6.1), it will be explained why the relevance of real-life cases for the motivational question - of whether societies worldwide can, in ideal circumstances, be effectively, acceptably and across generations guided by human rights - is limited. Subsequently, I will (in the second part of Section 6.1) explain the approach that will be taken instead - namely, giving a hypothetical indication of where the robust empirical evidence may lead - and why it seems more promising. In this approach, societies will (as will be explained) come into view via individuals, and Section 6.2 will develop a substantive hypothesis about individual motivation, starting from Richard Rorty (first part of Section 6.2), but revising his position at certain points (second part of Section 6.2). Section 6.3 will consider various objections to the hypothesis developed, and Section 6.4 will conclude.

The ambitions of this chapter are only explorative. For, although there is obviously an enormous literature about what it is that leads people actually to behave as they do - large parts of the social sciences are concerned with this - there is hardly any, for all I can see, explicitly dealing with the question of whether societies 
worldwide can realize human rights effectively and also acceptably and across generations.

Like the other chapters, this one, too, deals with ideal theory: it asks whether societies worldwide can effectively, etc. be guided by human rights in situations where, given people as they are, institutions are optimal. Focusing on ideal theory provides a minimum test for human rights - if they cannot even motivate in ideal situations, they will be unsuitable as an account of minimal global justice. Of course, there are also many interesting questions as to whether human rights will be able to motivate people in various kinds of non-ideal circumstances: of troubled socialization, certain kinds of conflicts and deprivation and, more generally, of institutions that are not the best ones imaginable. All of these non-ideal features are often found in our present world. Now, to think about motivation in ideal circumstances may sometimes not be relevant for non-ideal circumstances, but sometimes it will. ${ }^{9}$ In any case, it is relevant - as just explained - for the evaluation of human rights.

\subsection{How best to approach the motivational question}

One way to approach this chapter's central question - of whether societies worldwide can effectively, as well as acceptably and across generations, be guided by human rights - would be to look at real-life examples of societies where human rights have in fact been realized effectively, acceptably and across generations. As I will now argue, this approach has serious limits. The alternative I will subsequently propose is to look at robust evidence, or some approximation thereof, with regard to what motivates individuals to behave in accordance with human rights. Finally, some complications of that approach, such as doubts as to whether societal motivation can be investigated by looking at individual motivation, will be considered.

\section{The limited relevance of real-world cases}

Real-world cases only have limited relevance for showing that societies worldwide can effectively, acceptably and across generations be guided by human rights. This is because, first, they do not concern the entire world, but only particular times and places. There may, for example, be effective guidance by human rights in Canada in a particular period, but this says little about whether this could also be the case across the world and/or at different times. Second, there are very few good, let alone perfect, examples of human rights guiding a society effectively, acceptably and across generations. At first sight, one candidate for such an example might be post-World War II Western Europe, ${ }^{10}$ with the exception of, at least, Greece, Portugal and Spain because of the dictatorships they had until the mid-1970s, as well as, in all likelihood, the UK because of the conflict in Northern Ireland. Also, the post-war human rights record in other Western European countries is not exactly clean either, looking at (for example) the treatment of disabled people; but it arguably still remains relatively favourable. 
In addition, the relatively favourable human rights record of Western Europe after World War II emphatically only concerns its own citizens, and not the treatment of outsiders, including refugees. If this treatment is taken into account, the picture becomes different and decidedly less favourable. Concerning refugees, I am thinking of taking in very low numbers - in many Western European countries, far fewer than what could plausibly be a global fair share ${ }^{11}$ - and of keeping asylum seekers away from the EU's borders, as well as of the ways that asylum seekers are sometimes treated while waiting for a decision on their legal status. As for the treatment of outsiders more generally, one may, among other things, think of the role that many Western European countries play in helping to uphold an international institutional structure that is manifestly unfair to the global poor, for example because it includes privileges for dictators to borrow money and sell resources abroad. ${ }^{12}$

Moreover, even if the internal record of post-World War II Western Europe concerning human rights realization should be relatively favourable, this would certainly not include regard for the very important interests of future generations; nor would it, on reflection, show that societies could effectively and acceptably be guided by human rights across generations. After all, World War II is not that many generations ago, and it is to be seen whether Western European societies, even if one were to take a relatively favourable view of how they have been guided by human rights since World War II, will remain so guided. ${ }^{13}$ Perhaps the past 75 years have just been a lull in history.

\section{An alternative approach}

In short, an alternative approach is needed in order to get clear about whether human rights can effectively be realized in societies worldwide. A very promising one would be to look for robust empirical evidence. To be sure, this would not be evidence that shows that human rights have been realized effectively, etc. worldwide, for they have not been. Rather, it would be evidence that elucidated the conditions under which societies, and their institutions and individuals, could actually function and behave in accordance with human rights (effectively, acceptably and across generations). For institutions, this is an exceedingly complex and multifaceted task, which is too large for this chapter. Instead, I will concentrate on individuals. Furthermore, ideally one needs robust evidence, that is, evidence which transcends, so to speak, single investigations and research methods and establishes a record that remains constant through many different investigations and research methods. To provide such a record would, however, again be a huge undertaking and here I can only, by way of a relatively wellsupported hypothesis, give an indication of where one may end up.

Let me recall and elaborate a bit on what a society would broadly look like that is guided by human rights effectively, acceptably and across generations, and what the tasks of individuals in such a society would be. In such a society, there are institutional guarantees that official, and other, violations of human rights and lack of their realization (also through a lack of adequate resources) 
will not occur. There are also institutional mechanisms in place (juridical, social and political) to adequately react to the single violations that do occur. And guidance by human rights is not achieved through methods that violate plausible standards of social justice (fair procedures or, say, a modicum of equality of relevant opportunities) or other common ethical standards (for example, that people can understand themselves as acting for reasons). In order to maintain such a society, individual members of it will need, first, not to violate human rights themselves and, second, to do their fair part in the functioning of a society's human rights realizing institutions, and also in supporting and defending these institutions where needed - where it could turn out, as will become clear, that this fair part is not much more than not actively violating human rights.

The presupposition in what follows will be that, whenever individual members of a society act to maintain a human rights realizing society and its institutions, this will ultimately be sufficient to in fact maintain it. This is not to deny that there can be coordination problems and instances where individual good intentions translate into bad collective outcomes; nor that there can, for instance, be a lack of good ideas or other resources in order to actually translate the (more active or more passive) support of individuals into actual human rights realizing institutions. But I will assume that such problems can over time be overcome. ${ }^{14}$ Conversely, it will also be assumed that individual motivations to maintain a human rights society are necessary for maintaining it; in the absence of these motivations, such a society will over time not be sustainable. It is against this background - of individual motivation being necessary and, in the end, also sufficient for maintaining a human rights realizing society - that this chapter focuses on individuals.

I will make a couple of general background assumptions about the motivation of individual people. The first is that they are neither saints nor devils. ${ }^{15}$ That is to say, they are neither completely selfless and altruistic nor always relentlessly seeking their own interest (in a definite, hard sense) at the expense of others. Second, their motivations are considerably flexible, depending on the social and cultural contexts at hand, the varying hardships of their circumstances and the behaviour of others around them. These assumptions seem empirically defensible given, for example, the criticisms that a 'die hard' homo oeconomicus model of human behaviour has received, and given the evidence assembled by social scientists, among others, about cultural differences in individual behaviour. ${ }^{16}$ With these general assumptions in the background, I will now propose an empirical hypothesis as to when individuals will be motivated to act in accordance with human rights.

\subsection{What motivates individuals to act in accordance with human rights?}

\section{Rorty's hypothesis}

In developing my empirical hypothesis, I want to start from a remark that Richard Rorty makes in a well-known essay, and explain what I find strong and 
not so strong about this remark, and why. Rorty states that '[p]roducing generations of nice, tolerant, well-off, secure, other-respecting students ... in all parts of the world is just what is needed - indeed, all that is needed - to achieve an Enlightenment utopia'. ${ }^{17}$ I will read this remark as a hypothesis, saying (whether Rorty has in mind exactly this can for the present purposes remain open) that people will be motivated to behave in accordance with human rights if they are economically well-off (so do not need to worry about having enough to eat, etc.), secure (so do not need to worry about being killed or wounded, etc.) and well-educated (which may statistically influence the degree to which they feel threatened by people who lead their lives in ways differing from their own). And we may suppose, in line with what was said above, that people will not only be motivated to act in accordance with human rights if these conditions are fulfilled; but also, that human rights will be realized in societies - that is what Rorty's 'enlightenment utopia' is about - if there are nice, tolerant, etc. people in them.

\section{Amending Rorty}

Rorty's hypothesis will now be amended in a number of ways. This will make clearer what may be the thrust of that hypothesis. Rorty will then be further criticized - and, in a sense, also endorsed - with regard to the scope that he suggests for his hypothesis. In amending Rorty, I want to start from a recent article by Allen Buchanan and Russell Powell, in which they outline the conditions for moral progress. ${ }^{18}$ As I read them, they understand moral progress in the more particular sense of people developing an inclusivist morality, in which outsiders have moral standing, and these people (the insiders) consequently have moral concern for them, not only in word but also in deed. ${ }^{19}$ Going beyond Buchanan and Powell, I'd say that such an inclusivist morality will usually accept that all humans can legitimately claim, on their own behalf, that their very important interests ought to be reliably protected. In any case, this seems a very minimal form of inclusivism; I will come back to this shortly.

Now Buchanan and Powell base their argument on evolutionary theory but, very importantly for the present purposes, they suggest that their hypotheses are widely empirically supported. I am not sure to what extent this can really be concluded on the basis of their article; but there is, as I want to put it, at least an impression - even if not perhaps a watertight case - of widespread empirical support. $^{20}$

Buchanan and Powell hypothesize that an exclusivist (in the sense of a noninclusivist) morality will be prevalent when there are harsh conditions where outsiders threaten the food supply or the health of group members, and also threaten, inasmuch as functioning cooperative structures between different groups do not exist, a group's cooperative structures and cohesion. (Such harsh conditions were, Buchanan and Powell say, conditions that were present for a long time, namely in the age of hunter-gatherer societies.) Importantly, even if there are not actually harsh conditions, but the members of a group think there 
are, an exclusivist morality will still arise. An inclusivist morality will only develop if conditions become much more favourable in the regards just mentioned and outsiders thus no longer pose a threat, or are no longer regarded as posing one. ${ }^{21} \mathrm{I}$ take it, in this context without further argument, that sufficient conditions for a more inclusivist morality to be realized (which is what I take Buchanan and Powell to be talking about) are equivalent to sufficient conditions for a human rights realizing society to arise and be maintained. ${ }^{22}$

Going with the Buchanan-Powell account, Rorty's emphasis on (basic) economic well-being and security can be accepted. Furthermore, it should also be the case, according to their account, that outsiders are not a threat, or perceived as a threat, to the functioning of the group. And, I would make the addition that, more generally, outsiders should not be (perceived as) a threat to the ability of group members to develop and exercise their (relatively complex) key capacities (by which I mean very important capacities such as cognitive, emotional and creative capacities, as well as social ones: having standing among and vis-à-vis others) to some reasonable extent. ${ }^{23}$ Now, while economic well-being and security have (among other things) an important role in making sure that outsiders do not actually pose a threat to the various things mentioned, education may (among other things) be a mechanism that sometimes leads to outsiders not being perceived as a threat to one's group and oneself. Yet it is also plausible that more is needed here; Buchanan and Powell mention, for instance, how populist leaders can sometimes foster people's perception of being threatened by outsiders. $^{24}$

In short, my own hypothesis - call it hypothesis HR - would be that when people are secure and perceive themselves to be secure (1) in their very elementary interests being met (such as having enough to eat and having physical security) as well as (2) in their being able to develop and exercise relatively complex very important capacities to a reasonable extent (such as their cognitive, emotional, creative and social capacities), they will support human rights. ${ }^{25}$ This is, to be sure, an empirical hypothesis, and the Buchanan-Powell article suggests there may indeed be robust empirical support for it. More particularly and perhaps more modestly than Buchanan and Powell - I mean the hypothesis only to apply to people's non-engagement in human rights violations and to their not offering active support to such violations by, for example, supporting political parties that in certain ways want to curtail the fundamental rights of certain groups in their society, or elsewhere on earth. ${ }^{26}$ In this respect, I now want to criticize Rorty: he suggests that his hypothesis does more work than it actually does. ${ }^{27}$ This criticism is relevant for hypothesis HR. However, where I will end up, Rorty will in a sense still be endorsed, as will become clear.

\section{Criticizing Rorty - and, in a sense, endorsing him}

Rorty strongly suggests that 'nice, tolerant, well-off, secure, other-respecting students' - a characterization that may usually be apt for university students in Western Europe and in the USA - will act to actively help to sustain the human 
rights abiding institutions that already exist, and to make their societies more human rights abiding where needed. According to Rorty, this includes, I take it, that these students have appropriate regard for the human rights of people elsewhere on earth, through non-violation and adequate assistance. ${ }^{28}$ After all, such actions are what is needed for an 'enlightenment utopia': the maintenance of human rights realizing societies (and the emergence of such societies, but that concerns non-ideal theory, and therefore lies outside of the scope of the present chapter). However, I believe that there is reason to doubt that such students, or also people who meet the conditions specified in hypothesis HR, that is people who are secure in their elementary interests being met and also in being able to develop and exercise their key capacities to a reasonable extent, will act as Rorty believes they will. Take as an example the decline of the labour movement, and the fact that some of its legacy (good working conditions, not only in the sense of wages and working hours, but also of many so-called secondary working conditions, to do with pension and disability arrangements, holidays with pay, health and safety issues) is in fact endangered - by temporary contracts, by the fact that much work is done through recruitment agencies and by a reliance on increasing numbers of 'freelancers' with tenuous pension arrangements, etc. (I take the examples from the Netherlands.) This suggests that the roles of the labour movement are not all being taken over by other institutions. Now, not everything here is a matter of human rights, but some of it relates quite clearly to such human rights as the right to work and the right to a decent living standard. And, what seems to be happening is that, often, reliable human rights protection (or something much like it) has become so self-evident that insufficient action is taken by the highly educated, well-off, secure parts of the population to protect it where it is in jeopardy. ${ }^{29}$

What people who are secure in their elementary and also more complex very important interests will do, ${ }^{30}$ I suggested above - and this is still, I take it, broadly in line with Rorty and can thus in some sense be read as endorsement for him - is not actively undermine the very important interests of others, or the reliable protection of these interests; and they will not support people who undermine them, or institutions, over alternatives, where there are alternatives. More concretely, they will not beat people up (and certainly not because of the colour of their skin or sexual preference) or sabotage their fair trial, and they will not support people or institutions who do such things. I should add that compatibly with the hypothesis - individuals could still support even active violation of human rights, or an institution which does that, if they are not aware that it happens - or if, even though they are aware of it happening, they (are brought to) believe that it is inevitable or that there are very good reasons for it. This certainly complicates the hypothesis further. ${ }^{31}$

\section{An addition to hypothesis $H R$}

I want to suggest that, in order to realize human rights effectively (etc.), societies (unsurprisingly) need, in addition to rather passive support from a great majority 
of individual members, good institutions, with appropriate checks and balances and adequate powers and capacities (both reactive and proactive). And they need that such institutions are properly maintained and kept alive. This is something that requires input from professionals, but also, at least, from a certain number of very active citizens for whom doing this takes up many evenings, in line with what Oscar Wilde said. An avant-garde of a limited number of very active and committed citizens would, I think, suffice - in addition to a small avant-garde of professionals. ${ }^{32}$ I will not go into the question here of how such an avant-garde may be maintained - and come about - but I will just assume that this can happen, and more easily so than it is to motivate all individual members of a society (or at least a very large part of them) to a level of engagement that is even considerably less. If there is a human rights realizing institutional framework borne by such avant-gardes, then, according to hypothesis HR, the overwhelming majority of a society's people will prefer supporting that (rather passively perhaps) to supporting endeavours - which there may always to some degree be, even in ideal societies - to undermine it. I propose to call, for the case of individuals, supporting such a framework and not violating human rights: 'acting in accordance with human rights'. After all, such behaviour on the part of most individual members of a society (excluding, on the one side, some avant-garde citizens and professionals and, on the other side, some free riders and pathological cases) would be enough action from their side to actually realize human rights in such a society. (It is another question whether a fair division of moral labour would not require them to do more; perhaps, but that goes beyond the motivational question..$^{33}$ )

\subsection{Some objections}

The basic hypothesis proposed above (hypothesis HR) states that people will not actively violate human rights, and that they will not undermine institutions and people that realize human rights, when they are secure in their elementary interests being met and in there being opportunities for developing and exercising their key capacities to a reasonable extent; or, rather, what matters is their perception of this being so. Importantly, this hypothesis states sufficient conditions for people actually acting in accordance with human rights, not necessary conditions. This means at least two things. First, and generally, there may be other ways to get people (in acceptable ways) actually to behave in accordance with human rights; nothing in hypothesis HR excludes this, and a few alternatives will be briefly explored below. Second, and more particularly, the hypothesis does not imply that people for whom a number of very important interests, etc. are not securely met cannot also behave in accordance with human rights. ${ }^{34}$ If indeed they could not so behave, this would be quite tragic, for with many people these interests, etc. actually are not always securely met. But the hypothesis does not imply that they cannot.

So much for what the hypothesis does and does not say. I want now to consider three objections: (1) hypothesis HR tells us when people will effectively 
behave in accordance with human rights, but what about the acceptability of this behaviour, and its being capable of being reproduced across generations? (2) Is it plausible after all that the hypothesis applies to the reliable protection of future people's very important interests? (3) Are there other plausible hypotheses regarding individuals behaving in accordance with human rights effectively, acceptably and across generations? (This third question could, in fact, result in objections to the hypothesis investigated above, but it need not.)

\section{Acceptability, and guidance by human rights across generations}

Hypothesis HR regards it as jointly sufficient conditions for a society to be effectively guided in accordance with human rights, that people's very important elementary interests are reliably met and that they can rely on being able to develop and exercise their key capacities to a reasonable extent - and they need to perceive this as such. (In addition, an 'avant-garde' would be needed of a small part of a society's members and of professionals.) But can these conditions be met in a way that is also acceptable? Let me concentrate on two key elements. First, that fulfilling the conditions specified by hypothesis HR does not require that there be great injustices. Second, and this may well already be included in the first part, but still I want to mention it expressly, that it is compatible with the conditions specified by HR that people regard themselves, and are regarded by others, as acting for reasons. As for the first element, it brings out a remarkable thing about the above conditions - specifically, that people should be secure in their elementary important interests being fulfilled and being able to develop and exercise their key capacities to some reasonable extent namely that the conditions are very close to the realization of human rights itself. $^{35}$ The good news in this is that the conditions are very unlikely, indeed almost logically impossibly, in conflict with the fulfilment of human rights. ${ }^{36}$ The bad news is perhaps, at least at first sight, that the conditions tell us nothing about how to get to a society acceptably guided by human rights. However, why, on second thoughts, should they? Of course, ultimately one should get clear about how to arrive at a society guided by human rights. But this, however essential it is, is a question of non-ideal theory - more specifically of transformation - and, as such, almost entirely beyond the scope of this chapter. ${ }^{37}$

The second element of acceptability is that the condition should not make it impossible for people to regard themselves as acting for reasons - and also to be regarded by others as such. To explain further, people should not be regarded merely as 'things' on which things and other people have impacts and who then behave in a certain way in response. ${ }^{38}$ To be sure, this is part of the story: humans are of course part of the natural world of cause and effect; medicine might cure an illness and, if you do not watch out when crossing the road, you might run over by a car. But this is indeed only part of the story. And I do not see why the hypothesis proposed commits one to saying that it is the entire story. The hypothesis could allow that people are also beings who act for reasons, and that people regard each other as such. ${ }^{39}$ 
After discussing two elements to do with whether hypothesis HR can make for acceptable human rights realization, here is - briefly - one more such element, namely whether this hypothesis can allow for a plurality of cultures and social forms of life. The answer can be positive. To begin with, one should observe that, if human rights are realized, something happens that is close to what hypothesis HR envisages: people's very important elementary interests are reliably protected in a number of ways and certain safeguards are provided for them to be able to develop and exercise their key capacities to some reasonable degree. Now, in addition, human rights can be claimed to be universally valid, which implies that all societies should, if they are to be acceptable, realize human rights. And besides and this is the crucial point in the present context - it can also be claimed that the validity and importance of the realization of human rights can be recognized from a plurality of cultures and forms of life, that is, from a wide variety of backgrounds. ${ }^{40}$ Thus, the fulfilment of the conditions that hypothesis HR envisages will be compatible with a variety of cultures and forms of life as well.

Finally, hypothesis HR was about effective realization of human rights and I have just been asking whether the realization it envisages would also be acceptable. But what about the across-generations aspect? Does the hypothesis also show that the realization of human rights can hold across generations? If most members of a society only refrain from actively violating human rights, and the only thing they do in addition is not undermining institutions, citizens and professionals who are actively engaged in realizing human rights: is that enough to keep a society reliably guided by human rights across generations? I think that it follows directly from the hypothesis, indeed this is simply the content of the hypothesis, that if indeed this much - not actively violating human rights, etc. - is reproduced across generations, it is all that is needed. ${ }^{41}$

Yet the doubt is whether, if members of a society merely do not actively violate human rights and the like, this is not, on closer inspection, too meagre to allow for its own reproduction across generations. One may think that reproduction requires such activity as cannot be borne by an avant-garde alone: parents have to tell their children, teachers their students and the background culture of a society - the media, pub talk, birthday parties - has to convey (mostly rather implicitly to be sure) that the realization of human rights is essential. Or, somewhat more modestly, it has to convey in any case a general sense of what human rights are, and that some things count as violating human rights, not realizing them, etc., and that such violations, etc. are not inevitable or happening for very good reasons.

In short, the reproduction of a suitable human rights discourse would be needed, in families, schools and the background culture at large. And this goes beyond the hypothesis: if people are secure in their very important elementary interests being met, etc. - as the hypothesis deems necessary - they may still not reproduce such a discourse. It would be good news if telling stories could be enough, mainly stories perhaps (and alas) of abysses such as the Rwanda genocide or the Holocaust - and, in addition, it may be needed that people strongly interact in groups where such stories are told. ${ }^{42}$ The question is whether these 
stories, if coupled with interaction in groups, can become vivid enough to do the job, for people whose human rights are reliably realized; and if so, how such stories and groups can (arise and) stay around, and, if not, what other means there might be. There are also questions as to what the role of an avant-garde can be in all this, and what the limits of this role would be. But these questions must remain open here.

I would like to add a worry about avant-gardes here - a worry that concerns motivation across generations and acceptability at the same time. It is not so much that the idea of avant-gardes, who may perhaps, in a less friendly nomenclature, also be called 'elites', could well in several ways be unattractive and problematic, also morally. For example, seeing a role for avant-gardes could sit uneasily (at least on the face of it) with the idea, so central to human rights, of the fundamental equality of all human beings. However true and important this may be, I leave it aside for now. Presently, the worry is rather whether a society consisting of small avant-gardes and a rather passive majority can be stable. Will the avant-garde not start serving its own interests, and in the process also possibly undermine human rights? What is needed, in other words, is an account of how one can prevent an avant-garde - even if one assumes it is well-intended at the start - from getting derailed. One (partial) answer could be: there always need to be (real opportunities for the emergence of) a 'counter avant-garde' to the derailed one. People would then, according to hypothesis HR, support that counter avant-garde, at least as long as their elementary interests were securely met and as long as they had secure opportunities to reasonably develop their key capacities. But would such a counter avant-garde arise and be able to assert itself? For example, would the conditions specified by hypothesis HR not already be undermined once an avant-garde started to derail ${ }^{43}$ Perhaps, in ideal circumstances (which we are talking about), an alternative avant-garde would be able to assert itself: perhaps some persons would come forward from the people, and would also be able to make sure (with the rather passive support of the rest of the people) that the derailed avant-garde could not undermine people's elementary interests, etc. being met.

In a somewhat similar vein, to prevent an avant-garde from derailing, certain kinds of institutional checks-and-balances will in all likelihood be needed. An important question about these is whether they will only work well over time if they involve rather ambitious, say deliberative, democratic mechanisms of certain sorts, and if the people are quite active. (One is reminded of Hannah Arendt's insistence that people make their own history and that history is not, lest things go terribly wrong, to be left to politicians or scientists. ${ }^{44}$ ) But perhaps this is not so, and it is enough that some persons from the people come forward and form a counter avant-garde, which could perhaps be very vigorous. However, if more active involvement from the people is needed, hypothesis HR does not tell us how to get it, and one may have to look further into how to bring about democratic engagement. In short, then, the general problem of how to prevent an avant-garde from derailing, even if it is originally well-intentioned, will require further attention. 


\section{Intergenerational aspects of human rights}

As has been emphasized in Chapter 5 above, human rights have to take interests of future people into account, and the reliable protection of those interests. Yet, looking at, for instance, how hard it is to move people and societies into action to mitigate climate change, one may wonder whether hypothesis HR can really include the aspects of human rights that concern future people. If people's very important interests are reliably protected, etc., will they then indeed refrain from actively violating the very important interests of future people? And will they refrain from undermining institutions and people who aim to protect the interests of future people? I'd say that they will. That is, they will refrain from undermining future people's human rights as long as it is conspicuous to them that these human rights are being violated or that one set of institutions etc. realizes them clearly better than another set does. Conspicuousness then has at least two aspects. First, people should know that certain things are happening and second, they should frame these things as human rights violations or a certain degree of (lack of) realization of human rights, which happen to real people - and future people being 'future' may make it harder to genuinely perceive them as real (a bit like indirectness in global settings may make perceptions of realness harder). ${ }^{45}$ For instance, suppose that people do not know that certain forms of unequal treatment (to take a vivid example: of LGBTs) are happening, or that they do not frame these forms of unequal treatment as a violation or a lack of realization of human rights. Then, it seems to me that they might, compatibly with hypothesis HR, actively engage in these forms of unequal treatment, and that they may support institutions and people who let them persist and who may also more generally do badly at realizing human rights. The consequence is that, if there is a lack of conspicuousness, the hypothesis is, in the end, not applicable: there may still be individual motivation, or not; but the hypothesis ends up being silent about that.

Now, with the protection of the very important interests of future people there could very easily be a lack of conspicuousness: people currently alive may fail to know that future people's interests are affected (due, for instance, to all the uncertainties involved), and they may fail to frame things as a lack of human rights realization, for example because future people are usually quite literally out of sight. ${ }^{46}$ It will be important, then, to achieve conspicuousness and an appropriate framing. The means to do so may be the same as those that could keep a human rights culture alive in families, at schools and in the media, etc.: telling stories (and related forms of enhancing awareness) and doing so in groups in which people are strongly interacting.

Whether this can in fact be achieved I do not know. The prospects in our current situation, where there is so little action taken against climate change, are not encouraging. But in this chapter - except briefly in the conclusion - I am considering ideal situations, where the circumstances are the best, given human beings as they are; and things may be more hopeful there. 


\section{Other hypotheses}

Above, hypothesis HR and some additions to it have been discussed. Now, I want briefly to mention some other relatively well-supported hypotheses. ${ }^{47}$ These hypotheses may offer supplements to hypothesis HR or, where relatively wellsupported and not (fully) compatible with it, potential criticisms and modifications of it - to be investigated further if hypothesis HR is also well-supported. ${ }^{48}$

First, some psychological mechanisms can be used (by appropriate agents) to effectively move people into action. For example, people want to avoid cognitive dissonance, that is to say, the unease experienced because of a perceived tension between different beliefs or different actions of theirs, or between their beliefs and actions. ${ }^{49}$ For example, suppose they view themselves as caring for the environment and think that this implies recycling certain kinds of waste, while they do not behave accordingly. Then, they could either make themselves believe that they do, in some sense, so behave after all. Or they could tell themselves that they have a very good excuse for not doing this, so that they may still be generally environmentally friendly and not recycle. Or they could consider that being environmentally friendly does not really require recycling waste, etc. Or, importantly for the present chapter, they could change their behaviour and start recycling waste. All of these are ways in which to resolve the perceived tension and, thus, to get rid of the unease, and it is imaginable that the psychological mechanism of cognitive dissonance could be put to use to move people who already hold certain beliefs to actually behave in accordance with human rights.

The same is true for nudging, presently a very popular notion. There are various different ways to articulate what nudging is. ${ }^{50}$ Here, I will understand it as changing someone's choice environment with the intention that she will be more likely to make certain choices rather than others, and where this is achieved neither by appealing directly to her being a conscious chooser who chooses for reasons nor by bypassing her conscious choice altogether. Rather, it is achieved by doing something in between (something which, in addition, employs other means than coercion or altering economic incentives). For example, it is achieved by placing the apples in the supermarket where they are more likely to catch the eye (rather than the sweets), and likewise for the stairs in the hallway (rather than the elevator). And, it is not achieved by, on the one hand, telling people that it is healthier to eat the apples or by, on the other hand, exposing them to (say) subconscious advertisements sending a message about how delicious and healthy apples are. Nudging is thus in a grey zone between appealing to someone's autonomous choice and bypassing it altogether, and one of the most important things to do in order to further understand the (different varieties of the) concept and how to evaluate it would be to develop further what this grey zone looks like and where exactly nudging is in it.

To discuss this further is beyond the present scope. But, depending on how it turns out, realizing human rights by nudging may or may not be acceptable. Going for the moment with the examples of the apples and the stairs, it seems to 
me that there will at least be some forms of nudging - namely, among other things, those in these examples - that seem acceptable and that do not seem to bypass someone's acting for reasons too much. What should also come into the picture here, evidently, is who does the nudging and what it tries to achieve. As for the first question, a democratically elected government, held to a constitution guaranteeing fundamental rights and freedoms, may be a good candidate, and perhaps the only acceptable candidate to engage in nudging. ${ }^{51}$ At the same time and concerning the question of what subject matters and goals are concerned - it is not so difficult to think of forms of nudging that seem clearly unacceptable, also when done by a democratic government. Here one may, for example, think of nudges where certain rights are infringed, such as nudging people to vote for a green party or to adhere to one (comprehensive) worldview rather than another. By contrast, nudging people to act in accordance with human rights may not, as such, seem similarly problematic. ${ }^{52}$ But it does have to abide by certain constraints. For example, people should remain in a position to understand themselves as acting for reasons.

Finally, let me discuss one more motivational hypothesis, which I will call the self-interest hypothesis. It says that, whenever it is in people's self-interest to do their part in maintaining a society where human rights are reliably realized, they will do so. ${ }^{53}$ Self-interest should be understood in some definite way here and not be so broad as to basically mean anything. This hypothesis, it should be noted, is different from hypothesis HR, where the idea was (most importantly) that people will, if their very important elementary interests are reliably met and if they can rely on being able to develop and exercise their key capacities to some reasonable extent, not violate human rights and also refrain from undermining institutions and people that realize human rights. By contrast, the hypothesis that we are presently considering says that people will refrain from violating human rights, and from undermining the realization of human rights, if it is in their interest to refrain from all this. It has indeed been defended that having human rights reliably realized is generally in people's interest. ${ }^{54}$ It has likewise been defended that people do act so as to further their own interests economists, for one, often defend this. However, there have also been many criticisms of the idea of the homo oeconomicus (the idea that human beings always act so as to promote their self-interest); ${ }^{55}$ and it is also a question whether one should not rather say that people act on their perceived interests.

However this may be, it does seem plausible that people sometimes act so as to further their own interests, or perhaps rather their perceived interests. And it also seems the case that it is often in people's interests to have a society where human rights are reliably realized, and that they frequently understand this well. ${ }^{56}$ So, self-interest as a motivator for people to actually act in accordance with human rights retains importance, and it could also help, it seems, to maintain human rights realization over time and across generations. ${ }^{57}$

Nor need it be unacceptable for people to be acting to uphold a human rights realizing society because doing so is in their interest, rather than because such a society is just. For one thing, the interest hypothesis just described states, as I 


\section{Getting to realization}

understand it, that people behave in ways that further their interests, but not necessarily that they always consciously and intentionally act to do this. Where they behave unconsciously, saying that they behave to further their interests seems no more objectionable than saying, for example, that they behave in certain ways because they are secure or have a certain genetic set-up. Furthermore, is it necessarily problematic if people consciously and intentionally act so as to further their interests? I would say not. In any case, it seems to be too narrow to hold that people's reasons for upholding and furthering human rights can only be acceptable if they are moral reasons; that could then also exclude, depending on how exactly 'moral' is understood, actions brought about on account of stories or, say, certain religious ideas. Thus, the possibility is left open that acting in accordance with human rights for self-interested reasons, too, will remain both a plausible and an acceptable part of the answer to the motivational question.

\subsection{To conclude}

This chapter has proposed a hypothesis as to when individuals will - at least not actively violate human rights, and will refrain from hampering institutions and people that realize human rights. This hypothesis says that people's very important interests (such as having enough to eat) should be - and be seen by them as - securely met and they should reliably be able to develop and exercise their key capacities (such as their cognitive and creative capacities) to a reasonable degree. When formulating this hypothesis, I have regarded it as a necessary and, ultimately, also a sufficient condition for a society to be able to realize human rights that individuals are motivated to do their part in realizing them. This part might scarcely be more than not actively undermining human rights provided that some important additions are made, concerning the presence of an avant-garde and concerning the stories and group interactions needed to reproduce even quite passive support among individuals for human rights. ${ }^{58}$

Furthermore, in addition to proposing this hypothesis about what actually moves individuals to behave in accordance with human rights effectively and across generations, the chapter has also argued that this individual motivation could be achieved in acceptable ways. This includes, obviously, that human rights realization is not jeopardized, but also that people can understand themselves (and be understood by others) as acting for reasons. Moreover, it has been argued that the motivational hypothesis proposed can also work when we are talking about the interests of future people and the reliable protection of those interests.

In the end, then, the chapter has been relatively optimistic. Yet a few important points have remained to an extent unascertained, for example some points to do with the question of how to reproduce across generations that a society's members do - at least - not violate human rights actively, and rather passively endorse institutions and people that uphold human rights. Also, important doubts may remain about the role of an avant-garde of citizens and 
professionals in this chapter's hypothetical account. Bringing an avant-garde in may be deemed to be objectionably elitist or even to undermine the equal standing of all persons. ${ }^{59}$ Such doubts may perhaps be answered, but they would need more investigation. Moreover, how can one be sure that an elite would work to further human rights rather than to undermine them? Perhaps (real opportunities for the emergence and maintenance of) a 'counter avant-garde' would be needed here. But the minimum that would be needed is a well-functioning system of appropriate checks and balances, and it is an open question to what extent these would end up requiring a more active engagement on the part of the citizenry at large after all. If they did end up doing that, the motivational requirements on individuals would be more elaborate than suggested in the present chapter, and the conclusion to be drawn about the motivational question may have to be more pessimistic.

Another limitation of the present chapter is that it has engaged with ideal theory only, that is, with societies with the best institutions and arrangements there can be, given human beings as they are. If, even in ideal circumstances, human rights cannot be realized effectively, acceptably and across generations, they are certainly not appropriate as minimum standards of global justice. Besides, ideal theory is sometimes relevant in deciding how to go forward here and now. Yet evidently, a focus on ideal theory has its limitations. It is certainly a vital question how our world - with its widespread deprivation, conflict, dictatorships, aggressive behaviour by states, etc. - can with considerable speed make a transition to something much closer to the universal realization of human rights. And this transition should also happen in acceptable ways and have due regard for the very important interests of future people.

Now, I think that the motivational hypotheses proposed in this chapter could be of use for thinking about such a transition as well. If it could be ensured, as a start, that certain people's very important interests are reliably met and that their key capacities can be reliably developed and exercised to some reasonable extent, this could in some cases bring about virtuous cycles of support for human rights. Besides, the chapter may also provide a starting point for further investigating how certain kinds of group associations and the emergence or strengthening of certain kinds of avant-gardes - all of which should of course be brought about in an acceptable way - could contribute to progress in the realization of human rights. These are just some examples: non-ideal theory can come in very many kinds, depending on the place and timeframe one is talking about and, more generally, on the characteristics of the world which one (provisionally) takes as a given. ${ }^{60}$ The present chapter has not aimed even to begin to chart all this; that will be for another time.

\section{Notes}

1 Or, as I shall also say synonymously, can societies worldwide be effectively guided by human rights? (see also note 5 below) By speaking of 'societies worldwide', I do not mean already to decide the question of whether a global order should consist of largely sovereign states or be built upon, say, a suitable idea of subsidiarity. 


\section{Getting to realization}

2 Cf. Rawls (1999b), p. 7. According to Rawls, an ideal situation would also be one where there would be no problems arising because of non-compliance and great scarcity. But I think this should not be prejudged by making it part of the definition of what an ideal situation is.

3 More explanation will follow. In Rawlsian terminology, the last requirement concerns stability (Rawls 1999a, p. 6).

4 This chapter will sometimes be looking at real-world human rights regimes. Yet I take it that these regimes (in their lists of particular human rights, in being about the protection of the important interests of broad categories of people everywhere and always, etc.) are sufficiently in line with this book's conception of human rights to provide an indication as to whether this conception could motivate, in the sense of effectively guiding societies.

5 'Guidance by human rights' should not be taken so literally that individuals and institutions are moved by human rights per se (whatever that may mean), but only that individuals and institutions should be brought to act in accordance with what human rights require - which, for individuals, would mean that they are moved to do their part in institutions that realize human rights, on a plausible specification of what their part is. Cf. also Ch. 2, note 36 .

6 See Section 6.1 for a somewhat more precise and elaborate characterization of all this. I will not pursue the question here of what adequate resources are. Cf. Ch. 4 above.

7 Cf. Judt (2010, p. 164), who emphasizes that citizens' engagement should not be confined to matters relating to human rights.

8 This condition may also be specified in a relatively weak sense, for example in a suitably counterfactual one.

9 Pace Sen (2009). That human rights would be a suitable minimum account of ideal global justice does not, it is true, imply that they will be so in all non-ideal circumstances. But it does generally mean, I take it, that states, etc. should work towards full human rights realization.

10 Of course, it is not plausible that Western Europe after WWII can exemplify ideal theory. But if effective, acceptable guidance of societies in accordance with human rights were possible in clearly non-ideal circumstances, this would, in certain ways, be helpful and also encouraging to know.

11 This point would of course need much more discussion, which must await another occasion. Let me only remark here that the Dublin Regulation, which, incidentally, is hard to defend by any plausible standard of fair shares regarding the admission of refugees, only requires many Western European countries to take in very few refugees.

12 See Pogge (2008, 2005).

13 I thank Bernard Verlaan for pressing this point.

14 The 'sufficient' may come under discussion when, later in the chapter, it appears that, above all, rather minimal motivation of many individuals is plausibly achievable even though the chapter does not strictly exclude that more could also be achieved.

15 Loosely inspired by Immanuel Kant who, to be sure in a very different vein, thought (in his 1795 treatise Zum ewigen Frieden [Perpetual Peace], first supplement) that one could sometimes even get somewhere with a 'nation of devils'.

16 See, for a few examples from very many possible ones, Polanyi (1944); Sen (2009); Heine (2012).

17 Rorty (1994), p. 127.

18 Buchanan and Powell (2016). Thanks to Hanno Sauer for bringing this text to my attention.

19 Ibid., e.g. pp. 986ff., p. 997, p. 1009.

20 Ibid., e.g. p. 989, pp. 995f., pp. 1012 f. 
21 Buchanan and Powell are clear that people can still perceive threats even if they are not actually there. It could, I think, potentially also be the other way around: they perceive no threats where there are. But this perhaps less likely, especially in the longer run. (Note that Buchanan and Powell draw on evolutionary theory.)

22 An inclusivist morality, as I understand it, pays much attention to the interests of outsiders. Human rights, too, have the (reliable) protection of (very important) interests at their heart, with a strong idea of the equal status of all humans. They, thus, form a very inclusivist normative framework. Whether Buchanan and Powell's motivational hypothesis would show us how to go all the way to realizing human rights would need further discussion - in addition to them being perhaps slightly more cautious about outlining sufficient conditions. For now, I just want to observe that we would get, in important respects, close. About insiders and outsiders, also see the next footnote.

23 Cf. Maslow (1954) and Nussbaum (2000, pp. 78-80) - whose lists have a very different status and very different functions from what I (very freely) use them for here. I will make no attempt to define or further to specify 'key capacities' or 'reasonable extent'; the account only aims to provide a first direction.

The addition of more complex interests goes beyond Buchanan and Powell although it keeps thinking in terms of important interests having to be met. This addition has the effect of being more, rather than less, strict when thinking about what may be required (as a sufficient condition, as one may say in the line of Buchanan and Powell) for individuals to be motivated to act in accordance with human rights. Thus, if there is robust empirical evidence for Buchanan and Powell's hypothesis, this will remain so for my stricter hypothesis.

Of course, in a highly differentiated social order, people will be part of several groups. Talk of in- and outsiders will consequently need to be made more complex but it will not become obsolete. Sometimes insider vs. outsider distinctions will be clearer than in other cases. And sometimes, the outsiders will be within the same society, for example if one is talking about a society with deep ethnic or class conflicts; whereas sometimes they will be beyond a society or state. The addition that they may be beyond a society or state - i.e. global - is necessary for two reasons. First, it remains, to a degree, a moot point to what extent an ideal world would be largely state-centred or in a sense more globalized. Second, also in a largely state-centred world, human rights realization will imply certain duties (negative ones, etc.) of a state and its citizen towards those beyond one's own citizens/state. In any case, in the context of this chapter, I will regard the viability of an outsider-friendly morality as sufficient for the viability of global human rights realization.

24 Of course, one can ask the further question of when such leaders are more or less likely to get their way. This must to a large extent remain beyond the scope of the present chapter. An important line to pursue is that people will often do - although certainly not mechanically- what others in the groups relevant to them do (cf. Lichtenberg 2014, Ch. 6). This mechanism (which may loosely be called Durkheimian) can be used for good and bad, and it needs further investigation how it is best dealt with in specific cases, e.g. when it is or is not a good idea to stimulate that individuals engage more with particular groups.

25 That is to say, of everyone, also of outsiders. Thus, the hypothesis opens up the possibility that less may be needed for people to be motivated to realize the human rights of their group members.

When I speak of more complex capacities - where it may also be called an interest to develop these - vs. more elementary interests, there is no elaborate theory underlying this, although it has Maslowian resonances. Rather, I only want to signal that some interests are relatively straightforward (such as the need for fresh air), while others are decidedly less so (such as an interest in receiving social recognition) - with a whole lot in between. 


\section{Getting to realization}

26 As already remarked (see Ch. 2, note 36), according to some theories (cf. Pogge 2008), individuals cannot violate human rights, but only governments and some other institutions can. However, I build here on the conception of human rights developed in Ch. 2, where there are various potential duty bearers with regard to human rights, including individuals, and thus various parties that can actively violate human rights.

27 I have other problems with Rorty's text as well (for example, that he seems scarcely aware that he is formulating a largely empirical hypothesis), but leave these aside here.

$28 \mathrm{I}$ express this point as if the world were state-centred. However, the point could certainly be adapted to a non-state-centred world.

29 For a poignant diagnosis that reaches somewhat similar, but more severe, conclusions, see Judt (2010). One could also give examples of inaction, and often indifference, in the face of egregious human rights violations abroad (for many people this would e.g. be in Burma or Yemen).

30 Nothing in what follows depends on there being some exceptions, some pathological cases perhaps, as long as what follows is true for the overwhelming majority of people who are secure in their elementary and, also, in their more complex very important interests being met.

31 This is in line with Buchanan and Powell's account, which, more generally, refers to common psychological biases and socio-epistemic practices (2016, p. 1004ff.). The hope might be that security in meeting very important interests and being able to develop and exercise key capacities to some reasonable degree will also make for moral systems that are more perceptive with regard to the non-realization of human rights, as well as making talk of 'inevitability' and 'good reasons' regarding the nonrealization of human rights (also when abroad) less prevalent and convincing. The account of stories, etc. that will be discussed below (in the context of reproducing relevant human rights motivation across generations) is also pertinent here.

32 For thoughts about an avant-garde, see e.g. Ypi (2012). I will come back to the disadvantages and, indeed, dangers that may be associated with it (and which may be more readily visible if one calls it an 'elite'); cf. Buchanan and Powell (2016), pp. 1013f.

33 But fairness, or rather a perception of fairness, could easily come into motivational territory if it is correct - which may well be the case - that people are only willing to participate in social arrangements where they regard the contribution asked of them as fair and regard what others have to do as fair as well; and where they perceive most others as actually doing their fair share. This matter would have to be considered, among other things, when discussing how an avant-garde of citizens and professionals could be maintained.

34 Although Buchanan and Powell's hypothesis seems to go in this direction much more.

35 Importantly, the inclusion of more complex interests already implies, to my mind, that the emphasis should generally be on real freedoms rather than on just providing people with things regardless of what they want. Of course, realizing human rights can only provide the social background for securely meeting important interests and even more so for reliably being able to develop and exercise key capacities. So, human rights realization is not enough, but it is generally needed.

36 Concerning people's perceptions, things could be different.

37 However, there are a few remarks about transformation in the chapter's conclusion.

38 And see also pp. 98-99 above.

39 One could elaborate on this by showing how the hypothesis could be compatible with a plausible metaphysics. Cf. Van Miltenburg (2015), Nagel (2012). It can incidentally be noted that, in the social sciences, ideas are often thought of as possible explanations of behaviour, e.g. in traditions inspired by Max Weber (1979), etc. - and sometimes ideas in combination with other mechanisms such as group interaction. But this passes over the (metaphysical or close to metaphysical) question of whether one can coherently think this. 
40 Cf. Section 3.1. See that section as well for a defence of the universal validity of human rights. Now, it may admittedly be possible that something is valid yet need not, or even ought not, to be accepted at some places or times (e.g. for some pragmatic reason). But the universal validity of human rights - which is meant in an allthings-considered way - hinges on the universal importance of the interests concerned, in combination with suitable duty bearers being available everywhere and always. It is hard to see why universal validity that is grounded in this way does not bring with it the thought that all societies ought, certainly in ideal circumstances and generally also in non-ideal circumstances, also in fact be guided by human rights.

41 In addition to there being, in all generations, a suitable avant-garde. Some more about it in a moment - although I will not elaborate on how it could be reproduced.

42 One might call this a Durkheim-inspired thought (cf. Durkheim 1967). Of course, what I say here about reproduction extends to the present generation as well: they, too, will need stories and interaction in suitable groups.

43 If so, that could obviously be problematic, even if - as argued above - hypothesis HR should be read as specifying sufficient rather than necessary conditions for individual motivation to act in accordance with human rights.

44 See Arendt (1958); Young's (2011) 'social connection model' puts emphasis on a number of points that are rather similar.

45 This may, in a sense, also get us back to the 'non-existence problem' (Ch. 5, note 1).

46 This will also apply, of course, to certain other human rights violations (and other instances of a lack of realization of human rights), which do not concern future people.

47 Cf. Lichtenberg (2014) for an overview of a number of them.

48 For example, suppose that it turns out that, while hypothesis HR is met, people still do not offer (certain kinds of) support for realizing human rights. Then the self-interest hypothesis (discussed below) may have to offer supplements or modifications of hypothesis HR. Similarly, a condition may need to be added to hypothesis HR about people not being nudged in certain directions. However, I do not think that such additions and modifications are typically practically very important - although this would require further research. For example, hypothesis HR may well involve self-interest in the most important ways, and is naturally read as presupposing the absence of certain kinds of subconscious (etc.) steering.

49 Cf. Vaidis (2014), and the original study by Festinger (1957).

50 Richard Thaler and Cas Sunstein $(2008$, p. 6), who made the term prominent as a technical one, say that

a nudge ... is any aspect of the choice architecture that alters people's behavior in a predictable way without forbidding any options or significantly changing their economic incentives. To count as a mere nudge, the intervention must be easy and cheap to avoid. Nudges are not mandates. Putting fruit at eye level counts as a nudge. Banning junk food does not.

Usually - but not in the context of the present chapter - nudges are self-regarding: they want to achieve an outcome that a person herself desires, or that at least is somehow better for her.

51 This evidently raises a question about when such a government will itself be motivated to nudge (or also to act in different ways).

52 What exactly 'in accordance' with human rights is, was clear for hypothesis HR, but would need to be discussed again for the alternative hypotheses. This is beyond the present scope.

53 In the present context, it is not important to go further into what doing one's part is.

54 Cf. Nickel (2007), Ch. 4.

55 For one classic example (among many), see Sen (1977). 


\section{Getting to realization}

56 Of course, an elaborate account ought to take collective action problems into account here, and this may have to give the argument a twist, in certain contexts at least, in the direction of fairness. To further elaborate on this is beyond the present scope.

57 How far one gets with furthering the interests of future generations if present people act on their (perceived) self-interest is a related, and disputed, question. Cf. Birnbacher (2015).

58 I should add that the background assumption, or at least hope, has been that ideal circumstances are favourable enough to allow for the reliable protection of all very important interests of all human beings.

59 In addition and relatedly, human rights comprise, for one thing, certain political and democratic rights, and certain roles for an avant-garde could run counter to these rights and hence make for unacceptable forms of motivation.

60 Non-ideal theory, as before, in the sense of theory that takes certain characteristics of the world (provisionally) as a given, even if these characteristics would not be there in an ideal situation. 


\section{Conclusion}

This book has engaged with two challenges to human rights in the 21 st century, which I have called the challenge of global inequality and the challenge of future people. The book has also, third, discussed the motivational question.

First, the challenge of global inequality has asked whether one can be sincerely committed to human rights as a global ideal, even if there exist great global inequalities in human rights protection; and if these inequalities are, furthermore, connected to structures (namely, to a world order of largely sovereign states) to which one is also committed. Or would a commitment to human rights be too easy here, and could it indeed be deemed hypocritical? Doesn't either the commitment to a world order of largely sovereign states, or else the commitment to human rights, have to be abandoned? (This challenge is clearly very relevant in our own world, with its huge global inequalities; but it will likely be relevant also in an ideal world.)

Second, the challenge of future people, obviously relevant in the current times of climate change, but also in an ideal world, deals with how to include the claims of future people in human rights, especially given uncertainties - concerning, among other things, the threats they will face and what will protect them against these threats. Furthermore, questions about including future people in human rights will raise problems of when to prioritize the future or the present and, more generally, of how to set priorities among human rights.

Finally, the motivational question asks whether human rights can be effectively realized in societies worldwide, in acceptable ways, and also across generations. If they cannot, not even in ideal societies, that may raise serious issues about the suitability of human rights as a global moral ideal. ${ }^{1}$

The book has, in addition (in Chapter 3), also discussed a couple of common and influential more radical challenges, ${ }^{2}$ which I have dubbed the relativist challenge which says that human rights are not universally valid - and the political pawns challenge - which says that human rights are merely pawns in political power games.

There is, I have argued, good news for human rights inasmuch as the two central challenges just mentioned, and also the motivational question and the two more radical challenges, can be answered. Thus, I have offered a relatively upbeat assessment of human rights as a moral ideal for the world - or, somewhat more technically, as specifying the minimum requirements of global justice. ${ }^{3}$ 
I will now recapitulate how the three issues that have been central to the book - and, to begin with, also the relativist and political pawns challenges have been replied to.

As for the more radical challenges to human rights, the relativist challenge and the political pawns challenge, it has been argued in Chapter 3 that they can be answered, in the versions of them that matter most. At an abstract level, at least, human rights are universally valid. And, although there may be political abuse of human rights, this is not the whole story, but the picture is mixed. Furthermore, alternatives are unlikely to do better, and local repairs to human rights can be made on an ongoing basis.

Subsequently, I have, in Chapter 4, discussed the challenge of global inequality. I have argued that an ideal world order could plausibly be one of largely sovereign states and to an extent, but for now only to an extent, one based on subsidiarity (that is, where everything is organized at the lowest level where it can still be done in a just way). If so, some global inequalities in human rights protection may be inevitable and, thus, not at odds with a good-faith commitment to human rights. Yet it is important that these inequalities are, so to speak, residual cases; equality of protection - in the sense of people receiving the same protection of a very important interest if their need for protection is the same - should be provided unless there are very good reasons why it need not.

Concerning the challenge of future people, a beginning formal framework has been proposed for how to set priorities among human rights, and climate change has been the main case in Chapter 5 to help show how this framework may function. The framework that is to be used, after an initial adjudication as to which claims are to enter into the priority-setting exercise in the first place, consists of certain side constraints (ways in which priorities may not be set) as well as a number of more positive principles. These positive principles have a nonutilitarian flavour, although the number of people involved and the opportunity cost of providing a protection are also relevant considerations - among other considerations, such as the importance of the interests at issue, how much they are threatened and how much a certain protection helps against a certain threat. The framework also includes a suggestion for how to deal with genuine uncertainties about threats and protections, that is to say, with cases where no approximate probabilities about threats and protections are known. This suggestion is to visualize, by putting a number on it, the order of magnitude of the chance at hand. In order to think of uncertainties neither too highly nor too lowly when setting priorities among human rights, working with an appropriate visualization may well be better than just saying that we do not, even approximately, know the chance.

As for the motivational question, I have (exploratively) suggested in Chapter 6 that when people are - and regard themselves as - secure in their more elementary very important interests being met and in having the opportunity to develop and exercise their key capacities to a reasonable extent, they will in certain ways act to uphold a human rights realizing society. They will refrain from actively violating human rights, and they will support institutions and people that realize 
human rights. This may also be enough to uphold a human rights realizing society across generations, at least if there is an avant-garde of professionals and of a number of citizens, and if there are mechanisms for passing down - for example, through stories told at schools and in other groups - a minimal understanding of human rights.

All of this results in a rather favourable picture, in which universally valid human rights, although they are emphatically in need of local repairs on a continuous basis, are a global moral ideal that can be sincerely upheld in the face of global inequalities, that can include future people, and that can actually move people and societies to behave and to function in accordance with it. In other words, human rights as a global ideal can be actualized in the double sense of being shown to be of actual relevance (in the face of important and urgent challenges) and in the sense of actually moving individuals and societies into action.

Yet there are of course things that have had to remain outside the scope of this book, and I want to close by saying a word about these. Concerning the challenge of global inequality, the question remains - which is one of the big questions of global justice debates - as to what kind of a world order we should, in the end, want. Chapter 4 has argued that we should not want a world state, and that the exact shape and defensibility of a subsidiarity-based world order remains under discussion. At the same time, there also remain questions about a world order based on largely sovereign states. Thus, even if the underlying ideal of a world order based on human rights can be endorsed, what is the most appropriate institutional form it could take remains a big question. Further progress on this question will have direct implications for how to deal with the challenge of global inequality and, in particular, for where inequalities of protection could permissibly remain.

With regard to the challenge of future people, I have outlined a first (rather broadly applicable) framework of priority-setting among human rights, a framework which also speaks to the question of how to deal with uncertainties, particularly uncertainties concerning the future. Progress in specifying this framework further and making it more fine-grained can best be achieved, I think, by applying it further, following up on the outlines discussed in Chapter 5. The cases to which the framework can speak are myriad, and I have, for the main part, only referred to the (very important) case of climate change. Further application of the framework will bring its strengths and its weaknesses into greater relief and allow for its more detailed development.

The motivational question, finally, was treated in a very explorative way. The subject is daunting, and I have not attempted to move beyond individual motivation to the motivation of institutions. Vast arrays of theorizing and of empirical results from the social sciences are relevant to the motivational question, and much more extensive explorations remain possible and needed.

There continue to be, then, many important agendas for future research. Still, as yet, the arguments of this book have ended up striking an optimistic tone about the possibilities for actualizing human rights. 


\section{Conclusion}

\section{Notes}

1 All three issues - the two challenges and the motivational question - have been relatively neglected in the literature on human rights, and certainly in the philosophical human rights literature, to which this book particularly speaks. At the same time, all three issues are bound to be greatly important and worrying to a wide array of people who are interested in human rights and are this book's envisaged audience: lawyers, policymakers, academics, activists and citizens in general.

Usually, the challenges discussed have been cast as relating to ideal theory, that is to say, to thinking about the best possible situation given human beings as they are. This is theory of which we may at times - but by no means always - have a somewhat better grasp than of non-ideal theory, of which there can be very many forms: in ideal theory, the applicable background conditions will sometimes be clear. Moreover, generally speaking, if central challenges to human rights cannot even be answered in ideal theory, human rights clearly have a problem.

2 By contrast, the three issues central to the book are not radical or all-out, in the sense that one can, in principle, be very sympathetic to human rights as providing a moral ideal for the world, and still regard these issues as challenges.

3 Human rights can secondarily take on other roles, many of which may apply in ideal situations, but also in (very) non-ideal situations: roles such as guiding internal and external government policies, providing standards for international organizations and businesses, etc. and guiding activism.

I have concentrated on a notion of human rights that does not depend on highly controversial or theoretical commitments and that may be acceptable to people from widely different backgrounds. This notion has not aimed to interpret the post-WWII practice of human rights, or a part of that practice. But many aspects of it are quite in line with the practice (for example, central aspects of my understanding of what a right is, and of human rights as an ideal for the world) and, thus, this notion of human rights may provide orientation for the practice. 


\section{Bibliography}

Anderson, Joel and Jos Philips, eds. (2012), Disability and Universal Human Rights:

Legal, Ethical and Conceptual Implications of the Convention on the Rights of Persons with Disabilities, Utrecht: Netherlands Institute of Human Rights.

Arendt, Hannah (1958), The Human Condition, Chicago: University of Chicago Press.

Bauer, Joanne and Daniel Bell, eds. (1999), The East Asian Challenge for Human Rights, Cambridge: Cambridge University Press.

Beitz, Charles (2009), The Idea of Human Rights, Oxford: Oxford University Press.

Beitz, Charles and Robert Goodin, eds. (2009), Global Basic Rights, Oxford: Oxford University Press.

Birnbacher, Dieter (2015), 'Some Moral Pragmatics of Climate Change', in idem and May Thorseth, eds. (cited below), pp. 153-172.

Birnbacher, Dieter and May Thorseth, eds. (2015), The Politics of Sustainability: Philosophical Perspectives, Abingdon etc.: Routledge.

Bob, Clifford (2019), Rights as Weapons: Instruments of Conflict, Tools of Power, Princeton: Princeton University Press.

Bos, Gerhard and Marcus Düwell, eds. (2016), Human Rights and Sustainability: Moral Responsibilities for the Future, Abingdon etc.: Routledge.

Buchanan, Allen (2013), The Heart of Human Rights, Oxford: Oxford University Press.

Buchanan, Allen and Russell Powell (2016), 'Toward a Naturalistic Theory of Moral Progress', Ethics, 126, pp. 983-1014.

Buonanno, Laurie and Neill Nugent (2013), Policies and Policy Processes of the European Union, Basingstoke etc.: Palgrave Macmillan.

Buyse, Antoine (2015), 'Human Rights for Foxes and Hedgehogs', Inaugural Lecture, Utrecht: Utrecht University.

Caney, Simon (2005), Justice beyond Borders: A Global Political Theory, Oxford: Oxford University Press.

Caney, Simon (2009), 'Human Rights, Responsibilities, and Climate Change', in Charles Beitz and Robert Goodin, eds. (cited above), pp. 227-247.

Caney, Simon (2010), 'Cosmopolitan Justice, Responsibility and Global Climate Change', in Stephen Gardiner et al., eds., Climate Ethics: Essential Readings, Oxford: Oxford University Press, pp. 122-145.

Christiano, Thomas (2011), 'An Instrumental Argument for a Human Right to Democracy', Philosophy and Public Affairs, 39, pp. 142-176.

Cohen, G.A. (2000), If You're an Egalitarian, How Come You're So Rich? Cambridge MA: Harvard University Press. 


\section{Bibliography}

Donnelly, Jack (2013), Universal Human Rights in Theory and Practice, Ithaca NY: Cornell University Press. (3rd ed.)

Douzinas, Costas (2007), Human Rights and Empire: The Political Philosophy of Cosmopolitanism, London: Glass House Books.

Durkheim, Émile (1967[1897]), Le Suicide: Étude de sociologie, Paris: Presses Universitaires de France.

Düwell, Marcus (2012), 'Setting the Agenda for Ethical Debates about the Rights of Persons with Disabilities', in Joel Anderson and Jos Philips, eds. (cited above), pp. 185-194.

Düwell, Marcus et al., eds. (2014), Cambridge Handbook of Human Dignity, Cambridge: Cambridge University Press.

Düwell, Marcus, Gerhard Bos and Naomi van Steenbergen, eds. (2018), Towards the Ethics of a Green Future: The Theory and Practice of Human Rights for Future People, Abingdon: Routledge.

Dworkin, Gerald (1988), The Theory and Practice of Autonomy, Cambridge: Cambridge University Press.

Dworkin, Ronald (2000), Sovereign Virtue: The Theory and Practice of Equality, Cambridge MA: Harvard University Press.

Elster, Jon, ed. (1998), Deliberative Democracy, Cambridge: Cambridge University Press.

Ferréz (2000), Capão Pecado, São Paulo: Labortexto Editorial.

Festinger, Leon (1957), A Theory of Cognitive Dissonance, Stanford: Stanford University Press.

Follesdal, Andreas (2014), 'Subsidiarity and the Global Order', in Michelle Evans and Augusto Zimmerman, eds., Global Perspectives on Subsidiarity, Dordrecht: Springer, pp. 207-220.

Fraser, Nancy (2008), Scales of Justice: Reimagining Political Space in a Globalizing World, Cambridge: Polity.

Frick, Johann (2016), 'What We Owe to Hypocrites: Contractualism and the SpeakerRelativity of Justification', Philosophy and Public Affairs, 44, pp. 223-265.

Gardiner, Stephen (2006), 'A Core Precautionary Principle', Journal of Political Philosophy, 14, pp. 33-60.

Gardiner, Stephen (2011), A Perfect Moral Storm: The Ethical Tragedy of Climate Change, Oxford: Oxford University Press.

Gearty, Conor (2006), Can Human Rights Survive? Cambridge: Cambridge University Press. Gewirth, Alan (1978), Reason and Morality, Chicago: Chicago University Press.

Gewirth, Alan (2007), 'Duties to Fulfill the Human Rights of the Poor', in Thomas Pogge, ed., Freedom from Poverty as a Human Right, Oxford: Oxford University Press, pp. 191-216.

Gilabert, Pablo (2009), 'The Feasibility of Basic Socioeconomic Human Rights: A Conceptual Exploration', The Philosophical Quarterly, 59, pp. 559-581.

Gilabert, Pablo (2010), 'The Importance of Linkage Arguments for the Theory and Practice of Human Rights: A Response to James Nickel', Human Rights Quarterly, 32, pp. 425-438.

Göbel, Marie (2019), Human Dignity as the Ground of Human Rights, Utrecht: Utrecht University. (PhD thesis)

Goldschmidt, Jenny (2012), 'Shifting the Burden of Proof: A Conversation about How the CRPD is Transforming Our Understanding of Discrimination, Intersectionality, and Priorities', in Joel Anderson and Jos Philips, eds. (cited above), pp. 51-70.

Goodale, Mark, ed. (2014), Human Rights at the Crossroads, Oxford: Oxford University Press. 
Green, Michael (2005), 'Institutional Responsibility for Moral Problems', in Andrew Kuper, ed. (cited below), pp. 117-134.

Griffin, James (2008), On Human Rights, Oxford: Oxford University Press.

Harnacke, Caroline (2005), 'Capability and Disability: The CRPD from the Perspective of the Capabilities Approach', in Joel Anderson and Jos Philips, eds. (cited above), pp. 167-184.

Hartzell-Nichols, Lauren (2017), A Climate of Risk: Precautionary Principles, Catastrophes, and Climate Change, Abingdon: Routledge.

Heine, Steven (2012), Cultural Psychology, New York etc.: Norton.

Hermens, Janske (1999), We Are Poor People, They Do Not Care about Us, Nijmegen: Nijmegen University Press.

Hopgood, Stephen (2013), The Endtimes of Human Rights, Ithaca etc.: Cornell University Press.

Humphreys, Stephen, ed. (2010), Human Rights and Climate Change, Cambridge: Cambridge University Press.

Hurka, Thomas (2001), 'Future Generations', in Lawrence Becker and Charlotte Becker, eds., Encyclopedia of Ethics, Abingdon etc.: Routledge, pp. 586-589.

Ibhawoh, Bonny (2001), 'Cultural Relativism and Human Rights: Reconsidering the Africanist Discourse', Netherlands Quarterly of Human Rights, 19, pp. 43-62.

James, Susan (2005), 'Realizing Rights as Enforceable Claims', in Andrew Kuper, ed. (cited below), pp. 79-94.

Judt, Tony (2010), Ill Fares the Land, London etc.: Penguin.

Kennedy, David (2004), The Dark Sides of Virtue: Reassessing International Humanitarianism, Princeton: Princeton University Press.

Klaas, Brian (2016), The Despot's Accomplice, London: Hurst.

Koskenniemi, Martti (2011), The Politics of International Law, Oxford: Hart.

Kuper, Andrew, ed. (2005), Global Responsibilities: Who Must Deliver on Human Rights? New York etc.: Routledge.

Kymlicka, Will (2002), Contemporary Political Philosophy: An Introduction, Oxford: Oxford University Press.

Levi, Primo (1987), If This Is a Man, London etc.: Penguin. (orig. Italian, 1958)

Lichtenberg, Judith (2014), Distant Strangers: Ethics, Psychology, and Global Poverty, Cambridge: Cambridge University Press.

Lu, Catherine (2006), 'World Government', Stanford Encyclopedia of Philosophy. (online)

Malcontent, Peter (2015), 'Nederland en de mensenrechten [The Netherlands and Human Rights]', in Jacco Pekelder, Remco Raben and Mathieu Segers, eds., De wereld volgens Nederland: Nederlandse buitenlandse politiek in historisch perspectief [The World according to the Netherlands: Dutch Foreign Policy in an Historical Perspective]', Amsterdam: Boom, pp. 128-151.

Marmor, Andrei (2015), 'What is the Right to Privacy?' Philosophy and Public Affairs, 43, pp. 3-26.

Marx, Karl (1973[1849]), 'Lohnarbeit und Kapital', in Marx-Engels Werke, Band 6, Berlin: Dietz, pp. 397-423.

Maslow, Abraham (1954), Motivation and Personality, New York: Harper.

McCrudden, Christopher (2017), 'On Portraying Human Dignity', in A. Kemmerer et al., eds., Human Dignity in Context, Baden-Baden: Nomos.

Meyer, Lukas (2015), 'Intergenerational Justice', Stanford Encyclopedia of Philosophy. (online) 


\section{Bibliography}

Meyer, Lukas et al. (2018), 'Risk and Rights: How to Deal with Risks from a RightsBased Perspective', in Marcus Düwell et al., eds. (cited above), pp. 28-47.

Miller, David (2005), 'Distributing Responsibilities', in Andrew Kuper, ed. (cited above), pp. 95-116.

Miller, David (2007), National Responsibility and Global Justice, Oxford: Oxford University Press.

Miller, Richard (2010), Globalizing Justice: The Ethics of Poverty and Power, Oxford: Oxford University Press.

Moyn, Samuel (2012), The Last Utopia: Human Rights in History, Cambridge MA: Harvard University Press.

Moyn, Samuel (2018), Not Enough: Human Rights in an Unequal World, Cambridge MA: Harvard University Press.

Mulgan, Tim (2001), The Demands of Consequentialism, Oxford: Oxford University Press.

Mulgan, Tim (2011), Ethics for a Broken World: Imagining Philosophy after Catastrophe, Abingdon etc.: Routledge.

Nagel, Thomas (1991), Equality and Partiality, Oxford: Oxford University Press.

Nagel, Thomas (2005), 'The Problem of Global Justice', Philosophy and Public Affairs, 33 , pp. 113-147.

Nagel, Thomas (2012), Mind and Cosmos, Oxford: Oxford University Press.

Nickel, James (2007), Making Sense of Human Rights, Malden MA: Blackwell. (2nd ed.)

Nickel, James (2008), 'Rethinking Indivisibility: Towards a Theory of Supporting Relations between Human Rights', Human Rights Quarterly, 30, pp. 984-1001.

Nickel, James (2010), 'Indivisibility and Linkage Arguments: A Reply to Gilabert', Human Rights Quarterly, 32, pp. 439-446.

Nickel, James (2014), 'Human Rights', Stanford Encyclopedia of Philosophy. (online)

Nozick, Robert (1974), Anarchy, State and Utopia, New York: Basic Books.

Nussbaum, Martha (2000), Women and Human Development: The Capabilities Approach, Cambridge: Cambridge University Press.

Nussbaum, Martha (2006), Frontiers of Justice: Disability, Nationality, Species Membership, Cambridge MA: Harvard University Press.

O'Neill, Onora (2004), 'Global Justice: Whose Obligations?' in Deen Chatterjee, ed., The Ethics of Assistance: Morality and the Distant Needy, Cambridge: Cambridge University Press, pp. 242-259.

Orend, Brian (2005), 'War', Stanford Encyclopedia of Philosophy. (online)

Ostrom, Elinor (1990), Governing the Commons: The Evolution of Institutions for Collective Action, Cambridge: Cambridge University Press.

Ostrom, Elinor (2005), Understanding Institutional Diversity, Princeton: Princeton University Press.

Parfit, Derek (1984), Reasons and Persons, Oxford: Oxford University Press.

Parfit, Derek (1997), 'Equality and Priority', Ratio, 10, pp. 202-221.

Philips, Jos (2007), Affluent in the Face of Poverty: On What Rich Individuals Like Us Should Do, Amsterdam: Amsterdam University Press. (PhD thesis)

Philips, Jos (2012), 'Human Rights, the CRPD, and Priority Setting', in Joel Anderson and Jos Philips, eds. (cited above), pp. 147-165.

Philips, Jos (2014), 'On Setting Priorities among Human Rights', Human Rights Review, 15, pp. 239-257.

Philips, Jos (2016), 'Human Rights and Threats concerning Future People: a Sufficientarian Proposal', in Gerhard Bos and Marcus Düwell, eds. (cited above), pp. 82-94. 
Pissarskoi, Eugen (2018), 'The Controllability Precautionary Principle: Justification of a Climate Policy Goal Under Uncertainty', in Ravi Kanbur and Henry Shue, eds., Climate Justice: Integrating Economics and Philosophy, Oxford: Oxford University Press.

Pogge, Thomas (1992), 'Cosmopolitanism and Sovereignty', Ethics, 103, pp. 48-75.

Pogge, Thomas (2004), “Assisting' the Global Poor', in Deen Chatterjee, ed., The Ethics of Assistance: Morality and the Distant Needy, Cambridge: Cambridge University Press, pp. 260-288.

Pogge, Thomas (2005), 'Real-World Justice', Journal of Ethics, 9, pp. 29-53.

Pogge, Thomas (2008), World Poverty and Human Rights: Cosmopolitan Responsibilities and Reforms, Cambridge: Polity. (2nd ed., orig. 2002)

Polanyi, Karl (1944), The Great Transformation: The Political and Economic Origins of Our Times, New York: Farrar \& Rinehart.

Posner, Eric (2014), 'Martti Koskenniemi on Human Rights: An Empirical Perspective', University of Chicago Public Law \& Legal Theory Working Paper, nr. 467.

Rawls, John (1993), Political Liberalism, New York: Columbia University Press.

Rawls, John (1999a), A Theory of Justice, Cambridge MA: Harvard University Press, Cambridge MA. (2nd ed., orig.1971)

Rawls, John (1999b), The Law of Peoples, Cambridge MA: Harvard University Press.

Rawls, John (2007), Lectures on the History of Political Philosophy, Cambridge MA: Harvard University Press.

Riley, Stephen (2016), Human Dignity and Law: Legal and Philosophical Investigations, Abingdon etc.: Routledge.

Risse, Mathias (2005), 'What We Owe to the Global Poor', Journal of Ethics, 9, pp. 81-117.

Risse, Mathias (2012), Global Political Philosophy, Basingstoke: Palgrave Macmillan.

Robeyns, Ingrid (2005), 'The Capability Approach: A Theoretical Survey', Journal of Human Development, 6, pp. 93-114.

Robeyns, Ingrid (2017), Wellbeing, Freedom and Social Justice: The Capability Approach Reexamined, Cambridge: Open Book Publishers.

Rorty, Richard (1994), 'Human Rights, Rationality and Sentimentality', in Stephen Shute and Susan Hurley, eds., On Human Rights: The Oxford Amnesty Lectures 1993, New York: Basic Books, pp. 111-134.

Sachs, Albie (2009), The Strange Alchemy of Life and Law, Oxford: Oxford University Press.

Scheffler, Samuel, ed. (1988), Consequentialism and Its Critics, Oxford: Oxford University Press.

Scheffler, Samuel (1992), Human Morality, Oxford: Oxford University Press.

Scheffler, Samuel (2001), 'Individual Responsibility in a Global Age', in idem, Boundaries and Allegiances: Problems of Justice and Responsibility in Liberal Thought, Oxford: Oxford University Press.

Scheper-Hughes, Nancy (1992), Death without Weeping: The Violence of Everyday Life in Brazil, Berkeley CA: University of California Press.

Sen, Amartya (1977), 'Rational Fools: A Critique of the Behavioral Foundations of Economic Theory', Philosophy and Public Affairs, 6, pp. 317-344.

Sen, Amartya (1992), Inequality Reexamined, Cambridge MA: Harvard University Press.

Sen, Amartya (1999), Development as Freedom, Oxford: Oxford University Press.

Sen, Amartya (2009), The Idea of Justice, Cambridge MA: Harvard University Press.

Shields, Liam (2012), 'The Prospects for Sufficientarianism', Utilitas, 24, pp. 101-117.

Shue, Henry (1996), Basic Rights: Subsistence, Affluence, and U.S. Foreign Policy, Princeton: Princeton University Press. (2nd ed., orig. 1980) 


\section{Bibliography}

Shue, Henry (2010), 'Deadly Delays, Saving Opportunities', in Stephen Gardiner et al., eds., Climate Ethics: Essential Readings, Oxford: Oxford University Press, pp. 146-162.

Shue, Henry (2014), Climate Justice: Vulnerability and Protection, Oxford: Oxford University Press.

Sikkink, Kathryn (2011), The Justice Cascade: How Human Rights Prosecutions Are Changing World Politics, New York: Norton.

Sikkink, Kathryn (2017), Evidence for Hope: Making Human Rights Work in the 21st Century, Princeton: Princeton University Press.

Singer, Peter (1972), 'Famine, Affluence, and Morality', Philosophy and Public Affairs, 1, pp. 229-243.

Thaler, Richard and Cass Sunstein (2008), Nudge: Improving Decisions about Health, Wealth, and Happiness, New Haven: Yale University Press.

Vaidis, David (2014), 'Cognitive Dissonance Theory', Oxford Bibliographies. (online)

Van Miltenburg, Niels (2015), Freedom in Action, Utrecht: Utrecht University. (PhD thesis)

Weber, Max (1979[1904-05]), Die protestantische Ethik und der Geist des Kapitalismus, ed. by Johannes Winkelmann, Gütersloh: Gütersloher Verlagshaus Mohn.

Wenar, Leif (2007), 'Responsibility and Severe Poverty', in Thomas Pogge, ed., Freedom from Poverty as a Human Right: Who Owes What to the Very Poor? Oxford: Oxford University Press, pp. 255-274.

Wenar, Leif (2015), 'Rights', Stanford Encyclopedia of Philosophy. (online)

Williams, Bernard (2003), 'Human Rights and Relativism', in idem, In the Beginning Was the Deed: Realism and Moralism in Political Argument, Princeton: Princeton University Press.

Young, Iris Marion (2011), Responsibility for Justice, Oxford: Oxford University Press.

Ypi, Lea (2012), Global Justice and Avant-Garde Political Agency, Oxford: Oxford University Press. 


\section{Index}

alternatives to human rights $19 \mathrm{n} 14,32-3$

American Anthropological Association 24

Amnesty International 32

anarchy 47, 50-1

Arendt, Hannah 108

assumptions concerning interests and

number of future people $29,83-5$

autonomy, notion of 12

avant-garde of citizens and professionals

$105,108,112-13,118$ n59

'background culture' of a society 13, 19n16, 91n53, 107

Beitz, Charles 18n10, 19n13, 22n42

Buchanan, Allen 19n16, 58n1; Buchanan and Russell Powell on motivation 102-3, 115n21, 116n31, 116n34

causality, notion of $2 \ln 39$

challenge of future people, stated 1-2, 63, $1-5,7,63-86,120-1$; and assumptions concerning the interests and number of future people 83-85; and priority-setting among human rights 63-76; and uncertainties concerning future people 76-83 see also climate change challenge of global inequality, stated 1, 43, $1-5,6,43-58,120-1$; and alternatives to a world order of largely sovereign states 47-51; and diversity of cultures 53; and foreign assistance 46, 53-5; and levelling down 46-7, 55; see also equality of protection; fundamental equality of all humans; state-based world order

civil rights see list of human rights climate change, and challenge of future people 1, 3-4, 7, 63-9, 71, 72, 77-86, 120-1; and subsidiarity-based world order 50,52,60n41; and foreign assistance 53-4; example of endangered food provision 66-9, 71, 74, 77, 79-80, 86; and question of motivation 109 cognitive dissonance 31,110

conflicts among human rights, spurious 68-9

conspicuousness of non-realization of human rights 109

democracy 20n26; deliberative 108; see also political rights

duties (moral) in relation to human rights 16-17, 20n20, 21n $34,21 \mathrm{n} 27,22 \mathrm{n} 42$, 22n45, 26-7, 29 46, 90n40, 97, 115n23; duty bearers $16-17,20 \mathrm{n} 20,2 \ln 34$, $21 \mathrm{n} 36,21 \mathrm{n} 38,22 \mathrm{n} 42,22 \mathrm{n} 45,26-9,35$, 46, 63, 73-4, 79, 88n14, 116n26; 'respect, protect, fulfil' $21 \mathrm{n} 37$

entrance conditions, characterization of 66; enumerated 66-7

equal dignity, notion of $43,51,60 \mathrm{n} 37$ equality of protection (of human rights), characterization of $43-4,58 \mathrm{n} 2$; alternative characterizations $62 \mathrm{n} 53,76$; burden of proof for inequality of protection 51-2, 57, 62n54; and equivalent protection $58 \mathrm{n} 2,91 \mathrm{n} 53$; only limited scope for inequality of protection 57-8, 76; principle in priority-setting among human rights 76 ; see also challenge of global inequality equal moral status, notion of 43, 51, 60n 37 expression, freedom of 71, 88n14, 89n37; see also list of human rights

'families' of human rights $21 \mathrm{n} 32,25-6$ food provision see climate change 
foreign assistance see challenge of global inequality

fundamental equality of all humans, characterization of $43,51,60 \mathrm{n} 37,51-3$

future/end of human rights, debates about $23,36 \mathrm{n} 2,38 \mathrm{n} 37$

future people, challenge of see challenge of future people

Gardiner, Stephen 77-9

genocides 76; early-warning system for

32; Holocaust 107; Rwandan genocide of 199432,107

Gewirth, Alan 20n28

global inequality, challenge of see challenge of global inequality

global justice, human rights and 1, 11-13, 18n11, 19n14, 59n7; minimum requirements of $13-18,19 \mathrm{n} 12,22 \mathrm{n} 43$

group rights $21 \mathrm{n} 32,33,37 \mathrm{n} 21$; see also list of human rights

Hobbes, Thomas 50

homo oeconomicus model of human behaviour 101, 111

human right, notion of a 14-15

human rights, passim; role (s) of 12-13, 19n11; active disrespect /active violation of 71-2; as concerned with reliable protection of very important interests 14, 69; effective realization of human rights, characterization of $97-8$, 100-1; joint disrespect 72; see also 'families' of human rights; list of human rights; duties (moral) in relation to human rights; weight of human rights

Human Rights Watch 32

hypocrisy, notion of $44,58 \mathrm{n} 5,43,47$, $56-7,59 \mathrm{n} 7,70$

hypothesis HR (about motivation of individuals), stated 103, 103-13; other hypotheses $110-12,117 \mathrm{n} 48$

ideal theory $8 \mathrm{n} 16,59 \mathrm{n} 20,60 \mathrm{n} 32,97,99$, $113,114 \mathrm{n} 2,122 \mathrm{n} 1$

imminent threats 64,75

interdependence of human rights $89 \mathrm{n} 36$, 90n38

International Covenant on Civil and Political Rights 18n10, 45

International Covenant on Social, Economic and Cultural Rights $18 \mathrm{n} 10,45$ justice, importance of $12,18 \mathrm{n} 11,19 \mathrm{n} 13$; minimum requirements of justice, notion of 12 see also global justice

\section{labour movement 104}

legal aspects of the post-WW practice of human rights $18 \mathrm{n} 10$

legal protections of human rights $21 \mathrm{n} 42$

legal rights and moral rights 19n16

levelling down of human rights protection 46-7, 55

Levi, Primo 25

list of human rights $15-16$

motivation, notion of 97; effective motivation 97-8, 101-6; acceptable motivation 98, 106-7; due inclusion of human rights of future people 109; and fair division of moral labour 105 , 126n33; motivation across generations 98, 107-8; see also hypothesis HR; question of motivation

motivational question see question of motivation

movement, freedom of $86,94 \mathrm{n} 90$

Nickel, James 21n32, 21n34, 37n21, 89n36 non-contrivance entrance condition $66,77-9$

'non-existence problem' $87 \mathrm{n} 1$

non-ideal theory $61 \mathrm{n} 52,99,113,118 \mathrm{n} 60$, $122 \mathrm{n} 1$

'non-identity problem' $87 \mathrm{n} 3$

nudging 110-11

Nussbaum, Martha 22n43, 27, 115n23

plurality of cultures and social forms of life, and acceptance of human rights 20n27, 26, 107

Pogge, Thomas 19n14, 21n36, 59n15, 90n14

political pawns challenge, stated 2, 30, 2, $23,30-4,119-20$

political rights see list of human rights practice of human rights (post-WWII) 11-13, 18n9-18n10, 19n13, 24, 31, 33, $45,99-100$

precautionary approach 77 priority-setting among human rights 63-83; and assumptions concerning interests and number of future people 83-5; formal principles for prioritysetting 69-76; not between isolated human rights claims 66 ; principled 
approach to 65; two-step approach to 64; and uncertainties concerning future people 76-83

progressive realization of human rights 45-6

protection of human rights, notion of $58 \mathrm{n} 2$; global baseline of 55-6

question of motivation, stated 2, 97, 97-118; approach via robust empirical evidence about individual motivation 100 ' as concerning effective, acceptable motivation across generations, including the human rights of future people 97-8; limited relevance of realworld cases 99-100; see also motivation; hypothesis HR

Rawls, John 12-13, 18n11, 36n14, 59n20, 97

refugees, treatment of 100

relativist challenge, stated 2, 24, 23-30, 34, 119-20; see also universal validity of human rights

resources (wealth, technological, institutional) and demands of human rights 45, 54-6, 61n50, 68, 73

Responsibility to Protect 32, 34

Risse, Mathias 46, 48-50

Rorty, Richard 4, 101-4, 116n27

Scheffler, Samuel 73, 88n29

self-determination, political and cultural $54,6 \ln 45,6 \ln 49$

self-interest hypothesis 111-12

Sen, Amartya 27

Shue, Henry 14, 21n42, 77-9, 88n19

socio-economic rights see list of human rights

sovereignty of states, notion of 43,46 ; see also state-based world order standard of living, human right to an adequate 26-7 state-based world order/ world order of largely sovereign states, characterization of 43; alternatives to 47-51; and (un)equal human rights protection $43-58,76$

stories, and (universal) validity of human rights $15,24-5,27,36 \mathrm{n} 14,37 \mathrm{n} 17$, $37 \mathrm{n} 20$; and motivation of individuals for realizing human rights 107-9

subsidiarity-based world order, characterzation of 49, 49-50, 52, 58, 60n41, 120-1

terra incognita objection 48-50, 52, $60 \mathrm{n} 32,60 \mathrm{n} 41$

two levels of specificity of human rights 26-8, 66, 88n16

uncertainties, concerning future people 77-83; visualization of 80-3, 93n78; notions of risk, uncertainty and ignorance $77,92 \mathrm{n} 72$

Universal Declaration of Human Rights (UDHR) 16, 18n10, 21n33, 24, 26-7, 39n45, 66, 88n14, 90n48

universal validity of human rights $24-30$, $66,117 \mathrm{n} 40$; across time 28-9; and wide acceptance of human rights 26, 107; see also relativist challenge

utilitarianism of rights 69,71

violations of human rights see human rights

wealth disparities, global, and human rights see challenge of global inequality; resources and the demands of human rights

weight of human rights $17-18,67-8$

Williams, Bernard 28, 36n9

world governance 47,50

world state $43-4,47-50,121$

Young, Iris 90n42, 117n44 


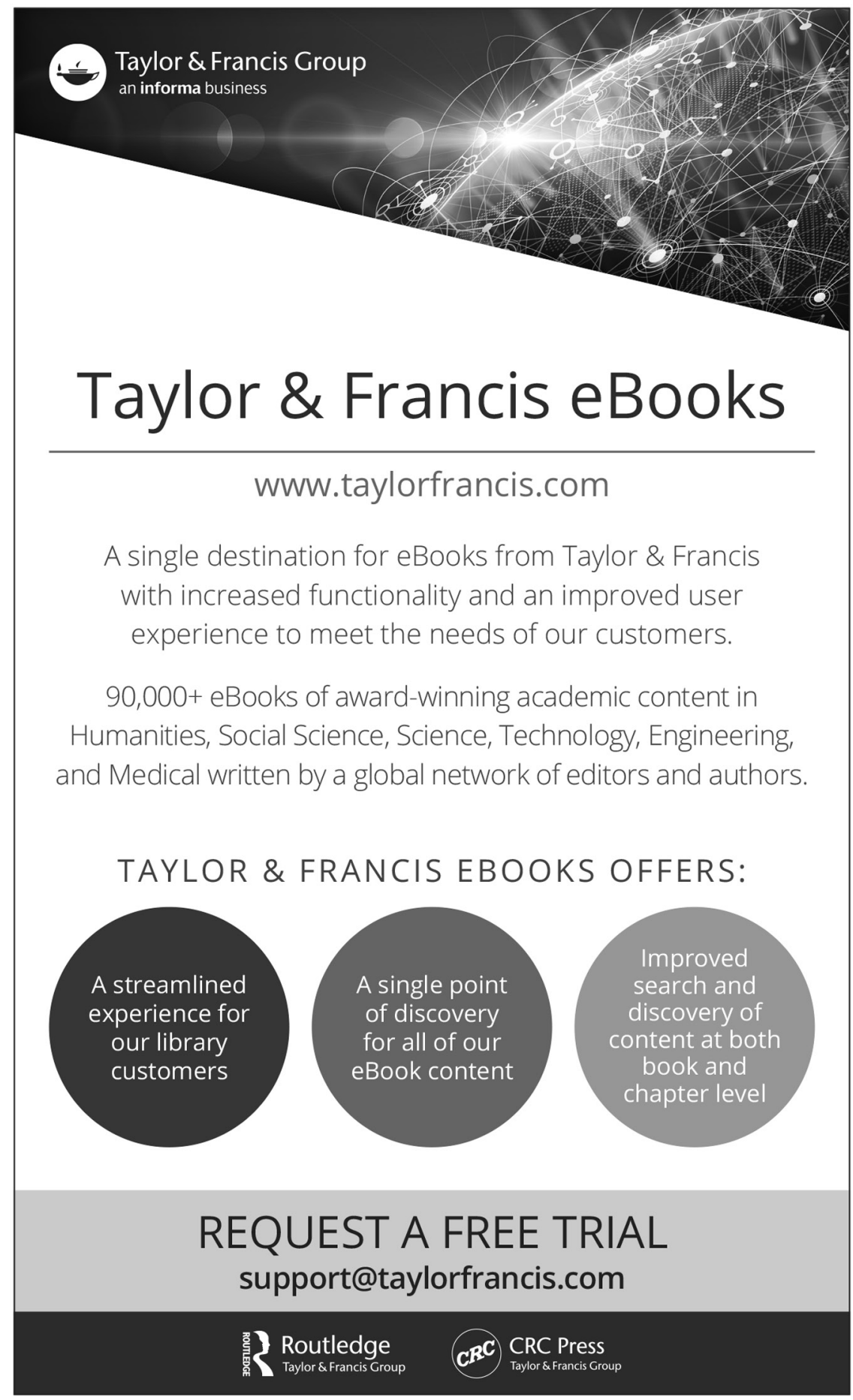

